\author{
Universidade de São Paulo \\ Instituto de Psicologia \\ Departamento de Psicologia Clínica
}

FELIPE ALCKMIN CARVALHO

\title{
BULLYING, PROBLEMAS DE COMPORTAMENTO E ADVERSIDADE FAMILIAR EM ADOLESCENTES DE ESCOLAS PÚBLICAS PAULISTAS
}




\section{BULLYING, PROBLEMAS DE COMPORTAMENTO E ADVERSIDADE FAMILIAR EM ADOLESCENTES DE ESCOLAS PÚBLICAS PAULISTAS}

(versão corrigida)

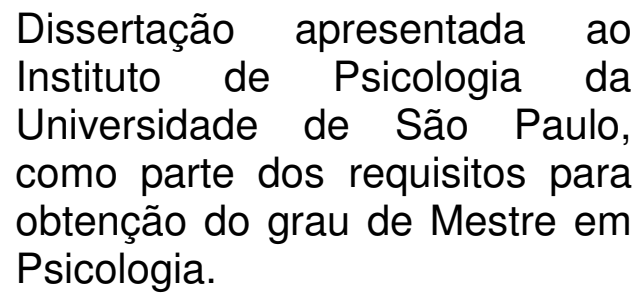

Área de Concentração: Psicologia Clínica

Orientadora: Prof ${ }^{a}$ Dr ${ }^{a}$ Márcia H. S. Melo Bertolla 
2014 
Autorizo a reprodução e divulgação total e parcial deste trabalho, por qualquer meio convencional ou eletrônico, para fins de estudo e pesquisa, desde que citada a fonte.

Alckmin-Carvalho, Felipe. Bullying, problemas de comportamento e adversidade familiar em adolescentes de escolas públicas paulistas /

Felipe Alckmin Carvalho; Orientadora: Márcia H. S. Melo Bertolla. São Paulo, 2014.

Dissertação (Mestrado) - Instituto de Psicologia da Universidade de São Paulo. Programa de Pós-graduação em Psicologia. Área de Concentração: Psicologia Clínica.

Palavras-chave: bullying, vitimização, violência na escola, problemas de comportamento, adversidade familiar. 
Título: Bullying, problemas de comportamento e adversidade familiar em adolescentes de escolas públicas paulistas.

Dissertação apresentada ao Instituto de Psicologia da Universidade de São Paulo para obtenção do título de Mestre em Psicologia Clínica

Aprovado em:

BANCA EXAMINADORA

\title{
$\operatorname{Prof}^{\underline{a}} \operatorname{Dr}^{a}$ Márcia Helena da Silva Melo Bertolla Universidade São Paulo
}

\author{
Prof $^{a} \mathrm{Dr}^{\mathrm{a}}$ Maria Cristina Triguero Veloz Teixeira \\ Universidade Presbiteriana Mackenzie
}

\author{
Prof ${ }^{\mathrm{a}} \mathrm{Dr}^{\mathrm{a}}{ }^{\mathrm{a}}$ Wagner Ribeiro \\ Universidade Federal de São Paulo
}


Dedico este trabalho ao meu pai, Carlos Henrique, à minha mãe, Jacqueline, e aos meus avós, Guilherme, Detinha e Wanda, como forma de demonstrar meu amor. 


\section{AGRADECIMENTOS}

À minha mãe, Jacqueline, e ao meu pai, Carlos Henrique, pelo amor e incentivo.

À Professora Márcia, orientadora deste trabalho, por ser flexível, amável, competente, e ainda, por estar sempre por perto.

Ao Taki, à Ester e à Patrícia, por acreditarem e cuidarem.

Aos meus amigos, Rafaela, Renatha, Mario, Carol, Letícia, Fernanda e Mayra, por estarem sempre presentes e pelos momentos felizes que temos passado juntos.

Aos membros do grupo de pesquisa do qual faço parte: Luan, Marcela, Sarah, Renata e Larissa.

Às minhas irmãs, Daniele e Maria Laura, pela doçura de todos os dias.

Às professoras Maria Eloisa e Cristiane, por me apresentarem o mundo acadêmico e por incentivarem o meu desenvolvimento.

A Maria Cristina, por estar sempre presente na graduação, como amiga fiel e como incentivadora.

Agradeço especialmente à Maria Lívia. As palavras não alcançam minha gratidão e minha admiração.

Ao Vinícius, pela ajuda valiosa nas análises estatísticas.

À Coordenação de Aperfeiçoamento de Pessoal de Nível Superior (CAPES), pela concessão da Bolsa de estudos.

Aos pais, professores e coordenadores que participaram do estudo.

A todos os adolescentes que participaram da pesquisa, e a tantos outros que têm sido vitimizados em escolas brasileiras. 
Nós recebemos e perdemos. E devemos ser capazes de sentir gratidão, e com essa gratidão, abraçar de coração inteiro qualquer coisa da vida que reste após as perdas.

Andre Dubus II, Broken Vessels 


\section{RESUMO}

Alckmin-Carvalho, Felipe. (2014). Bullying, problemas de comportamento e adversidade familiar em adolescentes de escolas públicas paulistas. Dissertação de Mestrado, Instituto de Psicologia, Universidade de São Paulo, São Paulo.

Sofrer bullying na infância e na adolescência se configura como fator de risco para a instalação e manutenção de problemas de comportamento e de transtornos psiquiátricos. A adversidade familiar, por sua vez, contribui para o envolvimento em situações de bullying. Os objetivos do presente estudo foram: (1) avaliar e comparar os escores de problemas de comportamento em dois grupos (vítimas e não vítimas de bullying), obtidos por meio do autorrelato e do relato dos professores e (2) verificar correlações entre os escores de adversidade familiar e de problemas de comportamento nos dois grupos. Participaram 154 adolescentes, dos quais $31(20,1 \%)$ foram identificados como vítimas de bullying, por meio da Escala de Violência Escolar (EVE) e da versão traduzida do Peer Assessment. Para avaliar os problemas de comportamento foram utilizadas as versões brasileiras do Youth Self Report/11-18 (YSR) e do Teacher Report Form (TRF). O índice de adversidade familiar (IAF) avaliou o nível de adversidade familiar entre as famílias. Mais adolescentes vítimas de bullying foram avaliados com problemas de comportamento internalizantes, externalizantes e totais em nível clínico, quando comparados ao grupo de não vítimas. As maiores diferenças entre grupos foram verificadas na subescala de Depressão e Ansiedade, a partir do relato dos adolescentes, e na escala de Comportamento Agressivo, de acordo com os professores. Os alunos alvos de bullying relataram mais problemas de comportamento internalizantes $(F=13,3$ e $p=0,001)$ e menos problemas de comportamento externalizantes $(F=6,63$ e $p=0,013)$, quando comparados ao relato de seus professores. A presença de discórdia conjugal foi mais frequente em famílias de alunos vítimas de bullying, atingindo diferença estatisticamente significativa entre os grupos $\left(\chi^{2}=4,2\right.$ e $\left.p=0,04\right)$. Houve correlação positiva e ligeira entre os escores de problemas de comportamento, relatados pelos alunos, e os escores de adversidade familiar $(\rho=0,288$ e $p=0,001)$. Embora os escores de problemas de comportamento, sobretudo internalizantes, relatados por vítimas de bullying tenham sido significativamente superiores aos relatados por não vítimas, e tenham atingido níveis clínicos, os professores parecem não estarem sensíveis a estes indicadores. Identificar problemas de comportamento e características familiares adversas associadas à vitimização, assim como avaliar a percepção dos próprios envolvidos e de seus professores, contribui para o desenvolvimento de medidas preventivas de bullying em escolas brasileiras.

Palavras-chave: bullying, vitimização, violência na escola, problemas de comportamento, adversidade familiar. 


\section{ABSTRACT}

Alckmin-Carvalho, F. (2014). Bullying, behavior problems and family adversity in youth from public school. Dissertação de Mestrado, Instituto de Psicologia, Universidade de São Paulo, São Paulo.

Being bullied in childhood and adolescence is configured as a risk factor for the installation and maintenance of behavioral problems and psychiatric disorders. Family adversity, in turn, contributes to involvement in bullying situations. The aims of the study were: (1) to evaluate and compare the scores of behavior problems in two groups (victims and non-victims of bullying), obtained by self-report and by teachers report, and (2) examine correlations between the scores of family adversity and behavior problems of the two groups. Participated 154 adolescents, of whom, 31 (20.1\%) were identified as victims of bullying, through the School Violence Scale (EVE) and through the translated version of the Peer Assessment. To assess the behavioral problems, the Brazilian versions of the Youth Self Report/11-18 (YSR) and the Teacher Report Form (TRF) were used. The family adversity index (LAI), from Rutter, assessed the level of family adversity among the families. Most adolescent victims of bullying were assessed with internalizing problems, externalizing, and total behavior at a clinical level, when compared with non-victims. The biggest differences between groups were found in the subscale of Depression and Anxiety, according to the teenagers and the Aggressive Behavior scale, according to teachers. The target of bullying students reported more internalizing behavior problems $(F=13.3, p=0.001)$ and fewer externalizing behavior problems $(F=6.63, p=0.013)$, when compared with their teachers. The presence of interparental conflict was more frequent in families of students bullied, reaching statistically significant difference between groups $\left(\chi^{2}=4.2, p=0.04\right)$. There was a slight and positive correlation between the scores of behavioral problems reported by students and the family adversity scores $(\rho=0.288, p=0.001)$. While scores of behavior problems, especially internalizing, reported by victims of bullying were significantly higher than those reported by non-victims, and have reached clinical levels, the teachers do not seem to be sensitive to these indicators. Identify behavior problems and family characteristics associated with victimization, and to evaluate the perception of the involved and their teachers contribute to the development of preventive measures of bullying in Brazilian schools.

Keywords: bullying, victimization, violence in school, behavioral problems, family adversity. 


\section{SUMÁRIO}

1. APRESENTAÇÃO

2. INTRODUÇÃO

Capítulo 1. Problemas de comportamento ........................................................ 19

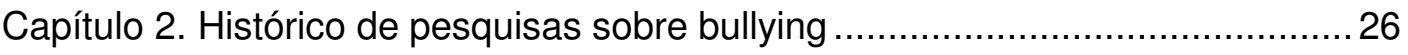

Capítulo 3. Problemas na conceituação do bullying ………….............................2 29

Capítulo 4. Formas de envolvimento e problemas associados ao bullying ............31

Capítulo 5. Formas de rastreamento e prevalência de bullying...............................36

Capítulo 6. Associação entre bullying e características familiares ........................43

Capítulo 7. Prevenção de bullying ..................................................................... 46

3. JUSTIFICATIVA

4. OBJETIVOS

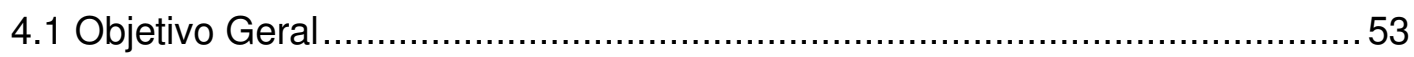

4.2 Objetivos Específicos .......................................................................... 53

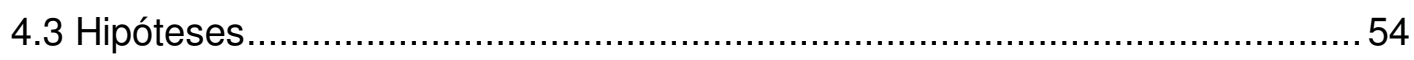

5. MÉTODO

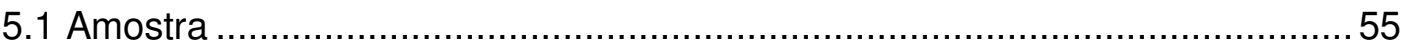

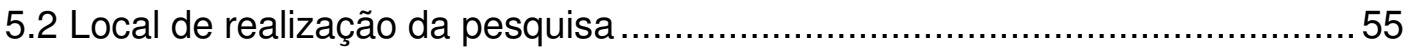

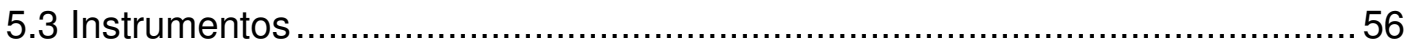

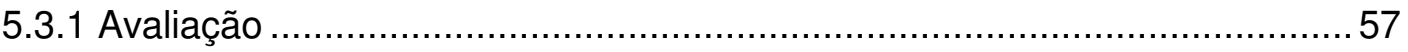

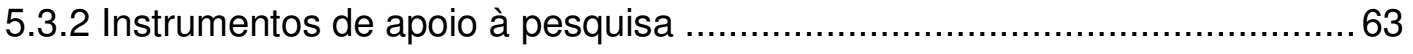

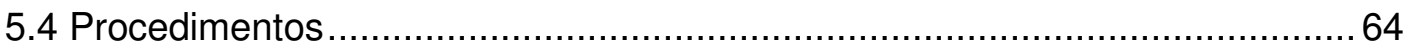

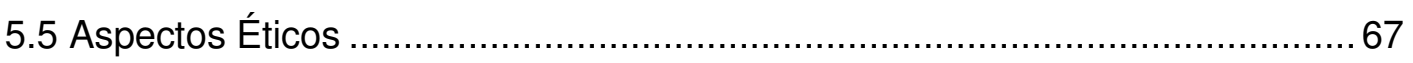

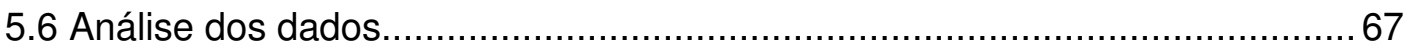

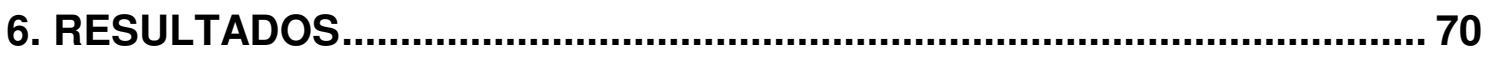

6.1 Problemas de comportamento avaliados pelo alunos ................................... 72

6.2 Problemas de comportamento avaliados pelos professores ...........................76

6.3 Diferenças na avaliação de alunos e professores quanto aos problemas de

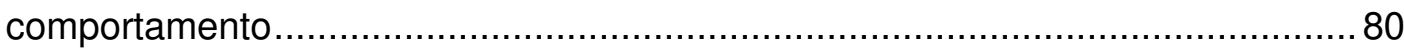

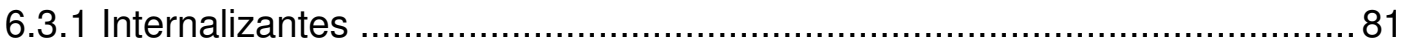

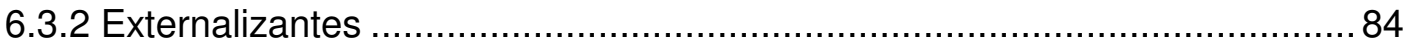

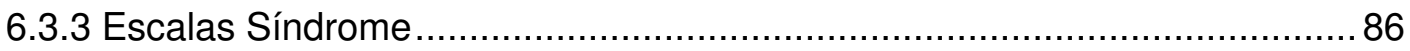

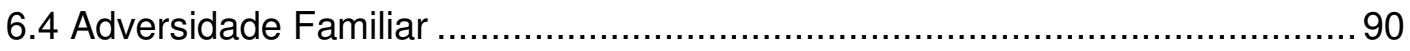

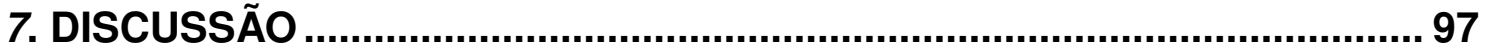

7.1 Problemas de comportamento em vítimas e em não vítimas de bullying .......97

$7.2 \mathrm{O}$ relato de alunos vítimas de bullying e de seus professores .........................99

7.3 Adversidade familiar em vítimas e não vítimas de bullying........................... 101 
7.4 Relação entre adversidade familiar e problemas de comportamento 103

8. CONSIDERAÇÕES FINAIS 106

9. LIMITAÇÕES E DESDOBRAMENTOS 109 10. REFERÊNCIAS 


\section{LISTA DE FIGURAS}

Figura 1. Variáveis de interesse, instrumentos utilizados, informantes e tempo de aplicação.

Figura 2. Apresentação das medianas dos escores das escalas síndromes, de acordo com o relato dos alunos pertencentes ao grupo CA e CO

Figura 3. Apresentação das medianas dos escores das escalas síndromes, de acordo com o relato dos professores

Figura 4. Distribuição das médias dos escores de problemas de comportamento internalizantes em CAs e COs, de acordo com o relato dos alunos e professores

Figura 5. Distribuição das médias dos escores de problemas de comportamento externalizantes em casos e controles, de acordo com o relato dos alunos e professores

Figura 6. Diferença do relato dos professores e alunos quanto às medianas dos escores obtidos nas escalas síndrome

Figura 7. Diferença de medianas das escalas síndromes do YSR e TRF .88

Figura 8. Histograma de adversidade familiar de casos e controles

Figura 9. Figura ilustrativa da associação entre problemas de comportamento totais, relatados pelos adolescentes e adversidade familiar

Figura 10. Figura ilustrativa da associação entre problemas de comportamento totais, relatados pelos adolescentes e adversidade familiar 


\section{LISTA DE TABELAS}

Tabela 1. Fatores de risco relacionados ao engajamento em comportamento de bullying

Tabela 2. Variáveis de interesse, instrumentos utilizados, informantes e tempo de aplicação

Tabela 3. Número de participantes com escores clínicos no YSR alocados nos grupos CA e CO.

Tabela 4. Medianas, escores máximos e mínimos das escalas síndromes que compõem o YSR, no grupo de CAs e COs

Tabela 5. Ranking médio das escalas síndrome avaliadas pelos alunos.

Tabela 6. Análise das diferenças do ranking médio das escalas síndromes nos grupos CA e CO.

Tabela 7. Número de participantes com escores clínicos e não clínicos,

relatados pelos professores

Tabela 8. Medianas, escores máximos e mínimos das escalas síndromes que compõem o TRF, no grupo CA e CO

Tabela 9. Ranking médio das escalas síndrome do grupo de CA e CO 79

Tabela 10. Análise das diferenças do ranking médio das escalas síndromes nos grupos CA e CO.

Tabela 11. Médias dos escores de problemas de comportamento internalizantes relatados por professores e alunos, nos grupos de vítimas e de não vítimas de bullying.

Tabela 12. Descrição do efeito das variáveis no modelo estatístico incluindo grupo e relato como preditores.

Tabela 13. Descrição do efeito das variáveis no modelo estatístico no grupo $C A$, incluindo o informante como preditor (variável independente).

Tabela 14. Análise da interação entre as variáveis informante e grupo para problemas de comportamento externalizantes.

Tabela 15. Descrição do efeito das variáveis no modelo estatístico incluindo grupo e relato como preditores.

Tabela 16. Diferenças de escores entre YSR e TRF, das medianas das escalas síndrome do grupo CA 
Tabela 17. Diferenças de escores das medianas das escalas síndrome do grupo CO...

Tabela 18. Teste de Wilcoxon para identificar diferenças entre os escores de cada subescala conforme respondidas via TRF ou YRS, no grupo CA

Tabela 19. Teste de Wilcoxon para identificr diferenças entre os escores de cada subescala conforme respondidas via TRF ou YRS, no grupo CO.

Tabela 20. Descrição dos escores de adversidade familiar nos grupos caso e controle

Tabela 21. Análise por meio do teste do teste de Mann-Whitney dos escores de IAF.

Tabela 22. Tabela descritiva da diferença dos Rankings dos participantes do grupo $\mathrm{CA}$ e $\mathrm{CO}$.

Tabela 23. Subitens de adversidade familiar analisados nos grupos CA e CO .93

Tabela 24. Associações entre as variáveis de adversidade familiar e os grupos $C A$ e $C O$ 


\section{LISTA DE ANEXOS}

Anexo 1. Tabela Seade (2007/2008) de distribuição das famílias, número de pessoas na família e número médio de filhos, segundo tipo de arranjo familiar e sexo do chefe da

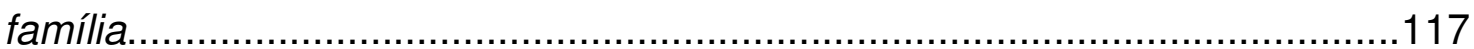

Anexo 2. Escala de Violência Escolar (EVE) - Versão Estudante..................118

Anexo 3. Peer Assessment .....................................................................119

Anexo 4. Parecer de aprovação do Comitê de Ética.......................................120 


\section{LISTA DE APÊNDICES}

Apêndice 1. Entrevista Semiestruturada para aferição do Índice de Adversidade

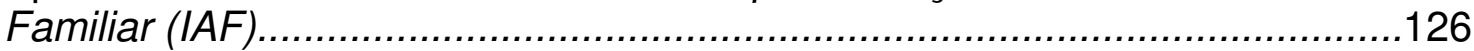

Apêndice 2. Termo de Consentimento Livre e Esclarecimento para Pais......127

Apêndice 3. Termo de Assentimento Informado...........................................129

Apêndice 4. Carta de apresentação do Projeto à Escola..................................131

Apêndice 5. Carta destinada aos pais explicativa do Índice de Adversidade

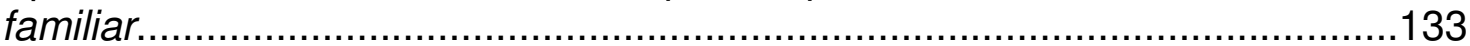




\section{APRESENTAÇÃO}

presente estudo investiga o fenômeno conhecido como bullying,
atualmente compreendido como um subgrupo de comportamento agressivo (Bosworth, Espelage, \& Simon, 1999; Carvalhosa, 2010; Sullivan, 2010), descrito incialmente em países europeus, na década de 70, e com estudos iniciados em países latino-americanos apenas na última década (Lopes Neto, 2005).

Pesquisas nacionais e internacionais têm apontado que o envolvimento em situações de bullying na infância e adolescência, tanto como vítima quanto como agressor, está associado a uma série de problemas de comportamento de curto, médio e longo prazo, que podem se estender para muito além do período em que a criança ou o adolescente frequenta a escola (Bifulco, Schimmenti, Jacobs, Bunn, \& Rusu, 2014; Copeland, Wolke, Angold, \& Costello, 2013; Lopes Neto, 2005; Lopes Neto \& Saavedra, 2003). Podem ainda evoluir para transtornos psiquiátricos, comprometendo o processo de aprendizagem, a qualidade de vida e a produtividade dos indivíduos em idade adulta (Bandeira, Rocha, Souza, Del Prette, \& Del Prette, 2006; D’abreu \& Marturano, 2010).

Entretanto, mesmo com a gravidade dos problemas de comportamento associados ao envolvimento em situações de bullying, são escassas, em cenário nacional, investigações empíricas que visem à avaliação do ambiente escolar e à investigação do perfil comportamental de indivíduos vitimizados. Neste sentido, espera-se que os dados provenientes desta pesquisa possam mostrar um retrato do relacionamento entre adolescentes em idade escolar, bem como contribuir para o entendimento das associações entre bullying, 
características familiares e problemas de comportamento, colaborando para o delineamento e a implementação de medidas preventivas, a exemplo do que vem sendo realizado nos países mais desenvolvidos.

A problemática deste projeto está inserida no campo de pesquisa da professora que o orienta: "Prevenção de problemas de comportamento, Rejeição entre Crianças e Habilidades Sociais", do Departamento de Psicologia Clínica do Instituto de Psicologia da Universidade de São Paulo (IP-USP).

Para auxiliar na compreensão dos pontos norteadores do trabalho, serão apresentados sete capítulos na seção de introdução. No primeiro, será descrita a noção de problemas de comportamento que sustenta a presente investigação. No segundo, será exposto um histórico das pesquisas sobre bullying no Brasil e no mundo, assim como a definição do fenômeno e os problemas em sua conceituação. Descrever-se-á, no terceiro capítulo, as formas de engajamento, os problemas de comportamento associados à experiência de perpetrar ou sofrer bullying e as formas de identificação do comportamento utilizadas em estudos nacionais e internacionais. No capítulo seguinte, serão apresentadas as possíveis associações entre o engajamento em bullying e características familiares. Por fim, no último capítulo, serão descritas as características principais de programas de prevenção de bullying e redução de violência em ambiente escolar. 


\title{
2. INTRODUÇÃO
}

\section{Capítulo 1. Problemas de comportamento}

\author{
O se revisar a literatura da área de Psicologia, encontram-se
Idiversas definições para problemas comportamentais (Bolsoni-
} Silva \& Del Prette, 2003). A compreensão do termo adotada na presente pesquisa abrange déficits ou excessos comportamentais que prejudicam o acesso da criança a novas contingências de reforçamento, as quais facilitariam a aquisição de repertórios relevantes para a aprendizagem e para 0 desenvolvimento (Bolsoni-Silva \& Del Prette, 2003).

Os problemas de comportamento podem ser entendidos nas dimensões internalizantes e externalizantes, conceituadas por Achenbach e Edelbrock, em 1978, e utilizadas em diversos estudos nacionais e internacionais para a descrição do perfil comportamental de crianças com desenvolvimento típico (Bolsoni-Silva \& Del Prette, 2003; Bolsoni-Silva, Paiva \& Barbosa, 2009; Patterson, Reid, \& Dishion, 2002; Rocha, Costa, \& Silvares, 2008) e atípico (Mesquita et al., 2010; Teixeira et al., 2011).

Os comportamentos internalizantes são aqueles vivenciados em nível privado, sendo os problemas a eles relacionados expressos nas formas de déficits no repertório comportamental e de padrões de isolamento social, o qual dificulta a aquisição de novos repertórios. São exemplos de problemas de comportamento do tipo internalizante: retraimento social, depressão, ansiedade, irritabilidade, tristeza, queixas somáticas, mau humor, timidez, apego excessivo aos adultos, insegurança e medo. Tais comportamentos nem sempre afetam diretamente amigos, familiares e outras pessoas do convívio 
diário do indivíduo, sendo mais difíceis de serem identificados e tratados (Achenbach \& Edelbrock, 1978). Os comportamentos externalizantes, por sua vez, expressam-se predominantemente em relação ao contexto em que a criança ou o adolescente vive. Dentre eles, destacam-se a impulsividade, o nervosismo, a agressividade, a impaciência/irrequietação, a destrutividade, a desobediência frequente, a agitação, as provocações e as brigas (Achenbach \& Edelbrock, 1978; Bolsoni-Silva \& Del Prette, 2003; Del Prette \& Del Prette, 2003). Estes problemas de comportamento afetam diretamente o ambiente em que a criança ou o adolescente se insere, tornando sua identificação mais fácil, quando comparados aos problemas de comportamento internalizantes, e mobilizando mais frequentemente seus cuidadores a procurar ajuda (Achenbach \& Edelbrock, 1978; Bolsoni-Silva \& Del Prette, 2003).

Ressalta-se que os problemas de comportamento, tanto os internalizantes quanto os externalizantes, são selecionados e mantidos no repertório comportamental de crianças e adolescentes por meio da interação destes com seu meio. Por este motivo, esses problemas devem ser entendidos como consequência de interações inadequadas entre o jovem e seu contexto, e não simplesmente respostas inadequadas que se originam do próprio indivíduo (Kauffman, 2005; Meyer et al., 2010; Sampaio \& Andery, 2012; Skinner, 1978).

Entre os ambientes em que a criança se insere, desde seu nascimento, têm destaque a família (Bolsoni-Silva \& Marturano, 2002) e a escola (Silvares, 2000; Weare \& Nind, 2011), os quais são fundamentais no processo de desenvolvimento e socialização. Se deficitários ou inadequados, estes contextos podem contribuir para a produção dos mais variados problemas de comportamento na criança, como o envolvimento em situações de bullying, que 
são frequentemente observados em escolas. Sendo assim, o ambiente escolar deve ser lócus de pesquisas que tenham como finalidades a identificação de problemas de comportamento precocemente e o desenvolvimento de medidas preventivas (Melo, 2003; Silvares, 2000).

Instrumentos padronizados são mundialmente empregados com a finalidade de identificar os problemas de comportamento (Borsa \& Bandeira, 2011; Duarte \& Bordin, 2000). Um dos sistemas integrados baseados em evidências e cujos instrumentos de avaliação comportamental atualmente são os mais utilizados no mundo é o Sistema Achenbach de Avaliação Empiricamente Baseada (ASEBA) (Achenbach \& Rescorla, 2001). Os instrumentos deste sistema permitem avaliar indicadores de competências nas áreas escolar e social, assim como um amplo espectro de problemas de comportamento externalizantes e internalizantes (Achenbach \& Rescorla, 2001).

Muitos dos inventários que compõem o ASEBA têm sido adaptados e estudos têm apresentado evidências de validade em mais de 80 idiomas. Existe ainda um número elevado de publicações científicas sobre estes instrumentos, especialmente sobre o Inventário de Comportamentos para Crianças e Adolescentes entre 6 e 18 anos (CBCL/6-18), a ser respondidos pelos pais ou cuidadores. Com menor frequência, apresentam-se o Formulário para Professores (TRF/6-18) e o Inventário de Autoavaliação para Adolescentes de 11 a 18 anos (YSR/11-18 anos) (Bordin et al., 2013).

No Brasil, o número, que já é expressivo, de pesquisas que utilizam os inventários ASEBA para a avaliação de problemas de comportamento (BolsoniSilva \& Loureiro, 2011, Mesquita et al., 2010; Rocha et al., 2008) tende a 
aumentar, uma vez que, em estudos recentes, o YSR apresentou evidências de validade para a população brasileira (Rocha, 2012).

O uso dos instrumentos ASEBA tanto para identificar o envolvimento em situações de bullying como para descrever o perfil comportamental dos envolvidos é recente. Por exemplo, Jiang, Walsh e Augimeri (2011) identificaram o engajamento em situações de bullying utilizando o item 16 do CBCL (“É cruel, intimida ou faz maldade com os outros?") e, para avaliar o perfil comportamental dos engajados, o relato dos cuidadores foi obtido por meio dos itens de problemas de comportamento do mesmo instrumento. Os resultados apontaram que os agressores tiveram pontuações maiores nos fatores de risco familiares, individuais e totais, além de apresentarem níveis mais elevados de problemas de comportamento, quando comparados aos não agressores.

Albores-Gallo, Sauceda-Garcia, Ruiz-Velasco e Roque-Santiago (2011), por sua vez, empregaram o Teste BULL-S para identificar, em uma amostra de 1.092 escolares, as crianças e os adolescentes envolvidos em bullying e o CBCL para avaliar os problemas de comportamentos nas 262 vítimas identificadas. O envolvimento em situações de bullying se associou a diversos problemas de comportamento, sendo que as vítimas-agressoras foram as que mais apresentaram dificuldades, tais como comportamentos de oposição, comportamentos externalizantes e indicadores de TDAH, seguidas pelos agressores, que apresentaram problemas de comportamento internalizantes e ansiedade e, em terceiro lugar, pelas vítimas, com escores clínicos nas escalas de depressão e de ansiedade. Ainda neste estudo, as vítimas e vítimaagressoras apresentaram escores mais elevados nas escalas de oposição e de TDAH do que o grupo controle. 
Especificamente sobre o envolvimento em situações de bullying como vítima, foco do presente trabalho, um estudo longitudinal que acompanhou crianças de 8 até 16 anos, utilizando o CBCL e o YRS como instrumentos de rastreamento de problemas de comportamento, apontou que sofrer bullying na infância esteve fortemente associado a problemas de comportamento internalizantes aos 16 anos, sobretudo depressão e ansiedade (Sourander, Helstelä, Helenius, \& Piha, 2000).

Uma metanálise que avaliou 18 estudos sobre problemas de comportamento em vítimas de bullying encontrou que problemas internalizantes foram, na amostra avaliada (aproximadamente 14.000 alunos em idade escolar), tanto antecedentes como consequentes à vitimização. Isso indica que esses problemas de comportamento funcionam tanto como um fator de risco para ser vitimizado, como também são maximizados quando a criança é vítima de bullying na escola (Reijntjes, Kamphuis, Prinzie, \& Telch, 2010). Resultados encontrados por Zwierzynska, Wolke e Lereya (2013), em uma amostra de 3.962 crianças canadenses, apontam na mesma direção.

A respeito das concordâncias e discordâncias entre informantes na identificação de problemas de comportamento feita com os instrumentos ASEBA, estudos têm apresentado resultados heterogêneos, uma vez que estes variam conforme a idade e a etnia dos informantes, além do tipo de problema de comportamento do avaliado (Youngstrom, Loeber, \& Stouthamer-Loeber, 2000). Além disso, os mesmos autores apontam que a presença de depressão e estresse nos informantes parece aumentar a discordância do relato.

Por exemplo, Salbach-Andrae, Lenz e Lehmkuhl (2009), ao investigaram o grau de concordância entre o TRF, o YSR e o CBCL, em uma amostra de 
611 crianças e adolescentes encaminhados ao departamento de psiquiatria de um hospital, identificaram concordância moderada entre os jovens e seus pais em termos dos problemas de comportamento externalizantes e totais, e baixa concordância no que se refere aos comportamentos internalizantes. O nível de concordância entre pais e professores foi inferior em relação aos problemas de comportamento internalizantes, quando comparados aos problemas de comportamento externalizantes e totais. Por fim, as correlações mais fracas foram encontradas entre os professores e os alunos, com baixa concordância nos escores de problemas de comportamento, sendo que professores relataram problemas de comportamento externalizantes na faixa clínica, enquanto os pacientes reportaram escores dentro da faixa normal.

Grigorenko, Geiser, Slobodskaya e Francis (2010) aplicaram, em uma amostra de 841 adolescentes russos, seus pais e professores, o CBCL (separadamente para pais e mães), o TRF e o YSR, com a finalidade de analisar as convergências e divergências dos problemas de comportamento reportados pelos diferentes informantes. Os resultados apontaram para a presença de alto nível de concordância entre pais e mães e entre mães e professores em todos os problemas de comportamento. Entre pais e professores, houve alta concordância em relação à avaliação de todos os problemas, com exceção dos problemas de pensamento. Encontrou-se, ainda, um nível de concordância moderado entre as avaliações das mães e de seus filhos, um grau de concordância pequeno entre os pais e seus filhos, e, por fim, um nível mínimo de concordância entre os adolescentes e seus professores.

Tendo em vista o fato de que conhecer o comportamento de crianças e adolescentes em diferentes contextos é fundamental para desenvolver medidas 
de intervenção adequadas (Borsa \& Nunes, 2009; Rocha, Ferrari, \& Silvares, 2011), optou-se, no presente estudo, por utilizar múltiplos informantes, tanto para a identificação de vítimas de bullying quanto para a avaliação de problemas de comportamento.

Destaca-se que, pela similaridade destes dois últimos inventários, os resultados relativos aos problemas de comportamento relatados por alunos e seus professores são passíveis de comparação, possibilitando a verificação de aspectos convergentes e divergentes sobre as dificuldades do público infantil e adolescente. Além disso, aponta-se que, no Brasil, poucos estudos utilizaram os inventários do ASEBA, mundialmente referenciados, para o rastreamento de problemas de comportamento entre crianças vítimas de bullying, sendo esta uma contribuição da presente pesquisa. 


\section{Capítulo 2. Histórico de pesquisas sobre bullying}

A violência é um problema de saúde pública crescente no mundo e acarreta uma série de consequências individuais e sociais (Oram, Stöckl, Busza, Howard, \& Zimmerman, 2012; Ribeiro et al., 2013; Veloso, Magalhães, Dell'Aglio, Cabral, \& Gomes, 2013). No Brasil, a partir de meados dos anos 1980, as mortes associadas a causas externas, sobretudo à violência, passaram a ter um papel de destaque, particularmente para adolescentes e jovens do sexo masculino, que aparecem nas estatísticas como os que mais morrem e os que mais matam. Se estas mortes prematuras associadas à violência pudessem ser evitadas, a expectativa de vida dos brasileiros ao nascer, que, em 2010, ficou estimada em 73 anos, seria acrescida de dois a três anos (Instituto Brasileiro de Geografia e Estatística, 2010).

Entre diversas formas de violência, o bullying, estudado desde o final da década de 1970 em países como Noruega, Finlândia, Reino Unido, Austrália e Estados Unidos, tem sido objeto de crescente atenção social, há algumas décadas, em países em desenvolvimento, como Brasil e México (Olweus, Limber \& Mihalic, 1999). Grande parte do trabalho inicial na formulação do conceito de bullying foi realizada pelo psicólogo Norueguês Dan Olweus, docente da Universidade de Bergen, que verificou, em ambiente escolar, um número elevado de conflitos entre pares.

O pesquisador levantou a hipótese de que havia uma forma específica de vitimização que estava associada a consequências desastrosas para o desenvolvimento de crianças e jovens a curto, médio e longo prazo (Olweus, 
1991; Olweus, 1993; Olweus et al., 1999). As investigações de Olweus ganharam força quando, em 1982, jornais da Noruega noticiaram o suicídio de três adolescentes, relacionando o ocorrido a severos episódios de vitimização na escola.

O bullying tem sido descrito como episódios de violência, expressa de diferentes formas, que ocorrem repetidamente, em um relacionamento no qual há um desequilíbrio de poder entre a vítima e o agressor, sendo difícil para o indivíduo intimidado se defender (Almeida, Lisboa, \& Caurcel, 2007; Lopes Neto \& Saavedra, 2003; Olweus, 1991; Olweus, 1993; Olweus et al., 1999; Palácios \& Rego, 2006).

Topograficamente, o fenômeno pode se expressar de diversas maneiras, como na forma de abuso físico ou verbal, com a utilização de apelidos, insultos e comentários racistas, homofóbicos e de diferenças religiosas, físicas, econômico-sociais, culturais, morais e políticas (Almeida et al., 2007; Lopes Neto, 2005; Lopes Neto \& Saavedra, 2003; Olweus, 1991; Olweus, 1993; Palácios \& Rego, 2006; Ramírez, 2001). Pode ainda assumir uma forma mais indireta, como a exclusão ou o isolamento sociais (Olweus, 1993; Rigby, 1996). Olweus (1991) destaca que não se deve considerar bullying quando as provocações são feitas de uma forma amigável e brincalhona. Além disso, não se classificam como bullying episódios em que dois estudantes com idades aproximadas e desenvolvimento cognitivo similares se engajam em brigas ou disputas.

No Brasil, os primeiros estudos sobre bullying surgiram a partir de 2000 (Constantini, 2004; Fante, 2005; Lopes Neto \& Saavedra, 2003). Entre as pesquisas iniciais, destaca-se a realizada pela Associação Brasileira de 
Proteção a Infância e ao Adolescente (Abrapia). Os resultados destes estudos revelaram que comportamentos de bullying foram verificados em escolas brasileiras, independente de sua localização, de seu tamanho, das séries atendidas e de serem públicas ou privadas. Apontaram, ainda, que o lugar indicado como de maior ocorrência de bullying foi a sala de aula. 


\section{Capítulo 3. Problemas na conceituação do bullying}

Embora o conceito de bullying tenha direcionado pesquisas bastante úteis nos últimos trinta anos, fomentando políticas públicas que têm como objetivo reduzir a prevalência e a incidência de violência em âmbito escolar, pesquisadores destacam que há limitações importantes na operacionalização do fenômeno, que, até o momento, não foram solucionadas (Finkelhor, Turner, \& Hamby, 2012; Mohaprata et al., 2010).

Entre as limitações na conceituação, ressalta-se que a definição clássica de Olweus exclui situações de violência muito graves perpetradas de maneira isolada, tais como agressão física e sexual (Finkelhor et al., 2012; Mohaprata et al., 2010). Outra limitação é a dificuldade de operacionalizar a assimetria de forças entre vítima e agressor, característica esta necessária para que os episódios de violência sejam classificados como bullying.

Pesquisadores afirmam também que o termo "bullying" é de difícil tradução para outras línguas, dificultando a concordância de seu uso em diferentes estudos (Finkelhor et al., 2012; Smith, 2004). A tradução se mostra difícil inclusive para o português ${ }^{1}$, sendo que, no Brasil, as expressões "intimidação por pares" e "violência entre pares" também têm sido utilizadas para se referir ao fenômeno do bullying (Pinheiro \& Williams, 2009).

Rigby (2003) destaca que problemas na conceituação do bullying podem selecionar "falsos positivos", ou seja, caracterizar como bullying situações de violência que não estão associadas ao fenômeno. O pesquisador aponta,

1 O termo bullying foi utilizado sem a marcação em itálico, que caracteriza seu estrangeirismo, uma vez que a expressão consta na lista de descritores em português da Biblioteca Virtual em Saúde (BVS). 
ainda, que definições vagas dificultam a interpretação dos resultados e a comparação entre os estudos. Tendo em vista as dificuldades de conceituação do fenômeno, há pesquisadores que defendem o desenvolvimento de programas de prevenção em ambiente escolar com foco na redução de episódios de agressão de maneira abrangente, minorando os índices de violência como um todo, sem ter como alvo específico comportamentos de bullying (Fekkes, Pijpers, \& Verloove-Vanhorick, 2005; Finkelhor et al., 2012; Mohaprata et al., 2010).

Mesmo com discordâncias acerca da definição do fenômeno, pesquisadores em todo o mundo concordam, de modo geral, quanto à gravidade das alterações comportamentais a que a exposição a repetidos episódios de intimidação e violência está associada, tanto para a vítima quanto para o agressor. Deste modo, investigações sobre as diversas formas de engajamento em situações de bullying e sobre os problemas de comportamento associados ao fenômeno são indispensáveis para a caracterização e compreensão do fenômeno. 


\section{Capítulo 4. Formas de envolvimento e problemas associados ao bullying}

Desde as primeiras investigações sobre bullying, pesquisadores da área têm descrito três formas específicas de envolvimento de crianças e adolescentes, de acordo com a atitude frente às situações de agressão, a saber: vítimas/alvos de bullying; agressores/perpetradores e vítimas/perpetradores, ou seja, crianças ou adolescentes que são alvos de bullying em um momento, e, em outro, perpetram bullying. Além dessas três categorias, é preciso atentar-se para as testemunhas, que, embora não estejam diretamente engajadas em situações de bullying, presenciam os episódios e podem exercer papel decisivo para sua perpetuação e seu agravamento ou para a sua extinção, a depender de seu posicionamento (Howard, Landau, \& Pryor, 2014; Samnani, 2013).

Considera-se vítima ou alvo de bullying o aluno exposto, de forma repetida e persistente ao longo do tempo a ações negativas, como incomodar, intimidar, agredir e humilhar, perpetradas por um ou mais alunos (Lopes Neto, 2005; Pearce \& Thompson, 1998; Ravens-Sieberer, Kökönyei, \& Thomas; 2004). Os alvos de bullying, via de regra, não dispõem de recursos para reagir ou cessar a violência. Geralmente, são pouco sociáveis, têm poucos amigos, são inseguros, passivos, retraídos e ansiosos (Lopes Neto, 2005). Além disso, apresentam a autoestima marcadamente comprometida. Em alguns casos, a autoestima de crianças vítimas de bullying pode estar tão prejudicada que elas acreditam ser merecedoras dos maus-tratos sofridos (Pearce \& Thompson, 1998; Ravens-Sieberer et al., 2004).

Os perpetradores de bullying, por sua vez, têm um perfil comportamental 
bastante diferente. Os agressores são geralmente populares e tendem a se engajar em uma ampla variedade de comportamentos-problema, como abuso de tabaco, álcool ou outras drogas, porte de armas e envolvimento em brigas. São tipicamente impulsivos e percebem sua agressividade como qualidade. Têm opiniões positivas sobre si mesmos e, em geral, são fisicamente mais fortes que seu alvo, sentindo prazer e satisfação em dominar, controlar e causar danos e sofrimentos a outros. Esses indivíduos têm um menor grau de satisfação com a escola e com suas famílias, estando mais propensos ao absenteísmo e à evasão escolar (Lopes Neto, 2005; Olweus, 1993; Olweus et al., 1999; Rigby, 2003). Com relação à faixa etária dos envolvidos em situações de bullying, estudos apontam que a prevalência é mais elevada entre alunos com idades de 11 a 13 anos, sendo menos frequente na educação infantil e no ensino médio (Eslea \& Rees, 2001; Ravens-Sieberer et al., 2004).

Diversas pesquisas indicam que as consequências do engajamento em bullying estão diretamente relacionadas à frequência, à duração e à severidade dos atos (Bifulco et al., 2014; Copeland et al., 2013) e afetam todos os envolvidos neste fenômeno, sobretudo as vítimas, que podem continuar a sofrer as consequências da exposição aos episódios de violência para além do período escolar. Há evidências bastante consistentes, provenientes de diversos estudos, deque sofrer bullying na infância e na adolescência se configura como um fator de risco importante para a instalação e manutenção de uma série de problemas de comportamento internalizantes, como isolamento, depressão e ansiedade (Ledwell \& King, 2013; Reijntjes et al., 2010), e externalizantes, como a agressividade (Vaillancourt, Brittain, McDougall, \& Duku, 2013; Van Lier, Vitaro, Barker, Brenden, Tremblay, \& Boivin, 2012).

Além disso, pesquisadores apontam que ser alvo de bullying tem 
associação com o aparecimento de transtornos psiquiátricos, tais como transtornos do estresse pós-traumático (Albuquerque, Williams, \& D'Affonseca, 2013), anorexia e bulimia nervosa (Frank \& Acle, 2014; George, 2013), mau rendimento acadêmico e evasão escolar (Kumpulainen \& Rasanen, 2000; Olweus, 1992; Olweus et al., 1999; Sourander et al., 2000).

Há, ainda, uma forte associação, verificada em estudos recentes, entre o engajamento em bullying como vítima, de um lado, e, de outro, a ideação suicida e o suicídio (Espelage \& Holt, 2013; Kim, Leventhal, Koh, \& Boyce, 2009; Klomek, Kleinman, Altschuler, Marrocco, Amakawa, \& Gould, 2013; Rivers \& Noret, 2013). Em uma rápida consulta ao site de vídeos, youtube.com, realizada em Janeiro de 2014, utilizando-se como palavras-chave em combinação "bullying and suicide", encontrou-se aproximadamente 243 mil resultados, sendo que em muitos desses vídeos, são descritas histórias de suicídio entre crianças e adolescentes associadas à vitimização, sobretudo nos Estados Unidos.

Em uma busca na base de dados PUBMED, utilizando-se estas mesmas palavras-chave, foram encontrados 41 artigos publicados em 2013. Nesta direção, uma revisão sistemática sobre bullying e suicídios entre crianças e adolescentes, analisou 37 artigos sobre a temática e mostrou que, a despeito das diferenças metodológicas e limitações de cada um dos estudos, está cada vez mais estabelecida a associação entre o engajamento em bullying e 0 suicídio (Kim \& Leventhal, 2008).

Além disso, há casos descritos em diversos países, como Alemanha, Suécia e Canadá (Muschert, 2007), de adolescentes que sofreram bullying por um longo período, em idade escolar, e promoveram atos de vingança extremos contra a escola, os quais, com a utilização de armas de fogo, culminaram com 
a morte de alunos, professores e funcionários. Este fenômeno, conhecido como School Shooting, tem sido foco de crescente interesse nos últimos anos, principalmente após um incidente nos Estados Unidos que ganhou repercussão mundial por conta da violência e do número de vítimas. Neste episódio, ocorrido em 1999, dois estudantes norte-americanos abriram fogo contra alunos, funcionários e professores da Columbine High School, no Estado do Colorado, levando à morte 12 estudantes e um professor e ferindo mais de 30 pessoas. O episódio teve como desfecho o suicídio dos dois adolescentes que protagonizaram o massacre (Phillips, 2007).

Anos mais tarde, em 2007, um novo episódio, com proporções ainda maiores, ganhou destaque quando um estudante do Virginia Polytechnic Institute and State University abriu fogo contra a escola, matando 32 pessoas e se suicidando ao final (Clabaugh \& Clabaugh, 2005; Lickel, Schmader, \& Hamilton, 2003; Vieira, Mendes, \& Guimarães, 2009). Em 2011, um caso semelhante ganhou grande repercussão no Brasil, onde um jovem matou 12 adolescentes e cometeu suicídio em uma escola do bairro de Realengo, periferia do Rio de Janeiro. De acordo com alunos, o jovem sofria bullying havia anos (Lima, 2011).

Nos fatos descritos, as agressões não tiveram alvos específicos, o que sugere a intenção do atirador de se vingar da escola como um todo, ambiente onde o sofrimento do adolescente foi diariamente negligenciado (Anderson et al., 2001; Muschert, 2007). Ademais, em todos esses episódios, há fortes indícios de que os atiradores eram vítimas de bullying severo, perpetrado por longos períodos, o que sugere que ser vitimizado na escola pode ser um fator de risco para protagonizar grandes episódios de School Shooting. 
Estudos nacionais e internacionais apontam que problemas de comportamento na infância, quando negligenciados, podem evoluir para transtornos psiquiátricos, condição esta de difícil manejo (Bandeira et al., 2006; D’abreu \& Marturano, 2010). Por exemplo, pesquisas destacam que se engajar em comportamentos agressivos repetidas vezes na infância pode ser um indicador precoce de Transtorno de Personalidade Antissocial, entre outros diagnósticos psiquiátricos, na fase adulta (Fergusson, Boden, \& Horwood, 2013; Webster-Stratton, Reid, \& Hammond, 2004; Webster-Stratton, Reid, \& Stoolmiller, 2008).

Deste modo, programas de prevenção e de rastreamento precoce de problemas de comportamento tem se mostrado bastante promissores (de Girolamo, Dagani, Purcell, Cocchi, \& McGorry, 2012; Melo \& Silvares, 2007; Patterson et al., 2002; Rios \& Williams, 2008; Weare \& Nind, 2011; WebsterStraton et al., 2004). 


\section{Capítulo 5. Formas de rastreamento e prevalência de bullying}

Tendo em vista as dificuldades na conceituação do bullying, somadas à multiplicidade de respostas que podem ser identificadas como manifestação do comportamento, a avaliação de vítimas e agressores se apresenta como uma tarefa complexa. Na tentativa de identificar comportamentos de bullying em escolas, pesquisadores têm adotado diversas estratégias, existindo alguma constância em três vertentes (Seixas, 2005). Em primeiro lugar, ainda que utilizadas com menor frequência, apontam-se as técnicas de observação direta dos alunos em seu cotidiano na escola. Para se utilizar este método, pesquisadores treinados para reconhecer comportamentos de bullying observam e registram tais comportamentos em ambiente escolar (Pepler \& Craig, 2000). Usualmente, são desenvolvidos protocolos de observação e de registro com categorias previamente definidas e operacionalizadas, sendo os alunos posteriormente identificados como vítimas, perpetradores e/ou testemunhas de bullying quando a frequência, duração e intensidade de seus comportamentos correspondem às enunciadas no protocolo (Arsenio, Cooperman, \& Lover, 2000).

A pesquisa observacional coloca em evidência a oposição entre aquilo que as pessoas fazem e aquilo que relatam fazer, tal como ocorre em questionários e escalas (Breakwell, Hammond, Fife-Schaw, \& Smith, 2010), trazendo como vantagem a oportunidade de verificar a ocorrência de comportamentos que não são relatados pelos alunos ou pelos professores. Ademais, a observação direta possibilita identificar com maior segurança os fatores responsáveis pela manutenção do comportamento e, assim, traçar estratégias para modificá-los (Vandenberghe, 2002). Por outro lado, pelo fato 
da definição de bullying estar associada a comportamentos agressivos que acontecem repetidamente e que perduram ao longo dos meses, o tempo exigido para a avaliação de sua ocorrência por meio de observação direta torna este método pouco utilizado em pesquisas brasileiras (Alckmin-Carvalho, Izbicki, Barufi \& Melo, 2013). Outra limitação desta estratégia, no que tange à identificação de bullying, é a dificuldade em acessar comportamentos de menor visibilidade, tais como isolar ou excluir o colega (Griffin \& Gross, 2004; Seixas, 2005).

Uma segunda maneira de identificar comportamentos de bullying, mais frequentemente utilizada, refere-se à escolha de instrumentos que aferem as resposta por parte dos próprios alunos, sejam eles autoaplicáveis ou administrados pelos pesquisadores. Nesta categoria, estão incluídas as escalas, os inventários e os questionários (Seixas, 2005).

A utilização de questionários e escalas para o rastreamento de bullying possibilita a avaliação de diversas pessoas em pouco tempo, sobretudo nos casos em que as aplicações podem ser realizadas em grupo. Sendo assim, trata-se de uma estratégia de fácil aplicação e baixo custo e que possibilita estudos com grandes amostras e tratamento estatístico dos dados. Os dados coletados por estes métodos têm como base o autorrelato dos alunos sobre seu envolvimento em situações de bullying ou o relato de seus pares, professores e pais acerca desse envolvimento.

No caso do autorrelato dos alunos, a fidedignidade das informações pode ser questionável na medida em que as respostas autênticas podem não ser as socialmente desejadas e, portanto, podem ser omitidas pelo adolescente, sobretudo quando se trata da avaliação de comportamento 
agressivo (Craig, 1998; Seixas, 2005). Além disso, o aluno pode estar sendo vítima de bullying, sem efetivamente se perceber como alguém que está engajado na situação, pelo fato de ser comum a criança ou o adolescente alvo de bullying que acredita ser merecedora dos maus-tratos sofridos (Pearce \& Thompson, 1998; Ravens-Sieberer et al., 2004).

A terceira estratégia e a mais utilizada nos Estados Unidos, Canadá, Austrália e em países europeus, mas ainda pouco empregada em estudos brasileiros, denomina-se "nomeação de pares". Ela consiste em disponibilizar às crianças ou aos adolescentes uma lista com os nomes de seus colegas de classe e perguntar quais destes se enquadram nas características associadas ao bullying, tais como quais colegas são provocados frequentemente, quais são agressivos e quais são isolados (Seixas, 2005). Pesquisadores apontam que, entre as vantagens deste método de avaliação, está o fato dos pares estarem mais atentos a quem costuma agredir e ser alvo de agressões além de passarem mais tempo e normalmente interagirem mais com os colegas, quando comparados a outros informantes, estando em posição privilegiada para informar sobre o comportamento de seus pares (Craig, 1998; Seixas, 2005).

Perry, Kusel e Perry (1988) destacam que os dados colhidos por um grupo de pares minimiza a influência de preferências individuais por determinados colegas e aumenta a fidelidade estatística. Barrio, Martín, Montero, Fernández e Gutiérrez (2001), em um trabalho sobre as reações frente ao bullying, verificaram que os alunos vitimizados relatam procurar ajuda mais frequentemente dos amigos e, menos frequentemente, da família e dos professores, o que coloca os colegas de classe em posição privilegiada para 
identificar os engajados em bullying. Além disso, estudos que avaliaram as qualidades psicométricas de procedimentos sociométricos apontaram uma fidedignidade satisfatória (Pakaslahti \& Keltikangas-Jarvinen, 2000). De modo semelhante, Crick e Grotpeter (1995) defendem a utilização de instrumentos de nomeação pelos pares, considerando-os melhores informantes e salientando a vantagem adicional destes providenciarem múltiplas avaliações do comportamento, uma vez que um mesmo sujeito é avaliado por todos os seus colegas, diferentemente do que ocorre quando se utiliza uma única avaliação (Seixas, 2005).

Pesquisadores apontam que o rastreamento de bullying por meio de um único informante frequentemente gera resultados diferentes daqueles obtidos quando são utilizados múltiplos informantes, e enfatizam a importância de obter o relato tanto da própria criança ou do adolescente, quanto de seus pais, colegas e professores (Griffin \& Gross, 2004).

A fim de minimizar as dificuldades inerentes à tarefa de avaliar a ocorrência de bullying em escolas, e frente aos diversos instrumentos e estratégias que podem ser empregados com essa finalidade, um grupo de pesquisadores americanos vinculados ao Centro Nacional de Prevenção e Controle de Doenças publicou um compêndio sobre os instrumentos de avaliação disponíveis mundialmente. Este compêndio pode orientar pesquisas que buscam estabelecer as taxas de prevalência e incidência de bullying, as quais variam amplamente, conforme dados apresentados a seguir, a depender, entre outros fatores, do método de avaliação utilizado (Hamburger, Basile, \& Vivolo, 2011). 
De acordo com estudos internacionais, a prevalência de estudantes que sofreram bullying varia de 8 a 46\%, e, de agressores, de 5 a 30\% (Lopes Neto \& Saavedra, 2003). Um estudo de revisão que avaliou a ocorrência de bullying e possíveis associações com sintomas físicos e psicológicos, em uma amostra de 123.277 alunos provenientes de 28 países, apontou taxas de vitimização com grande variação entre países, sendo a mais baixa na Suécia $(6,3 \%)$ e a mais alta na Lituânia (41,4\%) (Due et al., 2005). Outra pesquisa que verificou a prevalência de bullying encontrou, em uma amostra de mais de 200.000 estudantes de 13 a 15 anos, provenientes de 66 países, uma média de 32,1\% dos adolescentes sofrendo bullying pelo menos uma vez nos dois meses anteriores ao estudo, e de $37,4 \%$ dos estudantes sofrendo vitimização uma vez nos trinta dias anteriores (Due \& Holstein, 2008).

No Brasil, um estudo transversal denominado Pesquisa Nacional de Saúde do Escolar (PeNse), realizado em 2009, com parceria entre a Secretaria de Vigilância em Saúde, Ministério da Saúde, IBGE e os departamentos de Medicina e Enfermagem da Universidade de São Paulo, teve como objetivo identificar e descrever, por meio de questionários autoaplicáveis, a ocorrência de bullying em uma amostra de 60.973 escolares de 13 a 15 anos, de escolas públicas e privadas de 26 estados brasileiros (Malta et al., 2010). A análise dos dados apontou que 5,4\% dos estudantes relataram ter sido alvos de bullying sempre ou quase sempre nos 30 dias anteriores, enquanto $25,4 \%$ da amostra foram raramente ou às vezes vítimas de bullying, havendo variações regionais. O estudo aponta para a urgente necessidade de adoção de medidas intersetoriais a partir de políticas públicas e práticas educativas, com a finalidade de reduzir e prevenir a ocorrência do bullying em escolas brasileiras (Malta et al., 2010). Outro estudo, realizado por um grupo de pesquisadores de 
Pelotas, RS, avaliou a ocorrência de bullying em duas escolas públicas de ensino fundamental, de $1^{\underline{a}}$ a $8^{\underline{a}}$ série, apontando taxas de vitimização entre pares de 17,6\% (Moura, Cruz, \& Quevedo, 2011).

É preciso considerar que os resultados relativos à prevalência de bullying sofrem grande variação entre os estudos em razão de diferenças metodológicas, tais como o instrumento utilizado, a definição do conceito e o período a partir do qual se consideram os episódios de vitimização, que variam desde um mês até um ano.

Destaca-se que, até o momento, não existe um instrumento validado no Brasil com propriedades psicométricas reconhecidas para a identificação de situações de bullying. Assim, pesquisadores têm utilizando predominantemente versões traduzidas de escalas e questionários internacionais padronizados, não validados para a realidade brasileira (Alckmin-Carvalho et al., 2013).

O uso de instrumentos não validados apresenta vulnerabilidades, pois não considera as definições mais recentes de validade de testes psicológicos recomendadas para a investigação de um fenômeno, tais como a verificação da estabilidade dos escores quando se utiliza o mesmo teste em períodos diferentes, os padrões de concordância entre os desfechos de testes desenvolvidos com a mesma finalidade e a eficácia na distinção de grupos que já se sabe serem diferentes (por exemplo, vítimas e não vítimas de bullying) (Primi, Muniz, \& Nunes, 2009; Stelko-Pereira, 2012). Deste modo, apesar da adaptação de instrumentos já validados em outro país facilitar o intercâmbio de informações científicas, possibilitando estudos transculturais e oferecendo menores custos em comparação à criação de um novo instrumento, trata-se de uma prática que exige procedimentos rigorosos para que sejam mantidos o 
status científico e as inferências que os instrumentos podem fornecer (Pessotto, 2012). 


\section{Capítulo 6. Associação entre bullying e características familiares}

Ao buscar compreender o comportamento agressivo entre pares, não se pode deixar de considerar o papel da família, ambiente responsável pela transmissão de valores, crenças, ideias e significados presentes na sociedade, e no qual a criança desenvolverá repertórios comportamentais que serão reproduzidos na interação com outros ambientes, tal como no relacionamento entre colegas da escola (Assis, Avanci, \& Oliveira, 2009; Bolsoni-Silva \& Marturano, 2002; Del Prette \& Del Prette, 2003; Santos et al., 2008; Silva, Farias, Silvares, \& Arantes, 2008).

Alguns autores têm chamado a atenção para o fato de que problemas comportamentais apresentados na infância podem persistir na adolescência e na vida adulta e que os pais e/ou cuidadores possuem grande participação neste processo (Marler, Trainor, \& Davis, 2005; Sapienza \& Pedromônico, 2005). Assim, a ausência de interações saudáveis entre pais e filhos pode afetar o desenvolvimento das crianças e sua preparação para a vida social nos anos posteriores.

Estudos de abordagem analítico-comportamental consideram a importância das interações indivíduo-ambiente no desenvolvimento humano e apontam, entre os mais diversificados contextos em que o indivíduo se insere, a família como tendo um papel fundamental. É na família que a criança desenvolverá repertórios e habilidades que serão requeridos na interação em outros ambientes (Del Prette \& Del Prette, 2003). Assim, famílias que apresentam características como discórdia conjugal, habilidades parentais educacionais deficitárias, falta de monitoramento e negligência aumentam o 
risco de desenvolvimento de problemas de comportamento nas crianças (Costa, Teixeira, \& Gomes, 2000).

A associação entre características familiares e problemas de comportamento foi objeto de uma pesquisa de grande repercussão, realizada pelo psiquiatra inglês Michael Rutter. Nesse estudo, o autor circunscreveu, a partir de um amplo estudo populacional com crianças da ilha de Wight e de Londres, fatores familiares específicos e sua associação com o desenvolvimento de alterações comportamentais na infância (Rutter, 1981). Na investigação, foram verificadas diversas similaridades no funcionamento familiar das crianças que apresentavam um histórico de alterações comportamentais, sendo essas similaridades entendidas como fatores de risco para o desenvolvimento de tais alterações. Estes fatores passaram a compor um Índice de Adversidade Familiar (IAF), cuja investigação é realizada por meio de uma entrevista semiestruturada com os pais.

Cabe aqui salientar que se entende como fatores de risco as condições ou variáveis associadas à possibilidade de ocorrência de resultados negativos para a saúde, o bem-estar e o desempenho social (Jessor, Bos, Vanderryn, Costa, \& Turbin, 1995). Neste contexto, embora a presença de um único fator de risco, na investigação de Rutter, não tenha demonstrado associação com alterações comportamentais na amostra estudada, o acúmulo de dois fatores de risco aumentou em quatro vezes a probabilidade de algum comprometimento no desenvolvimento infantil (Rutter, 1981).

Destaca-se que o IAF (Rutter, 1981) tem sido utilizado até os dias atuais em diversos estudos nacionais e internacionais (e.g. Biederman et al., 1995; Fergusson \& Lynskey, 1996; Kim-Cohen, 2007; Silvares, 1993; Tavares da 
Silva, Farias, Silvares, \& Arantes, 2008). Além disso, vários pesquisadores têm estudado separadamente os fatores de risco descritos pelo autor, tais como baixo nível socioeconômico da família (Assis et al., 2009; Brancalhone, Fogo, \& Williams, 2004), estrutura familiar (Assis et al., 2009; Luizzi \& Rose, 2010), discórdia conjugal (Mohr, 2006;Pesce, 2009) e práticas parentais negativas (Bolsoni-Silva \& Loureiro, 2011; O'Connel, Boat, \& Warner, 2009).

Especificamente sobre as características familiares que tornam 0 indivíduo mais vulnerável para o envolvimento em situações de bullying, estudos têm encontrado correlações entre discórdia conjugal e ambiente familiar violento, de um lado, e o envolvimento como agressor, de outro (Baldry \& Farrington, 2000; Connolly \& O'Moore, 2003; Ferguson, San Miguel, \& Hartley, 2009). Pesquisas que avaliem as associações entre estas variáveis e o envolvimento em situações de bullying como vítima, por sua vez, são menos frequentes (Baker, 2012; Cummings, Goeke-Morey, \& Pap, 2003; Holt, Kaufman, Kantor, \& Finkelhor, 2008).

Buscando associações entre ambiente familiar violento e o engajamento em bullying, Pinheiro e Williams (2009) avaliaram uma amostra de 239 adolescentes, com idades entre 11 e 15 anos. Os resultados apontam que a exposição à violência interparental ou parental direta esteve associada com ser perpetrador e alvo de bullying na escola, com diferenças na forma de engajamento e no gênero, mas não para a vitimização. Os dados apresentados apontam para a importância da investigação de características familiares e as possíveis associações entre estas e o surgimento de problemas de comportamento, incluindo o envolvimento em situações de bullying (Pinheiro \& Williams, 2009). 


\section{Capítulo 7. Prevenção de bullying}

Ao buscarmos compreender como são selecionados e mantidos os comportamentos de bullying no repertório comportamental de crianças e adolescentes, não se pode deixar de considerar a análise das diferentes esferas da vida do indivíduo (Carvalhosa, 2010; Meyer et al., 2010; Sampaio \& Andery, 2012; Skinner, 1978). Uma vez que a ocorrência de bullying em ambiente escolar é multideterminada, sendo a etiologia bastante complexa, recomenda-se que pesquisadores e clínicos que se ocupam de estudar e propor medidas para lidar com o comportamento agressivo devam necessariamente atentar para um conjunto de fatores e processos, relacionados ao indivíduo e suas características de personalidade, aos seus colegas, à sua família, escola e comunidade (Carvalhosa, 2010).

Pesquisadores que investigam a prevenção de bullying têm identificado uma série de fatores de risco em cada um dos níveis acima descritos. A Tabela 1 descreve os fatores de risco para o engajamento em comportamentos de bullying, como vítima e como perpetrador (Baker, 2012; Carvalhosa, 2010; Holt et al., 2008; Olweus et al., 1999). 
Tabela 1

Fatores de risco relacionados ao engajamento em comportamento de bullying

Nível de análise

\begin{tabular}{cc}
\hline Características & $\begin{array}{c}\text { impulsividade; personalidade dominante; } \\
\text { falta de empatia; dificuldade de seguir } \\
\text { regras; baixa tolerância à frustração; força } \\
\text { individuais }\end{array}$ \\
$\begin{array}{c}\text { física (sobretudo entre meninos); Pouco } \\
\text { envolvimento em atividades escolares }\end{array}$
\end{tabular}

\begin{tabular}{|c|c|c|}
\hline $\begin{array}{l}\text { Características } \\
\text { Familiar }\end{array}$ & $\begin{array}{l}\text { falta de envolvimento e interesse; } \\
\text { permissividade parental; falta de } \\
\text { supervisão; punições físicas }\end{array}$ & $\begin{array}{l}\text { superproteção; } \\
\text { conflito entre os } \\
\text { pais }\end{array}$ \\
\hline $\begin{array}{l}\text { Relacionamento } \\
\text { entre pares }\end{array}$ & $\begin{array}{l}\text { atitude positiva dos pares frente a } \\
\text { episódios de violência; contato com outras } \\
\text { crianças que perpetram bullying }\end{array}$ & $\begin{array}{l}\text { poucos amigos } \\
\text { íntimos; déficits de } \\
\text { habilidades de } \\
\text { resolução de } \\
\text { problemas }\end{array}$ \\
\hline Escola & $\begin{array}{l}\text { falta de supervisão em períodos de } \\
\text { recreio; professores indiferentes ou } \\
\text { permissivos; indiferença dos professores } \\
\text { ao presenciar comportamentos de bullying }\end{array}$ & $\begin{array}{l}\text { presença de alunos } \\
\text { agressivos na } \\
\text { classe; falta de } \\
\text { supervisão em } \\
\text { períodos de recreio; } \\
\text { professores } \\
\text { indiferentes ou } \\
\text { permissivos }\end{array}$ \\
\hline
\end{tabular}

Sofrer bullying

insegurança; sensibilidade; problemas de assertividade; fraqueza física (sobretudo entre meninos)

Destaca-se que, embora um fator de risco não esteja relacionado ao surgimento de problemas de comportamento, a presença de variados fatores de risco, em diferentes níveis da vida do indivíduo, aumenta a vulnerabilidade para o engajamento em bullying e outros problemas de comportamento (Dumka, Roosa, Michaels, \& Suh, 1995; Sá, Bordin, Martin, \& Paula, 2010).

Programas de prevenção de bullying, em diferentes níveis, devem primeiramente identificar fatores de risco, descrevê-los, estudar a sua relação com o engajamento em bullying e, somente após esses procedimentos, desenvolver estratégias eficientes para lidar com esses fatores (Carvalhosa, 
2010). Até o momento, o Bullying Prevention Program (BPP), programa de prevenção de bullying desenvolvido por Dan Olweus (1993), é considerado um dos mais bem documentados e efetivos na redução da violência entre pares. $O$ BPP foi desenvolvido, refinado e sistematicamente avaliado em projetos de intervenção envolvendo 2.500 crianças e adolescentes de 42 escolas, na cidade de Bergen, Noruega, durante um período de dois anos.

O programa de Olweus (1993) apresenta como meta modificar o ambiente escolar por meio da participação ativa dos adultos e da mudança nas normas sociais que promovem a aceitação passiva das pessoas que presenciam o bullying na escola (Olweus, et al., 1999). A mensagem básica do programa é: "Bullying não é aceitável em nossa escola e nós vamos fazer com que este comportamento chegue ao fim". De acordo com Olweus, para tal mudança, faz-se necessário o engajamento dos funcionários e diretores da escola, que são considerados os principais implementadores do programa em um momento inicial (Olweus et al., 1999).

O autor aponta que o interesse de pais, funcionários e educadores pode ser despertado por meio da aplicação do Bully/Victim Questionnaire (BVQ), um instrumento padronizado desenvolvido por Olweus para a verificação da prevalência do bullying na escola. A constatação de que há episódios de bullying na escola, somada à conscientização dos adultos sobre suas consequências no desenvolvimento dos engajados no fenômeno, é uma estratégia fundamental para aumentar o interesse na implementação do programa.

O BPP é constituído por 12 componentes principais, aplicados em três níveis: na estrutura escolar, em sala de aula e individualmente. Com isso, 
espera-se que os estudantes sejam expostos a mensagens consistentes, vindas de diferentes fontes, sobre o modo de funcionar da escola e o posicionamento frente ao bullying (Olweus et al., 1999). Os componentes do programa são classificados como principais e altamente desejáveis. Comparações entre implementações em diversas escolas demonstraram, tanto estatisticamente como pela experiência direta dos pesquisadores consultores, que as intervenções em sala de aula são as mais promissoras, estando relacionadas aos melhores resultados. Entre elas, destacam-se duas: (1) Estabelecimento e reforçamento de regras em sala de aula sobre bullying; Discussão regular sobre vários aspectos do bullying e de comportamentos antissociais e (2) Encontros regulares dos consultores do programa com alunos com o objetivo de desenvolver diversas atividades, tais como grupos de discussão, role-playing e atividades escritas sobre bullying (Olweus et al., 1999).

Entre os principais resultados da implementação do BPP nas escolas de Bergen, destacam-se a redução dos comportamentos de bullying em aproximadamente $50 \%$ e diminuição de comportamentos antissociais, tais como vandalismo e roubo, avaliados por questionários autoaplicáveis e pelo relato dos professores. Posteriormente, o BPP foi desenvolvido em diversos países, como EUA, Inglaterra, Canadá e Alemanha, sendo os resultados mais modestos, mas, ainda assim, bastante significativos (Olweus et al., 1999).

Tendo em vista a variedade e gravidade das alterações comportamentais de curto, médio e longo prazo a que a exposição ao bullying está associada, tanto para a vítima quanto para o agressor, faz-se premente o desenvolvimento de programas de prevenção a serem incluídos no cotidiano 
das escolas brasileiras, a fim de garantir um ambiente escolar sadio e seguro (Fekkes et al., 2005; Lopes Neto \& Saavedra, 2003; Mohaprata et al., 2010). 


\section{JUSTIFICATIVA}

partir do exposto até aqui, compreende-se que ser vítima de
bullying traz consequências desastrosas para o desenvolvimento humano, gerando sofrimento e comprometendo a autoestima dos envolvidos, além de se configurar como um fator de risco para o suicídio (Espelage \& Holt, 2013; Kim et al., 2009; Klomeket al., 2013; Rivers \& Noret, 2013) e para o desenvolvimento de diversos problemas de comportamento e transtornos psiquiátricos (Frank \& Acle, 2014; George, 2013; Ledwell \& King, 2013; Reijntjes et al., 2010).

Uma vez que estudos longitudinais apontam que há uma associação entre a vitimização na infância e adolescência e a busca por tratamento psiquiátrico em idade adulta (Sourander et al., 2009), os custos dos tratamentos oferecidos na rede pública para problemas associados ao envolvimento em situações de bullying podem onerar os sistema públicos de saúde, incluindo o doBrasil.

Deste modo, intervir precocemente em situações de bullying é importante na medida em que a perpetuação deste fenômeno em escolas brasileiras pode colocar em risco a segurança pública, haja vista que casos de School Shooting têm ocorrido recorrentemente em diversos países (Clabaugh \& Clabaugh, 2005; Lickel et al., 2003; Muschert, 2007), inclusive no Brasil (Lima, 2011; Vieira et al., 2009).

A literatura aponta que conhecer o comportamento de crianças e adolescentes em diferentes contextos é fundamental para elaborar medidas de prevenção e de tratamento adequadas (Borsa \& Nunes, 2009; Rocha, Ferrari \& 
Silvares, 2011). No entanto, nota-se uma escassez de trabalhos nacionais que utilizam múltiplos informantes, presentes nestes diferentes contextos, para a avaliação de problemas de comportamento em vítimas de bullying. Deste modo, torna-se essencial a realização de investigações que obtenham informações nos diferentes contextos dos quais o aluno participa.

Neste sentido, o presente estudo difere de outras pesquisas realizadas no Brasil até o momento, por utilizar uma metodologia mais compreensiva, tanto para a identificação de bullying (o próprio aluno e seus pares) como para a avaliação de problemas de comportamento nos alunos vitimizados e seus controles (autorrelato e relato dos professores). E ainda, por comparar o relato entre os informantes.

Questões relacionadas à vitimização e sua relação com características da família e outros problemas de comportamento ainda carecem de investigações empíricas, especialmente no cenário nacional, que visem a desenvolver medidas preventivas eficazes que minimizem as alterações comportamentais a que o envolvimento em situações de bullying está associado. As intervenções devem ter como meta a promoção de formas mais adequadas de convivência em grupo, estimulando comportamentos pró-sociais, cujos efeitos serão a diminuição de problemas e um melhor aproveitamento dos investimentos públicos nas áreas da saúde, da educação e da segurança, a exemplo do que tem sido realizado em países mais desenvolvidos. 


\section{OBJETIVOS}

\subsection{Objetivo Geral}

dentificar possíveis associações entre 0 envolvimento de adolescentes em situações de bullying como vítima, seus problemas de comportamento e suas características familiares.

\subsection{Objetivos Específicos}

(1) Avaliar problemas de comportamento em vítimas e não vítimas de bullying, reportados pelos alunos e por seus professores e comparar os escores nos dois grupos;

(2) Comparar os problemas de comportamento reportados por vítimas de bullying e por seus professores;

(3) Comparar o índice de adversidade familiar entre adolescentes vítimas e não vítimas de bullying;

(4) Verificar possíveis associações entre o Índice de Adversidade Familiar e os problemas de comportamento. 


\subsection{Hipóteses}

(1) Alunos vítimas de bullying relatarão mais problemas de comportamento internalizantes, externalizantes e das escalas síndrome de depressão e ansiedade;

(2) Os professores avaliarão mais problemas de comportamento externalizantes e nas escalas síndrome de comportamento agressivo e de quebrar regras em vítimas de bullying;

(3) Os professores relatarão mais problemas de comportamento do tipo externalizante, enquanto os alunos vítimas de bullying relatarão mais problemas internalizantes;

(4) Os alunos vítimas de bullying apresentarão maior índice de adversidade familiar;

(5) Haverá associação entre os problemas de comportamento e o índice de adversidade familiar. 


\section{MÉTODO}

\subsection{Amostra}

presente estudo é do tipo descritivo, observacional, com
delineamento caso-controle. Foram comparados dois grupos: o primeiro foi composto por alunos alvo de bullying e constituiu o grupo caso (CA); o segundo, formado por alunos não vítimas de bullying e que também não foram classificados como agressores, constituiu o grupo controle (CO). Trata-se de uma amostra probabilística e o local de seleção dos participantes seguiu critérios de conveniência.

Participaram do estudo adolescentes regularmente matriculados no segundo ciclo do ensino fundamental de duas escolas públicas do município de São Paulo. Participaram, ainda, os pais e professores das disciplinas de Português e Matemática dos referidos adolescentes. Os critérios de inclusão dos jovens na pesquisa são: a) estar regularmente matriculados em escolas de Ensino Fundamental II e b) estar presente nos dias em que as avaliações forem realizadas.

\subsection{Local de realização da pesquisa}

Os dados foram coletados nas dependências de duas escolas públicas, localizadas na região centro-sul e oeste da cidade de São Paulo/SP; a primeira, em que foi realizado o estudo piloto, e a segunda, onde aconteceu a coleta de dados após o refinamento da metodologia do estudo. 


\subsection{Instrumentos}

Para auxiliar na compreensão dos instrumentos utilizados na presente pesquisa, primeiramente será apresentado um quadro descritivo das variáveis de interesse do estudo, dos instrumentos utilizados para avaliá-las e do informante requerido em cada avaliação (Tabela 2). Posteriormente, será apresentado mais detalhadamente cada instrumento.

Tabela 2

Variáveis de interesse, instrumentos utilizados, informantes e tempo de aplicação

\begin{tabular}{|c|c|c|c|}
\hline $\begin{array}{l}\text { Variável de } \\
\text { interesse }\end{array}$ & Instrumento/ autores & $\begin{array}{l}\text { Informante } \\
\text { requerido }\end{array}$ & $\begin{array}{l}\text { Tempo de } \\
\text { aplicação }\end{array}$ \\
\hline \multirow{2}{*}{$\begin{array}{l}\text { Vítimas de } \\
\text { bullying }\end{array}$} & $\begin{array}{c}\text { EVE } \\
\text { (Stelko-Pereira, 2012) }\end{array}$ & Adolescentes & $20 \mathrm{~min}$ \\
\hline & $\begin{array}{c}\text { Peer assessment } \\
\text { (Rubin, Bukowski, \& Parker, } \\
\text { 1998) }\end{array}$ & Pares & $20 \mathrm{~min}$ \\
\hline \multirow{2}{*}{$\begin{array}{l}\text { Perpetradores de } \\
\text { bullying }\end{array}$} & & Adolescentes & $20 \mathrm{~min}$ \\
\hline & ( & Pares & $20 \mathrm{~min}$ \\
\hline $\begin{array}{l}\text { Adversidade } \\
\text { familiar }\end{array}$ & $\begin{array}{c}\text { Índice de Adversidade Familliar } \\
\text { (IAF) } \\
\text { (Rutter, 1981) }\end{array}$ & $\begin{array}{c}\text { Pais dos } \\
\text { adolescentes } \\
\text { vítimas e não } \\
\text { vítimas de } \\
\text { bullying }\end{array}$ & $10 \mathrm{~min}$ \\
\hline
\end{tabular}
YSR/11-18 anos
(Achenbach \& Rescorla, 2001)
Adolescentes $\quad 30 \mathrm{~min}$

Problemas de comportamento

TRF/6-18 anos

(Achenbach \& Rescorla, 2001)
Professores de

Português e

Matemática
$30 \mathrm{~min}$ 


\subsubsection{Avaliação}

A - Escala de Violência Escolar (EVE) - Versão Estudante (Stelko-Pereira, 2012) (ANEXO 2)

A EVE é uma escala autoaplicável que investiga a violência escolar a partir de múltiplos informantes da escola, apresentando quatro versões, uma para cada informante (alunos, professores, inspetores e diretores ou coordenadores pedagógicos) (Stelko-Pereira, 2012). Esta escala é utilizada com alunos de 6 a 9 ano do Ensino Fundamental, em aplicação coletiva ou individual, e tem como objetivos investigar a frequência e a gravidade de violência em ambiente escolar e avaliar a frequência com que alunos e funcionários são vítimas e autores de violência.

A primeira versão do instrumento, fruto da dissertação de Mestrado de Stelko-Pereira (2009), chamava-se Questionário de Investigação de Prevalência de Violência Escolar (QIPVE), tendo sido desenvolvido com base nos instrumentos da UNESCO (Abromovay, 2005) e do Ministério de Educação e Justiça dos Estados Unidos (Dinkes, Cataldi, Kena, Baum, 2006). Desde então, foram feitas aplicações do instrumento em cinco escolas públicas, envolvendo, no total, cerca de 2.000 alunos, 200 professores, cinco diretores e cinco inspetores. Além disso, foi realizada avaliação das propriedades psicométricas do instrumento na versão para alunos e professores, tanto em relação à análise de consistência interna, quanto à análise de componentes principais (Stelko-Pereira, 2012).

Até o momento, não há uma forma padrão de interpretação do escore do instrumento. Tal carência na padronização não é exclusiva da EVE, uma vez 
que tanto instrumentos nacionais quanto internacionais têm apresentado dificuldade em definir um ponto de corte que indicaria indivíduos em situação de vítima e autor-vítima e escolas que necessitam de intervenção. Esta dificuldade se deve à complexidade em se delimitar um parâmetro adequado, tal como um nível mínimo de violência que não esteja associado ao surgimento de problemas de comportamento e transtornos psiquiátricos, ou seja, um nível de violência aceitável nas relações sociais. Utilizar o critério da normalidade para definir um ponto de corte também traz problemas, uma vez que as escolas brasileiras deveriam ter médias muito inferiores do que as atuais em relação à violência (Stelko-Pereira, Williams \& Freitas, 2010). A autora do instrumento sugere adotar o critério da curva normal para avaliar o engajamento em bullying, ou seja, verificar a média ou mediana da amostra e considerar o aluno acima de um desvio padrão da média ou mediana como engajado em situação de bullying.

\section{B - Lista de características dos amigos de sala de aula - Versão traduzida do Peer Assessment (Rubin et al., 1998) (ANEXO 3)}

Consiste em um instrumento sociométrico com trinta afirmativas que descrevem características comportamentais de amigos/colegas da sala de aula. O respondente deve escrever, ao lado de cada afirmativa, o nome de colega(s) de sala que, em sua opinião, mais é(são) identificado(s) com os comportamentos listados. As afirmativas são agrupadas em três fatores: Fator 1 (características pró-sociais), Fator 2 (características de comportamento agressivo) e Fator 3 (características comportamentais de vitimização). O instrumento original desenvolvido por Rubin et al. (1998) foi traduzido para o 
português e retraduzido para o inglês por pesquisadores bilíngues diferentes (back-translation), conforme estudo de Lisboa (2005).

Lisboa (2005), comparando os resultados de seus estudos com os da pesquisa de Rubin et al. (1998) determinou o ponto de corte que é utilizado em estudos brasileiros para classificar os alunos como vítimas de bullying ou como agressores (Binsfeld \& de Macedo Lisboa, 2010; Calbo, Busnello, Rigoli, Schaefer, \& Kristensen, 2009; Dias, Lisboa, Koller, \& De Sousa, 2011). Destaca-se que, no presente estudo, utilizou-se apenas as afirmativas do instrumento referentes às características associadas à vitimização.

\section{C - Entrevista semiestruturada para aferição do índice de adversidade familiar (Rutter, 1981) (APÊNDICE 1)}

Para a avaliação do Índice de Adversidade Familiar, foi realizada uma entrevista semiestruturada com os pais dos adolescentes que constituíram a amostra, a qual versou sobre seis itens considerados adversos para 0 desenvolvimento infantil, segundo Rutter (1981): (1) Discórdia conjugal; (2) Baixa renda familiar; (3) Histórico de transtorno psiquiátrico nos pais; (4) Histórico de criminalidade nos pais; (5) Número excessivo de filhos e (6) Número excessivo de moradores na mesma casa. Para cada item de adversidade, será atribuído 0,2 ponto, totalizando um escore máximo de 1,4 ponto, e um mínimo de nenhum ponto.

Conforme apresentado nos procedimentos, tomando por base os dados da Pesquisa de Condições de Vida, conduzida pela Fundação Sistema Estadual de Análise de Dados (2006), foi considerada a presença do fator "Número excessivo de filhos" quando a família tinha mais que 1,955 filhos (valor referente à média de 1,9 filhos acrescido de um erro padrão no valor de 
0,035). Foi considerado que o fator "Número excessivo de pessoas na mesma casa" estava presente quando residiam mais que 3,258 pessoas na mesma residência (valor referente à média de 3,21 filhos acrescido de um erro padrão no valor de 0,048$)$. Em relação ao fator "Baixa renda mensal", foi considerado fator presente quando os rendimentos da família es a $\mathrm{R} \$ 2.147,67$ (valor referente à média de rendimentos de $\mathrm{R} \$ 2.001,00$ acrescido de um erro padrão no valor de 146,67). Foram considerados como transtornos psiquiátricos os casos de alcoolismo, adição a drogas, esquizofrenia e demais patologias mentais. Quando os pais eram separados e as mães solteiras ou viúvas, a criança pontuou como positivo para presença de discórdia conjugal.

\section{D - Inventário de Autoavaliação para Adolescentes - Versão brasileira do} Youth Self Report/11-18 (YSR/11-18; Achenbach \& Rescorla, 2001). ${ }^{2}$

É um instrumento que permite levantar a ocorrência de problemas de comportamento em jovens entre 11 e 18 anos de idade, a partir do ponto de vista dos próprios adolescentes. O inventário é dividido em duas partes: a primeira é composta por itens destinados à avaliação das competências dos jovens, incluindo prática de esportes, atividades extraescolares, relacionamentos com amigos e desempenho acadêmico; a segunda parte do YSR inclui uma lista com 105 itens, que se referem à avaliação de problemas emocionais/comportamentais (exs.: "Comporto-me de maneira infantil para a minha idade", "Machuco-me de propósito" ou "Já tentei me matar"), e outros 14 itens, que correspondem a comportamentos socialmente desejáveis (exs.: "Sou

2 Um exemplar do questionário pode ser visualizado no endereço eletrônico: http://www.aseba.org/forms/ysr.pdf 
bastante honesto(a)" e "Tento ajudar os outros quando posso") e que compõem a escala Aspectos Positivos.

As escalas de problemas de comportamentos são reunidas em três índices gerais, a saber, Escala de Internalização, Escala de Externalização e Escala Total de Problemas Emocionais/Comportamentais. A Escala de Internalização engloba as três primeiras escalas avaliadas; a Escala de Externalização abrange as duas últimas escalas; e a Escala Total de Problemas Emocionais/Comportamentais engloba todos os itens de problemas de comportamento analisados pelo inventário, possibilitando uma visão geral sobre os comportamentos dos adolescentes a partir da autoavaliação. Os escores podem ser classificados em não-clínicos, clínicos e limítrofes. De acordo com o manual do Inventário, os casos considerados limítrofes podem ser incluídos na categoria clínica para fins de pesquisa. Segundo as normas brasileiras (Rocha, 2012), para os escores totais (soma das oito escalas), os pontos de corte determinam que o escore deve ser inferior a 60 para a categoria não-clínica; para a categoria limítrofe, deve estar entre 60 e 63; e deve ser maior que 63 para categoria clínica. A pontuação bruta obtida no YSR, em cada uma das escalas e agrupamentos, é convertida em escores T. Pesquisadores brasileiros têm utilizado esta forma de correção (e.g. Borsa \& Nunes, 2008; Pacheco et al., 2003; Schöen-Ferreira, 2007; Valverde, Vitalle, Sampaio, \& Schöen, 2012). 


\section{E - Lista de Verificação Comportamental para Professores - Versão}

brasileira do Teacher Report Form/6-18 (TRF/6-18; Achenbach \& Rescorla, 2001). ${ }^{3}$

A Lista de Verificação Comportamental para Professores foi desenvolvida com o objetivo de obter relatos dos professores sobre seus alunos de 6 a 18 anos. O instrumento é constituído de duas partes: a primeira, que avalia o funcionamento adaptativo (FA), e a segunda, que avalia os problemas de comportamento que integram o repertório comportamental infantojuvenil. O FA constitui uma escala geral e se refere a uma pontuação global obtida a partir da soma dos escores em cinco itens ou subescalas: (1) desempenho acadêmico (DA) e grau de dedicação nos trabalhos escolares; (2) adequação do comportamento da criança no ambiente escolar; (3) nível de aprendizagem e (4) o quão feliz ela é. Nesta escala geral, as crianças e os adolescentes que obtiverem escores abaixo ou igual a 40 estão incluídas na faixa clínica.

A segunda parte da avaliação, referente aos problemas comportamentais, é composta por 113 itens (havendo possibilidade de 0 respondente acrescentar até cinco dificuldades), os quais devem ser pontuados pelos professores com 0,1 ou 2. Os comportamentos são agrupados em oito subescalas, que avaliam os aspectos internalizantes e externalizantes e 0 funcionamento global, cujos escores acima ou iguais a 60 são incluídos na faixa clínica do questionário. Destaca-se que a classificação "clínica" significa que as crianças e adolescentes podem evidenciar necessidade de 
acompanhamento psicológico e/ou pedagógico, sendo desejável que se obtenham informações de variadas fontes antes de emitir julgamento conclusivo sobre intervenções destinadas às crianças.

\subsubsection{Instrumentos de apoio à pesquisa}

A - Termo de Consentimento Livre e Esclarecido (APÊNDICE 2): autorização por escrito, a ser assinada pelo responsável do adolescente, sujeito de pesquisa, no qual declara que este aceita colaborar com todas as etapas da pesquisa. Nesta autorização, o pesquisador garante o seguimento de questões éticas, tais como o sigilo da identidade dos participantes.

B - Termo de Assentimento Informado (APÊNDICE 3): tem como objetivo explicar a pesquisa ao adolescente, em linguagem clara e amigável, além de colher sua autorização por escrito e sua declaração de que entende e aceita colaborar com as etapas da pesquisa.

C - Carta de apresentação do projeto à escola (APÊNDICE 4): descreve as etapas da pesquisa e colhe a anuência, por escrito, da instituição na qual será realizada a coleta de dados. 


\subsection{Procedimentos}

Inicialmente, foi realizado contato com uma escola da Rede Pública de Ensino Fundamental da cidade de São Paulo, onde foi feito o estudo piloto. Esta etapa do estudo, realizado com alunos de duas turmas, de $6^{\circ}$ e $7^{\circ}$ ano, de uma escola municipal situada na periferia de São Paulo, foi desenvolvida a fim de refinar a metodologia do estudo final, especificamente no que tange à estratégia a ser utilizada para a identificação de alvos de bullying. , sendo constituída por alunos com famílias de baixa renda. Com o objetivo de testar qual seria a melhor forma de avaliação do envolvimento em situações de bullying como vítima, duas formas de aplicação dos instrumentos escolhidos foram testadas: a primeira, no $6^{\circ}$ ano, em que o pesquisador entregou os questionários destinados à identificação de bullying e solicitou aos alunos que o preenchessem, cada um em seu ritmo; e a segunda, em que o pesquisador leu em voz alta cada uma das questões e solicitou que os alunos 0 acompanhassem.

As questões do EVE foram lidas em voz alta em um primeiro momento, em uma sala com 30 alunos, com colaboração de uma aluna de mestrado do Instituto de Psicologia da Universidade de São Paulo. Em uma segunda aplicação, o pesquisador responsável leu em voz alta cada uma das questões, a fim de evitar alunos retardatários e questionários incompletos. A leitura em voz alta se mostrou mais apropriada. Durante a avaliação, os pesquisadores circularam na sala de aula com o objetivo de evitar dispersão e conversas paralelas entre os alunos.

O LCASA foi aplicado em voz alta e coletivamente. Novamente, a leitura de cada uma das 30 questões se mostrou mais apropriada. Para a aplicação 
deste instrumento, as cadeiras foram separadas e pediu-se aos alunos que não falassem os nomes que escreveram no preenchimento do instrumento. A fim de prover maior privacidade, o instrumento foi desenvolvido em duas folhas: a primeira, utilizada com a finalidade de esconder os nomes mencionados em cada uma das características, caso o aluno sentisse necessidade, continha somente um questionário de identificação dos alunos informantes; a segunda, contemplava as questões e o espaço para nomear os alunos.

A coleta de dados do estudo final ocorreu entre agosto e novembro de 2013 e foi realizada em uma escola com características semelhantes às da instituição que participou do estudo piloto. No contato inicial com a escola, foi apresentado o projeto para o coordenador e foram discutidas as implicações decorrentes da participação da instituição, de seus alunos e professores na pesquisa, informações estas descritas no TCLE. Após a aprovação da escola, os adolescentes foram convidados a participar do estudo, assim como seus pais e professores.

As avaliações dos alunos foram realizadas nas dependências da escola, durante seu horário de funcionamento, e aconteceram em três momentos: no primeiro, os adolescentes que preencheram os critérios de inclusão descritos anteriormente foram convidados a responder à EVE e à LCASA. No segundo, foram identificadas as vítimas de bullying, que compuseram o grupo de casos (CAs), as quais foram pareadas por idade, sexo e sala de aula, aos seus controles (COs). Destaca-se que foram excluídos do grupo controle os participantes identificados pelo LCASA como perpetradores de bullying. Os alunos dos dois grupos tiveram seus perfis comportamentais avaliados por 
meio do YSR/11-18 (Youth Self Report) e do TRF/6-18 (Teacher Report Form), preenchido pelos professores das disciplinas de Português e Matemática.

Por fim, no terceiro momento, foi avaliada a adversidade familiar do grupo de CAs e COs. Foi enviado, por meio da secretaria da escola, um envelope com uma carta destinada aos pais dos participantes, explicando brevemente a pesquisa (APÊNDICE 5), juntamente com o formulário avaliação do índice de adversidade familiar. Dentro do envelope, havia uma etiqueta com a indicação para que os pais preenchessem o formulário e entregassem à escola, por meio de seus filhos, os envelopes lacrados, a fim de garantir o sigilo das informações fornecidas. Dado que menos da metade dos envelopes foram retornados, o que inviabilizaria as análises estatísticas, o pesquisador responsável entrou em contato por telefone com os pais dos dois grupos.

A Figura 1 ilustra as fases do estudo.

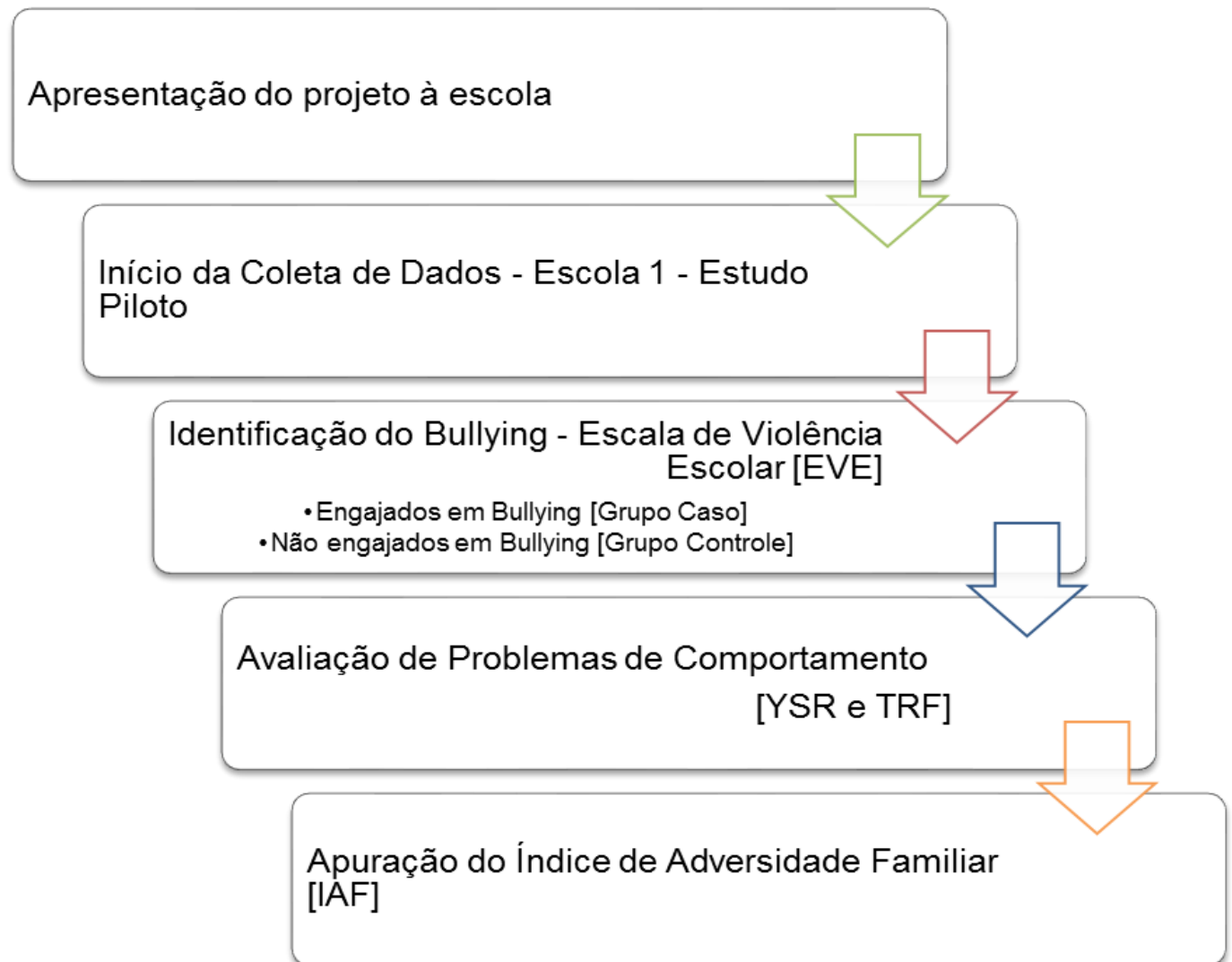

Figura 1. Descrição das fases do estudo. 


\subsection{Aspectos Éticos}

O projeto foi aprovado, no dia 11 de Março de 2013, pelo Comitê de Ética em Pesquisa com Seres Humanos do Instituto de Psicologia da Universidade de São Paulo, sob o Processo CEP/IP 210.822, CAAE 04741913.3.0000.5561 (ANEXO 3).

A instituição, os adolescentes, pais e professores, na qualidade de informantes sobre o comportamento infantil/juvenil, receberam os documentos estabelecidos pelo Conselho Nacional de Saúde em relação à pesquisa com sujeitos humanos (Carta de Informação, Termo de Consentimento Livre e Esclarecido e Termo de Assentimento Informado). Todos os participantes tiveram o direito de desistir ou interromper o processo de avaliação a qualquer momento sem nenhum encargo para eles ou para o representante legal.

As informações obtidas foram analisadas em conjunto, assegurando 0 sigilo da identificação de todos os participantes. Ao final do procedimento de coleta, foi realizada uma entrevista devolutiva com alunos, pais e professores, para que os resultados encontrados na pesquisa fossem devidamente informados. Além disso, os participantes avaliados como alvos de bullying foram encaminhados para acompanhamento psicológico em clínicas-escola de psicologia ou outros serviços da rede pública de saúde.

\subsection{Análise dos dados}

Os dados obtidos foram tratados por meio de recursos da estatística e da informática, recorrendo ao programa de tratamento estatístico SPSS (Statistical Package for Social Science), em sua $19^{\text {a }}$ versão. Foram 
empregadas técnicas da Estatística Descritiva e Estatística Inferencial, apresentando, os dados de frequências absolutas e relativas, de médias aritméticas e de desvios-padrão, segundo as normativas de métodos estatísticos em Psicologia, descritas por Wilkinson (1999). Adotou-se nível de probabilidade de 95\% $(p<0,05)$ para a rejeição das hipóteses de nulidade.

As vítimas de bullying foram analisadas a partir da utilização de dois instrumentos, a saber, LCASA (sociométrico) e EVE (questionário de autorelato). Em ambos os instrumentos, as vítimas de bullying foram identificadas a partir de um desvio-padrão acima da média da classe a que o adolescente pertencia.

Com relação aos problemas de comportamento de vítimas e não vítimas de bullying, as respostas dos casos, dos controles e de seus professores foram analisadas a partir do Software Assessment Data Manager (ADM), que classifica a criança nas categorias clínica, limítrofe e não-clínica (Achenbach, 1991). No presente estudo, optou-se por incluir os adolescentes categorizados como Limítrofes na categoria Clínica, conforme recomendação de Achenbach para pesquisas com os instrumentos ASEBA (Achenbach, 2004).

Ainda em relação aos problemas de comportamento, investigou-se a distribuição dos dados das variáveis em cada um dos grupos, por meio de análise gráfica e do teste Shapiro-Wilk. Também foi verificada a distribuição das variáveis resultantes da diferença entre os escores do TRF e YRS no grupo caso e no grupo controle para problemas internalizantes e externalizantes, condição necessária para a análise de medidas repetidas. A análise mostrou que cada uma dessas variáveis apresentava distribuição aproximadamente normal, de forma que foram conduzidas duas Análises de 
Variância (ANOVA) para medidas repetidas, uma para problemas internalizantes e outra para problemas externalizantes. Foram considerados, em cada uma das análises, o grupo ao qual o adolescente pertencia (caso ou controle) e o sexo como variáveis entre grupos e o questionário utilizado como variável intragrupos. Além dos efeitos principais de cada uma dessas variáveis, foi investigado também o efeito de interação entre o grupo e o questionário utilizado. Utilizou-se uma matriz de covariância não estruturada para os dados repetidos.

Depois de terem sido verificadas diferenças nos totais de problemas internalizantes e externalizantes entre os grupos caso e controle no YRS e TRF, considerando-se as variáveis envolvidas, buscou-se verificar as diferenças entre cada uma das subescalas que compõem esses totais, para melhor compreender os resultados. Uma análise da distribuição dos dados obtidos nas subescalas mostrou não ser possível considerar uma distribuição normal. Isto já era esperado, dadas as características do teste. Por esta razão, optou-se pelo uso de testes não paramétricos. Foi utilizado o teste de MannWhitney para a comparação entre os grupos no YRS e TRF separadamente e, também, o teste de Wilcoxon para medidas repetidas quando foram comparados os resultados das subescalas entre o TRF e YRS para cada grupo separadamente.

Quanto à avaliação dos itens de adversidade familiar, primeiramente foi avaliado se a análise da distribuição desta variável poderia ser considerada normal, tanto graficamente quanto por meio dos testes de Shapiro-Wilk e Kolmogorov-Smirnov. Como a distribuição se mostrou não-paramétrica, foi utilizado o teste de Mann-Whitney, a fim de buscar correlações entre o 
engajamento em bullying e o nível de adversidade familiar. Foi verificado, ainda, por meio deste mesmo teste, a relação entre os escores de adversidade familiar e os problemas de comportamento em vítimas e não vítimas de bullying. Por fim, foi avaliada a correlação entre cada item do IAF com o desfecho de engajamento em bullying. Para a classificação da intensidade da correlação entre adversidade familiar e problemas de comportamento adotouse os seguintes intervalos: de 0 a 0.30 - correlação ligeira; de 0,30 a 0,70correlação moderada e de 0,7 a 1 - forte correlação entre variáveis.

\section{RESULTADOS}

articiparam do estudo 204 adolescentes com idades entre 11 e 13
anos, regularmente matriculados no segundo ciclo do ensino fundamental de duas escolas públicas do município de São Paulo, sendo 50 participantes selecionados para o estudo piloto e 154 para o estudo final. Deste total, 31 participantes $(20,1 \%)$ foram identificados como engajadas em situações de bullying por pelo menos um dos instrumentos desenvolvidos para este fim. Um adolescente que pertencia ao grupo de vítimas de bullying foi transferido de escola e não foi possível contatá-lo a partir dos telefones disponibilizados pela secretaria. Deste modo, foram avaliados os problemas de comportamento e o Índice de Adversidade Familiar em 30 casos (vítimas de bullying) e 30 controles (não vítimas de bullying e não agressores), pareados por sexo, idade e sala de aula, totalizando 60 participantes.

O grupo de vítimas de bullying apresentou média de idade de 12,4 anos $(\mathrm{DP}=0,76)$ e, o grupo controle, de $12,40(\mathrm{DP}=0,81)$. Tanto o grupo CA quanto o CO foram constituídos de 24 participantes do sexo masculino (80\%) e seis do 
feminino $(20 \%)$. Os participantes do estudo final foram selecionados em uma escola localizada em um bairro de classe média da cidade de São Paulo. A renda familiar média dos participantes foi de 2,6 salários mínimos ${ }^{4}$. A fim de organizar a apresentação dos dados, dividiram-se os resultados em subitens, que serão descritos a seguir:

4 Os dados de renda foram calculados com base nas informações fornecidas por 42 dos pais dos adolescentes, que preencheram o questionário de adversidade familiar. O Salário Mínimo, na data de realização da pesquisa era de $\mathrm{R} \$ 678,00$. 


\subsection{Problemas de comportamento avaliados pelo alunos}

A Tabela 3 descreve o número de participantes vítimas e não vítimas de bullying que apresentaram, segundo o relato dos alunos, escores não clínicos e clínicos para problemas de comportamento internalizantes, externalizantes e totais. Os adolescentes com escores na faixa limítrofe foram classificados como clínicos, de acordo com as recomendações dos autores do instrumento (Achenbach \& Rescorla, 2001).

Tabela 3

Número de participantes com escores clínicos no YSR alocados nos grupos CA e CO

\begin{tabular}{ccccccc} 
CA & \multicolumn{3}{c}{ CO } \\
\hline Classificação & $\begin{array}{c}\text { Inter.* } \\
\%\end{array}$ & $\begin{array}{c}\text { Exter.* } \\
\%\end{array}$ & $\begin{array}{c}\text { Total } \\
\%\end{array}$ & $\begin{array}{c}\text { Inter. }^{*} \\
\%\end{array}$ & $\begin{array}{c}\text { Exter.** } \\
\%\end{array}$ & $\begin{array}{c}\text { Total } \\
\%\end{array}$ \\
\hline \multirow{2}{*}{ Não clínico } & 14 & 19 & 17 & 25 & 26 & 26 \\
& $(46,7)$ & $(63,3)$ & $(56,7)$ & $(83,4)$ & $(86,7)$ & $(86,7)$ \\
\hline Clínico & 16 & 11 & 13 & 5 & 4 & 4 \\
& $(53,3)$ & $(36,7)$ & $(43,3)$ & $(16,6)$ & $(13,3)$ & $(13,3)$ \\
\hline Total & 30 & 30 & 30 & 30 & 30 & 30 \\
participantes & $(100)$ & $(100)$ & $(100)$ & $(100)$ & $(100)$ & $(100)$ \\
*inter=problemas de comportamento internalizantes. \\
**exter=problemas de comportamento externalizantes.
\end{tabular}

De acordo com o relato dos alunos, mais participantes vítimas de bullying atingiram escores clínicos em problemas de comportamento internalizantes, externalizantes e totais, comparados aos participantes não envolvidos em situações de bullying. A maior diferença entre os grupos se refere aos problemas de comportamento internalizantes, que atingiram níveis clínicos em mais da metade dos casos, aproximadamente três vezes mais que o encontrado no grupo CO.

A partir deste momento, serão apresentadas as medianas, os valores máximos e os mínimos dos escores referentes às escalas síndromes que 
constituem o YRS, uma vez que a distribuição de cada uma delas não obteve grau de normalidade satisfatório. A Tabela 4 apresenta as diferença entre as medianas dos escores nas escalas síndrome, avaliadas nos dois grupos pelo YRS.

Tabela 4

Medianas, escores máximos e mínimos das escalas síndromes que compõem o YSR, no grupo de CAs e COs

\begin{tabular}{cccccccc}
\cline { 2 - 7 } Escala síndrome & \multicolumn{3}{c}{ CA } & \multicolumn{3}{c}{ CO } \\
\cline { 2 - 7 } & Mediana & Máximo & Mínimo & Mediana & Máximo & Mínimo \\
\hline Depressão/Ansiedade & 64 & 79 & 50 & 54 & 72 & 50 \\
\hline Isolamento & 56 & 79 & 50 & 51 & 79 & 50 \\
\hline Queixas Somáticas & 56 & 80 & 50 & 51 & 73 & 50 \\
\hline Problemas Sociais & 57 & 75 & 50 & 51 & 68 & 50 \\
\hline Problemas Pensamento & 54 & 75 & 50 & 50 & 79 & 50 \\
\hline Problemas Atenção & 53 & 77 & 50 & 50 & 73 & 50 \\
\hline Quebrar Regras & 53 & 69 & 50 & 50 & 66 & 50 \\
\hline Comportamento Agressivo & 56 & 89 & 50 & 50 & 73 & 50 \\
\hline
\end{tabular}

As medianas de todas as escalas do grupo CA foram mais elevadas em relação às escalas correspondentes do grupo $\mathrm{CO}$. Verifica-se que, nos dois grupos, a mediana dos escores mais elevada se refere à escala de depressão e ansiedade, ainda que tenha atingido níveis clínicos apenas no grupo CA. No grupo $\mathrm{CO}$, nenhuma das escalas apresentou a mediana dos escores com níveis clínicos, embora haja, nas oito escalas, casos isolados de participantes que atingiram escore clínicos. A Figura 2 ilustra as diferenças das medianas entre os grupos, a partir do relato dos alunos. 


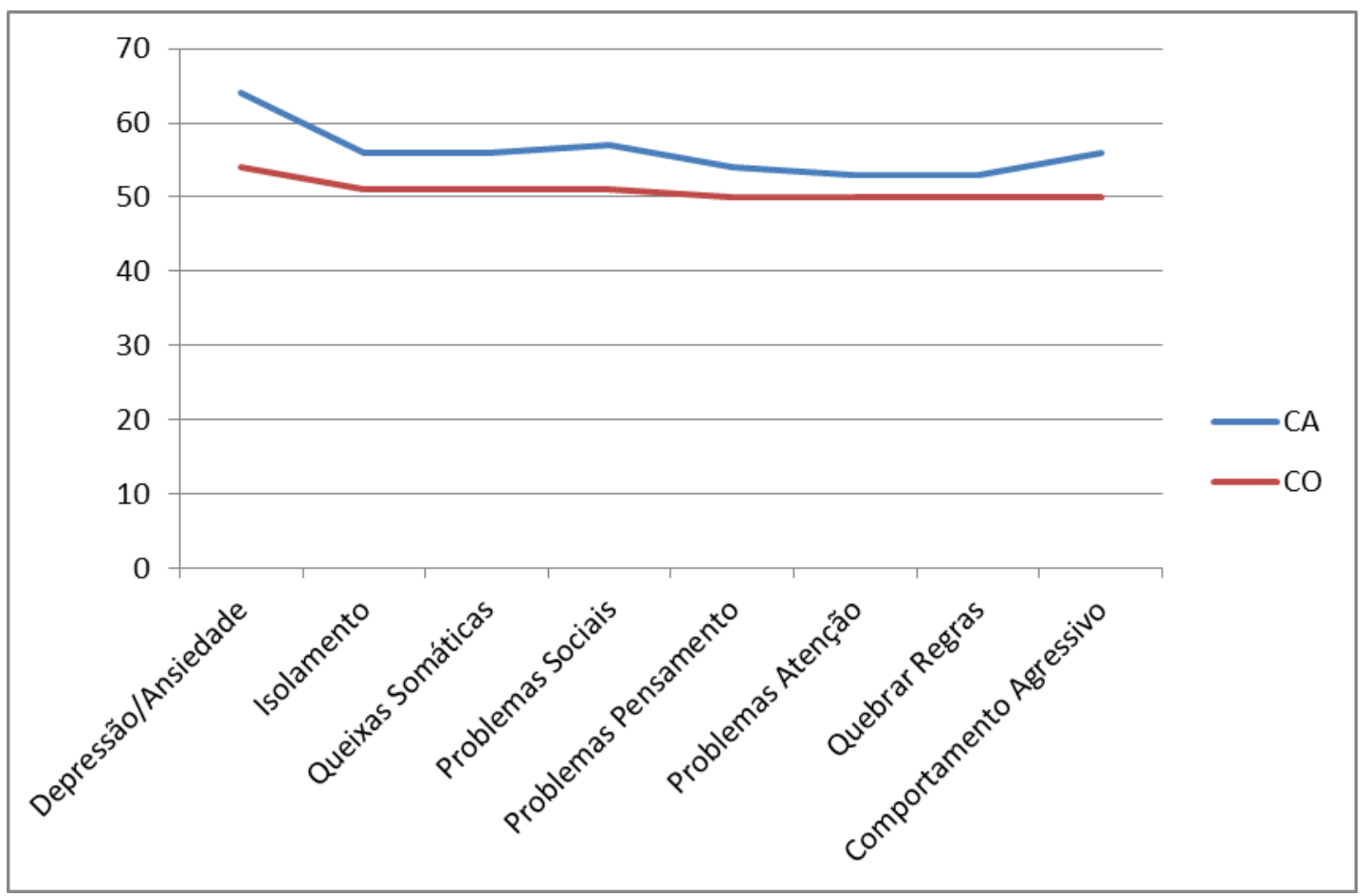

Figura 2. Medianas dos escores das escalas síndromes, de acordo com o relato dos alunos pertencentes ao grupo CA e CO. 
A Tabela 5 descreve o ranking médio, em cada escala síndrome, de acordo com o grupo a que o participante foi alocado. Os rankings médios do grupo CA foram mais elevados em todas as escalas síndrome avaliadas, quando comparados aos do grupo CO.

Tabela 5

Rankings médios das escalas síndrome avaliadas pelos alunos

\begin{tabular}{|c|c|c|c|}
\hline Escala Síndrome & Grupo & $\mathbf{n}$ & $\begin{array}{c}\text { Ranking } \\
\text { Médio }\end{array}$ \\
\hline \multirow{3}{*}{ Depressão } & Controle & 30 & 22,52 \\
\hline & Caso & 30 & 38,48 \\
\hline & Total & 60 & \\
\hline \multirow{3}{*}{ Isolamento } & Controle & 30 & 25,45 \\
\hline & Caso & 30 & 35,55 \\
\hline & Total & 60 & \\
\hline \multirow{3}{*}{ Queixas Somáticas } & Controle & 30 & 22,13 \\
\hline & Caso & 30 & 38,87 \\
\hline & Total & 60 & \\
\hline \multirow{3}{*}{ Problemas Sociais } & Controle & 30 & 23,77 \\
\hline & Caso & 30 & 37,23 \\
\hline & Total & 60 & \\
\hline \multirow{3}{*}{ Problemas Pensamento } & Controle & 30 & 22,78 \\
\hline & Caso & 30 & 38,22 \\
\hline & Total & 60 & \\
\hline \multirow{3}{*}{ Problemas Atenção } & Controle & 30 & 24,9 \\
\hline & Caso & 30 & 36,1 \\
\hline & Total & 60 & \\
\hline \multirow{3}{*}{ Quebrar Regras } & Controle & 30 & 25,25 \\
\hline & Caso & 30 & 35,75 \\
\hline & Total & 60 & \\
\hline \multirow{3}{*}{ Agressividade } & Controle & 30 & 22,85 \\
\hline & Caso & 30 & 38,15 \\
\hline & Total & 60 & \\
\hline
\end{tabular}

A Tabela 6, por seu turno, apresenta as diferenças entre os rankings médios que atingiram significância estatística. 
Tabela 6

Diferenças entre os rankings médios das escalas síndromes nos grupos CA e CO

\begin{tabular}{lccc}
\hline \multicolumn{1}{c}{ Escala Síndrome } & Mann-Whitney & $\mathbf{Z}$ & Valor $\mathbf{p}$ \\
\hline Depressão/Ansiedade & 210,5 & $-3,561$ & 0,000 \\
\hline Isolamento & 298,5 & $-2,288$ & 0,022 \\
\hline Queixas Somáticas & 199 & $-3,748$ & 0,000 \\
\hline Problemas Sociais & 248 & $-3,017$ & 0,003 \\
\hline Problemas Pensamento & 218,5 & $-3,578$ & 0,000 \\
\hline Problemas Atenção & 282 & $-2,611$ & 0,009 \\
\hline Quebrar Regras & 292,5 & $-2,53$ & 0,011 \\
\hline Comportamento Agressivo & 220,5 & $-3,527$ & 0,000 \\
\hline
\end{tabular}

Verificou-se que os escores de todas as subescalas que compõem o YRS apresentaram diferenças estatisticamente significativas quando foram comparados os adolescentes vítimas e não vítimas de bullying.

\subsection{Problemas de comportamento avaliados pelos professores}

No que se refere ao relato dos professores quanto aos problemas de comportamento, a Tabela 7 indica o número de participantes pertencentes aos grupos CA e CO, com escores clínicos e não clínicos para problemas de comportamento internalizantes, externalizantes e totais. 
Tabela 7

Número de participantes com escores clínicos e não clínicos, relatados pelos professores

\begin{tabular}{ccccccc}
\hline & \multicolumn{3}{c}{ CA } & \multicolumn{3}{c}{ CO } \\
\hline Classificação & $\begin{array}{c}\text { Inter. }^{*} \\
\%\end{array}$ & $\begin{array}{c}\text { Exter. } \\
\%\end{array}$ & $\begin{array}{c}\text { Total } \\
\%\end{array}$ & $\begin{array}{c}\text { Inter. }^{*} \\
\%\end{array}$ & $\begin{array}{c}\text { Exter. }^{* *} \\
\%\end{array}$ & $\begin{array}{c}\text { Total } \\
\%\end{array}$ \\
\hline \multirow{2}{*}{ Não clínico } & 23 & 18 & 19 & 26 & 26 & 28 \\
& $(76,7)$ & $(60,0)$ & $(63,3)$ & $(86,7)$ & $(86,7)$ & $(93,4)$ \\
\hline Clínico & 7 & 12 & 11 & 4 & 4 & 2 \\
& $(23,3)$ & $(40)$ & $(36,7)$ & $(13,3)$ & $(13,3)$ & $(6,6)$ \\
\hline Total & 30 & 30 & 30 & 30 & 30 & 30 \\
participantes & $(100)$ & $(100)$ & $(100)$ & $(100)$ & $(100)$ & $(100)$ \\
\hline
\end{tabular}

* inter=problemas de comportamento internalizantes.

${ }^{* *}$ exter=problemas de comportamento externalizantes.

Os professores avaliaram, com escores clínicos em problemas de comportamento internalizantes, um número de participantes vítimas de bullying aproximado ao de não vítimas. A maior diferença foi encontrada no número de participantes com problemas de comportamento externalizantes na faixa clínica, ambos mais frequentes no grupo de CAs.

A Tabela 8 descreve as medianas e os escores máximos e mínimos nos CAs e Cos, a partir do relato do professor.

Tabela 8

Medianas, escores máximos e mínimos das escalas síndromes que compõem o TRF, no grupo CA e CO

\begin{tabular}{cccccccc}
\cline { 2 - 7 } Escala síndrome & \multicolumn{3}{c}{ CA } & \multicolumn{3}{c}{ CO } \\
\cline { 2 - 7 } & Mediana & Máximo & Mínimo & Mediana & Máximo & Mínimo \\
\hline Depressão/Ansiedade & 52 & 71 & 50 & 50 & 57 & 50 \\
\hline Isolamento & 56 & 74 & 50 & 55 & 68 & 50 \\
\hline Queixas Somáticas & 50 & 58 & 50 & 50 & 62 & 50 \\
\hline Problemas Sociais & 57 & 68 & 50 & 50 & 67 & 50 \\
\hline Problemas Pensamento & 50 & 74 & 50 & 50 & 60 & 50 \\
\hline Problemas Atenção & 56 & 69 & 50 & 50 & 63 & 50 \\
\hline Quebrar Regras & 54 & 81 & 50 & 50 & 69 & 50 \\
\hline Comportamento Agressivo & 59 & 92 & 50 & 50 & 78 & 50 \\
\hline
\end{tabular}


As medianas dos escores de problemas de comportamentos avaliados pelos professores foram iguais ou ligeiramente maiores no grupo $\mathrm{CA}$, quando comparadas às do grupo $\mathrm{CO}$. Os escores não atingiram níveis clínicos em nenhum dos grupos, embora a mediana de Comportamento Agressivo do grupo CA tenha sido próximo ao ponto de corte referido pelo instrumento. A figura 3 ilustra as diferenças de medianas entre os grupos.

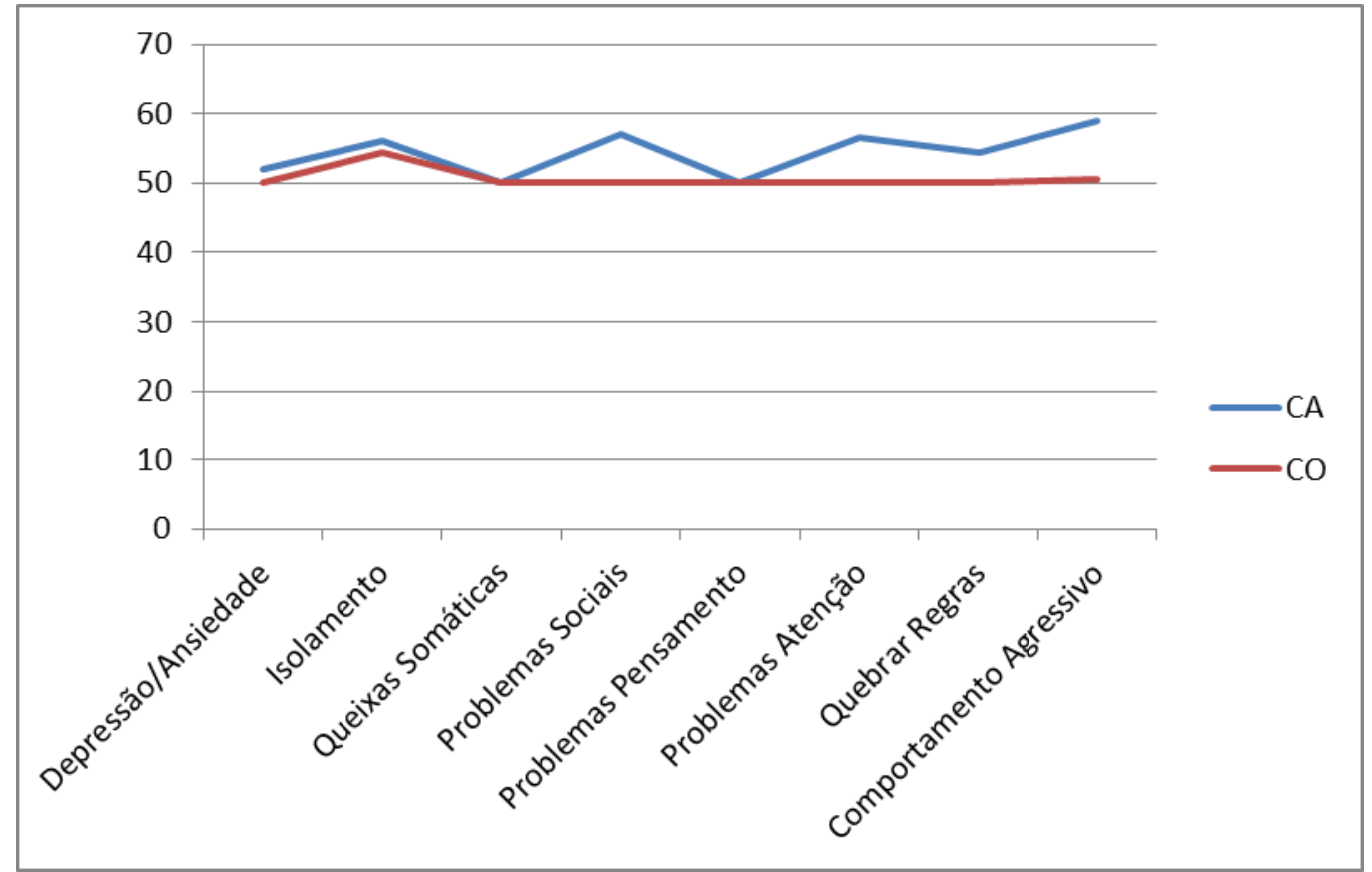

Figura 3. Apresentação das medianas dos escores das escalas síndromes, de acordo com o relato dos professores.

A Tabela 9 descreve o ranking médio em cada escala síndrome, de acordo com o relato dos professores, no grupo CA e CO. 
Tabela 9

Rankings médios das escalas síndrome do grupo de CA e CO

\begin{tabular}{|c|c|c|c|}
\hline Escala Síndrome & Grupo & $\mathbf{n}$ & $\begin{array}{c}\text { Ranking } \\
\text { Médio }\end{array}$ \\
\hline \multirow{3}{*}{ Depressão } & Controle & 30 & 25,23 \\
\hline & Caso & 30 & 35,77 \\
\hline & Total & 60 & \\
\hline \multirow{3}{*}{ Isolamento } & Controle & 30 & 29,60 \\
\hline & Caso & 30 & 31,40 \\
\hline & Total & 60 & \\
\hline \multirow{3}{*}{ Queixas Somáticas } & Controle & 30 & 29,07 \\
\hline & Caso & 30 & 31,93 \\
\hline & Total & 60 & \\
\hline \multirow{3}{*}{ Problemas Sociais } & Controle & 30 & 24,85 \\
\hline & Caso & 30 & 36,15 \\
\hline & Total & 60 & \\
\hline \multirow{3}{*}{ Problemas Pensamento } & Controle & 30 & 26,90 \\
\hline & Caso & 30 & 34,10 \\
\hline & Total & 60 & \\
\hline \multirow{3}{*}{ Problemas Atenção } & Controle & 30 & 21,92 \\
\hline & Caso & 30 & 39,08 \\
\hline & Total & 60 & \\
\hline \multirow{3}{*}{ Quebrar Regras } & Controle & 30 & 21,83 \\
\hline & Caso & 30 & 39,17 \\
\hline & Total & 60 & \\
\hline \multirow{3}{*}{ Agressividade } & Controle & 30 & 21,97 \\
\hline & Caso & 30 & 39,03 \\
\hline & Total & 60 & \\
\hline
\end{tabular}

Novamente, o ranking médio do grupo CA foi mais elevado em todas as escalas síndrome avaliadas, quando comparado ao do grupo $\mathrm{CO}$, embora as diferenças tenham sido pequenas nas subescalas Isolamento e Queixas Somáticas.

A Tabela 10 aponta se as diferenças entre os rankings médios atingiram significância estatística. 
Tabela 10

Diferenças entre os rankings médios das escalas síndromes nos grupos CA e CO

\begin{tabular}{cccc}
\hline Escala Síndrome & Mann-Whitney & $\mathbf{Z}$ & Valor $\mathbf{p}$ \\
\hline Depressão/Ansiedade & 292 & $-2,452$ & 0,014 \\
\hline Isolamento & 423 & $-0,405$ & 0,685 \\
\hline Queixas Somáticas & 407 & $-1,327$ & 0,185 \\
\hline Problemas Sociais & 280,5 & $-2,832$ & 0,005 \\
\hline Problemas Pensamento & 342 & $-2,218$ & 0,027 \\
\hline Problemas Atenção & 192,5 & $-4,02$ & 0,000 \\
\hline Quebrar Regras & 190 & $-4,15$ & 0,000 \\
\hline Comportamento Agressivo & 194 & $-3,841$ & 0,000 \\
\hline
\end{tabular}

Com exceção das subescalas Isolamento e Queixas Somáticas, todas atingiram diferença estatisticamente significativa entre o ranking médio das escalas síndromes do grupo CA e do grupo CO.

\subsection{Diferenças na avaliação de alunos e professores quanto aos problemas de comportamento}

A comparação dos escores de problemas de comportamento relatados por alunos vítimas e não vítimas de bullying e por seus professores será apresentada separadamente, e nesta ordem: problemas de comportamento internalizantes, externalizantes e, por fim, escalas síndrome. 


\subsubsection{Internalizantes}

A Tabela 11 descreve as diferenças entre as médias dos escores de problemas de comportamento internalizantes relatados por professores e alunos nos grupos CA e CO.

Tabela 11

Médias dos escores de problemas de comportamento internalizantes relatados por professores e alunos, nos grupos de vítimas e de não vítimas de bullying

\begin{tabular}{ccccrr} 
& & & & \multicolumn{2}{c}{ IC $^{* *}(95 \%)$} \\
\cline { 5 - 6 } Grupo & Informante & Média & \multirow{2}{*}{ GI $^{*}$} & $\begin{array}{c}\text { Limite } \\
\text { inferior }\end{array}$ & $\begin{array}{c}\text { Limite } \\
\text { superior }\end{array}$ \\
& & & & & \\
\multirow{2}{*}{ CA } & Aluno & 58,624 & 66,257 & 54,622 & 62,625 \\
& Professor & 50,790 & 64,425 & 48,053 & 53,527 \\
\hline \multirow{2}{*}{ CO } & Aluno & 46,890 & 66,257 & 42,889 & 50,892 \\
& Professor & 47,924 & 64,425 & 45,187 & 50,661 \\
\hline
\end{tabular}

${ }^{*} \mathrm{Gl}=$ grau de liberdade. ${ }^{\star *} \mathrm{IC}=$ Intervalo de Confiança.

A média de problemas de comportamento internalizantes foi mais elevada no grupo de CAs em relação ao grupo de COs, quando avaliados tanto pelos próprios alunos quanto por seus professores, sendo que a diferença entre as médias foi maior no relato dos alunos. Como pode ser verificado na Tabela 12, a análise dos dados apresentou uma interação entre a variável grupo (CA ou CO) e a variável informante (professor ou aluno) $(F(1,60)=7,90$ e $\mathrm{p}=0,007)$. 
Tabela 12

Efeito das variáveis no modelo estatístico incluindo grupo e relato como preditores

\begin{tabular}{cccc}
\hline Variável & Gl $^{\star}$ denominador & $\mathbf{F}$ & Valor $\mathbf{p}$ \\
\hline Intercepto & 64,501 & 2572,00 &, 000 \\
\hline Grupo & 59,656 & 19,306 &, 000 \\
\hline Sexo & 60 & 10,126 &, 002 \\
\hline Grupo / Informante & 60 & 7,899 &, 007 \\
\hline Informante & 60 & 4,646 &, 035
\end{tabular}

${ }^{*} \mathrm{Gl}=$ grau de liberdade

Desta forma, para identificar esse efeito entre as variáveis, foram conduzidas ANOVAS de medidas repetidas independentemente para o grupo CA e CO. Os resultados são apresentados nas Tabelas 13 e 14, respectivamente.

\section{Tabela 13}

Efeito das variáveis no modelo estatístico no grupo $C A$, incluindo o informante como preditor (variável independente)

\begin{tabular}{cclll}
\hline Variável & $\begin{array}{c}\mathbf{G I}^{*} \\
\text { numerador }\end{array}$ & $\begin{array}{c}\mathbf{G l}^{*} \\
\text { denominador }\end{array}$ & $\mathbf{F}$ & Valor $\mathbf{p}$ \\
\hline Intercepto & 1 & 31,254 & 1388,212 &, 000 \\
\hline Sexo & 1 & 30,000 & 5,734 &, 023 \\
\hline Informante & 1 & 30,000 & 13,397 &, 001
\end{tabular}

${ }^{*} \mathrm{Gl}=$ grau de liberdade 
Tabela 14

Efeito das variáveis no modelo estatístico no grupo $\mathrm{CO}$, incluindo o informante como preditor (variável independente)

\begin{tabular}{lcccc}
\hline Variável & $\begin{array}{c}\mathbf{G l}^{*} \text {. } \\
\text { numerador }\end{array}$ & $\begin{array}{c}\mathbf{G l}^{*} \text {. } \\
\text { denominador }\end{array}$ & $\mathbf{F}$ & Valor $\mathbf{p}$ \\
\hline Intercepto & 1 & 33,332 & 1190,557 &, 000 \\
\hline Sexo & 1 & 30 & 3,902 &, 057 \\
\hline Informante & 1 & 30 & 0,199 &, 659 \\
\hline * Gl=grau de liberdade & & &
\end{tabular}

Analisando os dois grupos separadamente, verifica-se que não houve diferenças entre os escores de problemas internalizantes do TRF e do YRS no grupo $\mathrm{CO}(\mathrm{F}(1,30)=0,20$ e $\mathrm{p}=0,659)$. Entretanto, essa diferença esteve presente no grupo CA, no qual os escores médios do TRF foram menores do que os do YRS $(F(1,30)=13,40$ e $p=0,001)$.

A Figura 4 tem por objetivo apresentar a comparação entre o relato dos alunos e o de seus professores quanto aos problemas de comportamento internalizantes.

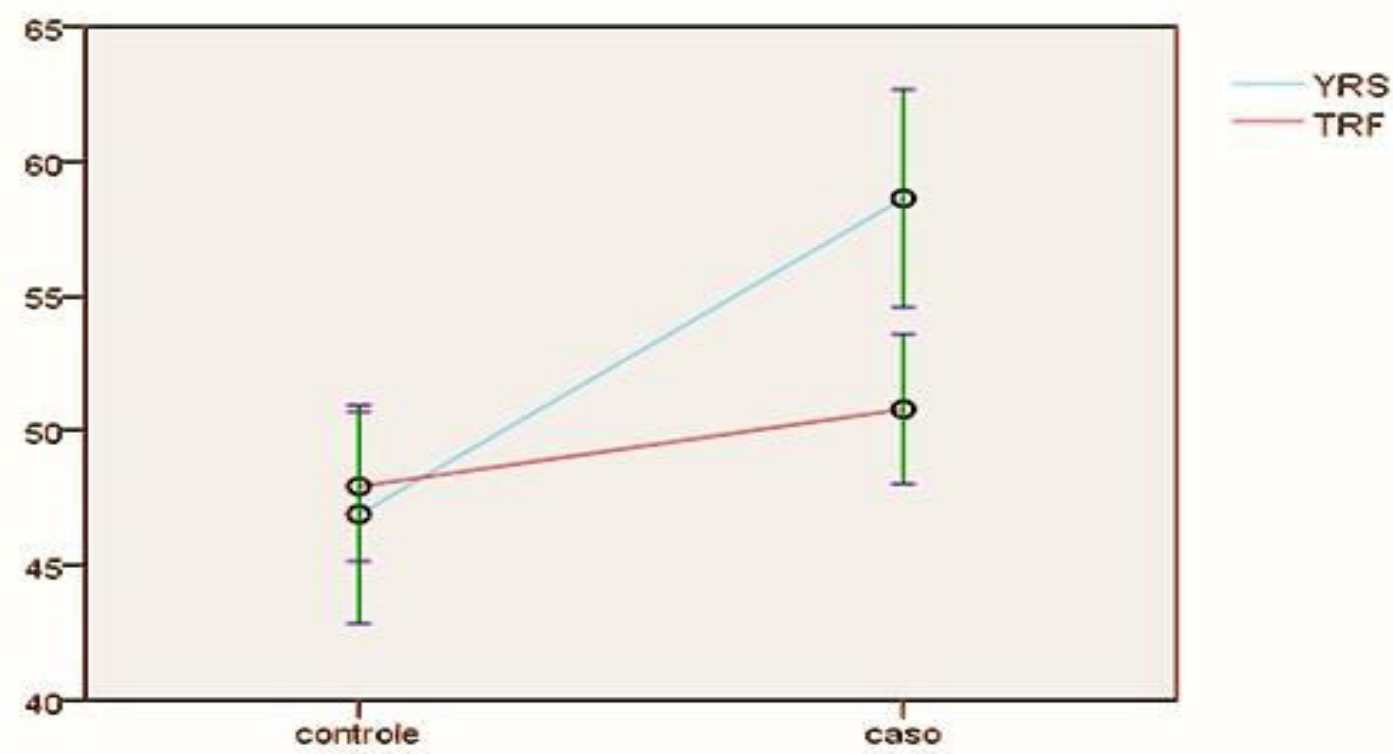


Figura 4. Distribuição das médias dos escores de problemas de comportamento internalizantes em CAs e COs, de acordo com o relato dos alunos e professores.

Observa-se que a diferença entre as médias dos escores de problemas de comportamento internalizantes relatados por professores e alunos foi maior no grupo caso e bastante sobreposta no grupo controle.

\subsubsection{Externalizantes}

A Tabela 15 descreve as diferenças entre as médias dos escores de problemas de comportamento externalizantes relatados por professores e alunos nos grupos CA e CO.

\section{Tabela 15}

Análise da interação entre as variáveis informante e grupo para problemas de comportamento externalizantes

\begin{tabular}{ccccccc}
\hline \multirow{2}{*}{ Grupo Informante } & Média & Erro Padrão & Gl $^{\star}$ & & \multicolumn{2}{c}{ IC $^{\star \star}(95 \%)$} \\
\cline { 6 - 7 } & & & & & Limite inferior & Limite superior \\
\hline \multirow{2}{*}{ CA } & Aluno & 55,169 & 2,098 & 66,36 & 50,979 & 59,358 \\
& Professor & 58,402 & 1,758 & 64,834 & 54,891 & 61,912 \\
\hline \multirow{2}{*}{ CO } & Aluno & 43,069 & 2,098 & 66,36 & 38,879 & 47,258 \\
& Professor & 48,435 & 1,758 & 64,834 & 44,925 & 51,946 \\
\hline
\end{tabular}

${ }^{*} \mathrm{Gl}=$ grau de liberdade. ${ }^{*} \mathrm{IC}=$ Intervalo de confiança.

Como pode ser observado na Tabela 16, não houve interação entre a variável informante e a variável grupo em relação aos escores dos problemas externalizantes, de forma que estas variáveis puderam ser avaliadas em seus efeitos principais. Salienta-se que também não foi observado um efeito de sexo nos resultados obtidos. 
Tabela 16

Efeitos das variáveis no modelo estatístico incluindo grupo e relato como preditores

\begin{tabular}{cccc}
\hline Variável & GI $^{*}$. denominador & $\mathbf{F}$ & Valor $\mathbf{p}$ \\
\hline Intercepto & 61,088 & 1844,181 &, 000 \\
\hline Grupo & 59,831 & 32,862 &, 000 \\
\hline Sexo & 60 &, 019 &, 890 \\
\hline Grupo / Relato & 60,000 &, 408 &, 526 \\
\hline Relato & 60,000 & 6,627 &, 013
\end{tabular}

${ }^{*} \mathrm{Gl}=$ grau de liberdade

Foi observado um efeito de grupo, com os adolescentes do grupo CO apresentando, em média, escores inferiores aos apresentados pelos adolescentes pertencentes ao grupo de CAs $(F(1,60)=32,86$ e $p<0,001)$. Houve, também, um efeito da variável informante, sendo que, em média, os escores do TRF foram maiores que os do YRS, independentemente do grupo $(F(1,60)=6,63$ e $p=0,013)$. A seguir, a Figura 5 ilustra as duas situações:

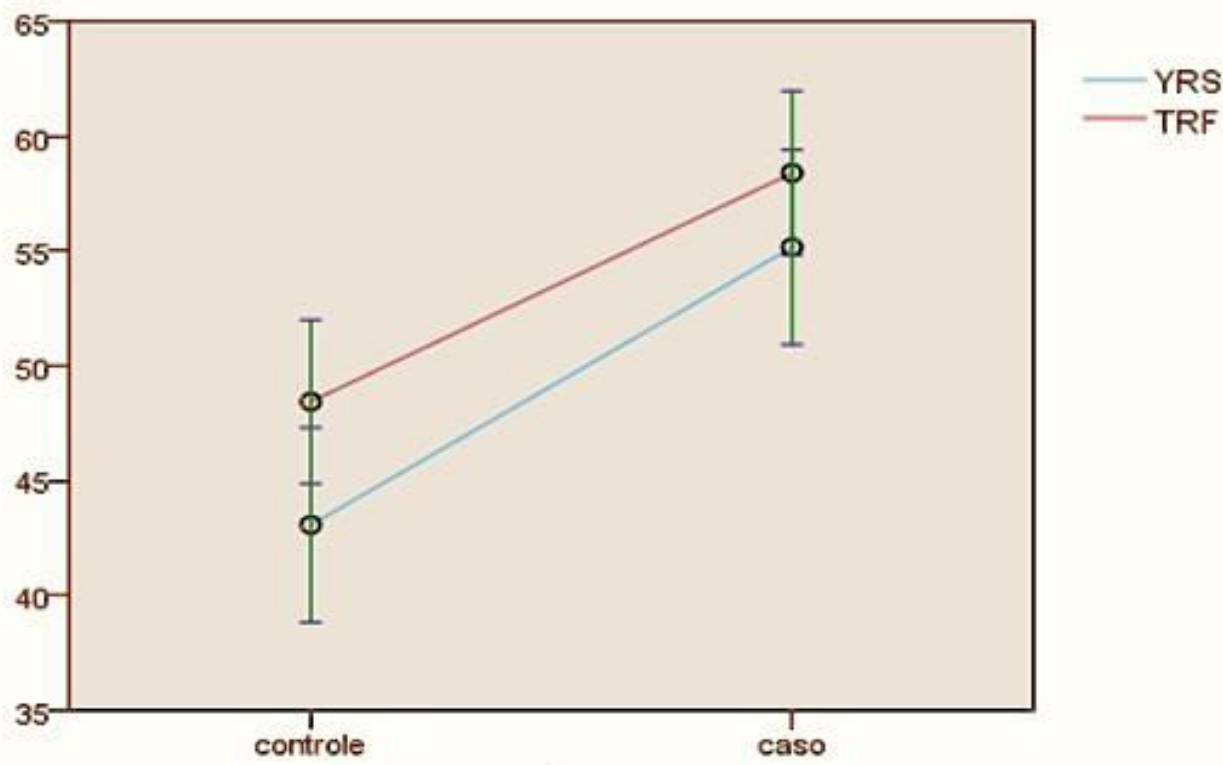

Figura 5. Distribuição das médias dos escores de problemas de comportamento externalizantes em casos e controles, de acordo com o relato dos alunos e professores. 
Com relação às diferenças das médias dos escores de problemas de comportamento externalizantes, houve sobreposições mais evidentes entre o relato dos professores e alunos, o que indica que estes comportamentos são mais frequentemente identificados pelos primeiros.

Em resumo, a partir da comparação das medianas dos escores do YSR e TRF, foi possível apreender que problemas de comportamento do tipo internalizante, como depressão, ansiedade e queixas somáticas, foram relatados com maior frequência pelos alunos vítimas de bullying. Por outro lado, os comportamentos externalizantes, como quebrar regras e comportamento agressivo, foram mais relatados pelos seus professores, embora esta diferença tenha sido pequena.

\subsubsection{Escalas Síndrome}

A Tabela 17 apresenta a comparação entre as medianas dos escores de problemas de comportamento avaliados por alunos do grupo CA e por seus professores.

Tabela 17

Diferenças entre as medianas dos escores do YSR e do TRF do grupo CA

\begin{tabular}{lcc}
\hline \multicolumn{1}{c}{ Escala Síndrome } & Mediana (YSR) & Mediana (TRF) \\
\hline Depressão/Ansiedade & 64 & 52 \\
\hline Isolamento & 56 & 56 \\
\hline Queixas Somáticas & 56 & 50 \\
\hline Problemas Sociais & 57 & 57 \\
\hline Problemas Pensamento & 54 & 50 \\
\hline Problemas Atenção & 53 & 56 \\
\hline Quebrar Regras & 53 & 54 \\
\hline Comportamento Agressivo & 56 & 59 \\
\hline
\end{tabular}


Observa-se que as maiores diferenças de medianas de problemas de comportamento referem-se aos escores da escala de Depressão e Ansiedade, que atingiu uma mediana dentro da faixa clínica, quando referida pelos alunos vítimas de bullying, e não clínica, quando avaliado pelos professores. A Figura 6 ilustra as diferença entre as medianas dos escores obtidos pelo relato dos professores e dos alunos nas escalas síndrome.

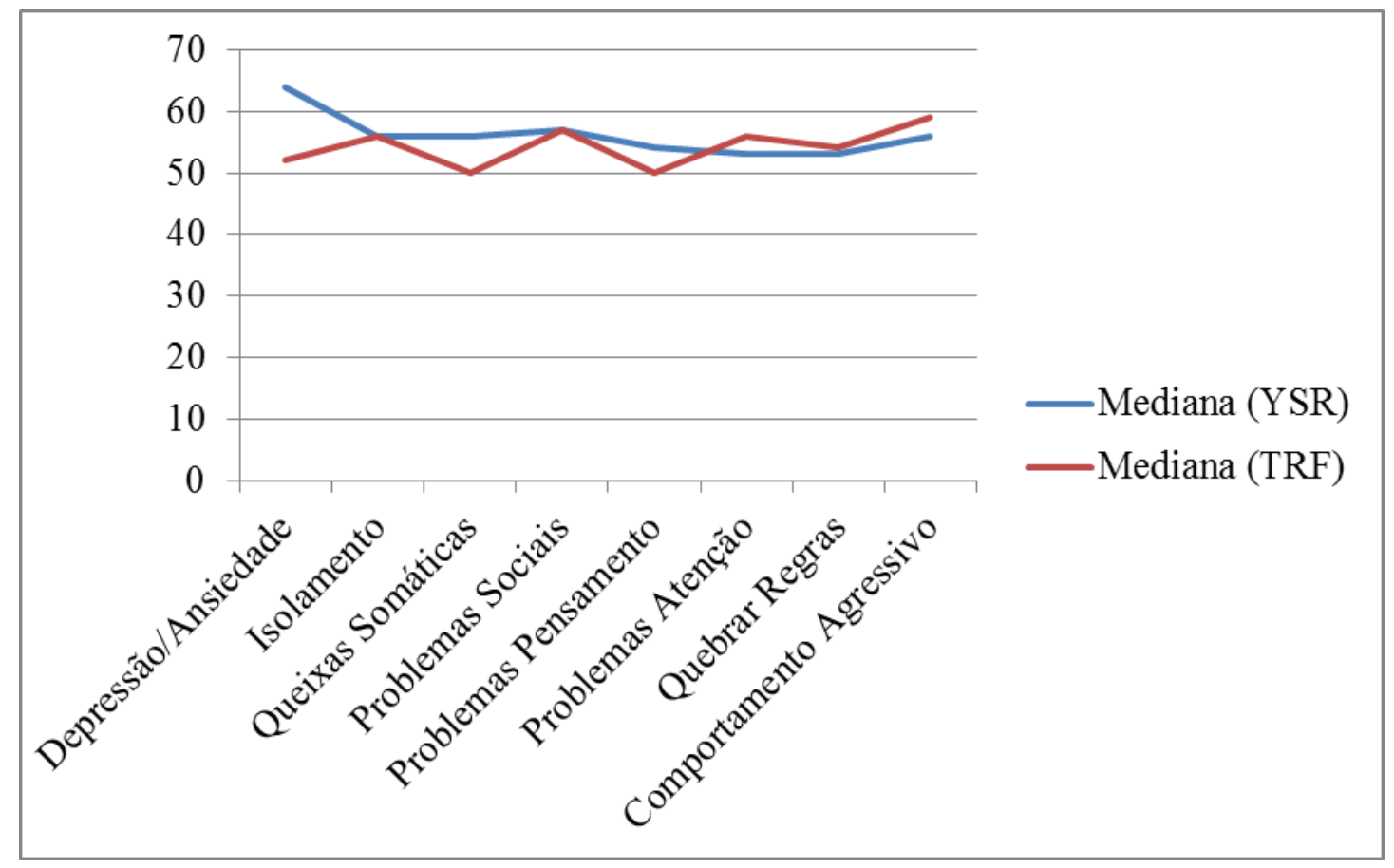

Figura 6. Diferença do relato dos professores e alunos quanto às medianas dos escores obtidos nas escalas síndrome.

A Tabela 18 compara as medianas dos escores de problemas de comportamento avaliados por alunos e professores, no grupo CO. 
Tabela 18

Diferenças entre as medianas dos escores do YSR e do TRF do grupo CO

\begin{tabular}{lcc}
\hline \multicolumn{1}{c}{ Escala Síndrome } & Mediana (YSR) & Mediana (TRF) \\
\hline Depressão/Ansiedade & 55 & 51 \\
\hline Isolamento & 54 & 55 \\
\hline Queixas Somáticas & 53 & 50 \\
\hline Problemas Sociais & 53 & 52 \\
\hline Problemas Pensamento & 51 & 50 \\
\hline Problemas Atenção & 52 & 51 \\
\hline Quebrar Regras & 51 & 51 \\
\hline Comportamento Agressivo & 52 & 53 \\
\hline
\end{tabular}

Os relatos dos professores e dos alunos foi bastante semelhante no que se refere às escalas síndrome do grupo $\mathrm{CO}$, sendo que a maior diferença entre os escores pode ser verificada na escala de Depressão e Ansiedade.

A Figura 9 ilustra as diferença entre as medianas dos escores obtidos a partir dos relatos dos professores e dos alunos nas escalas síndrome.

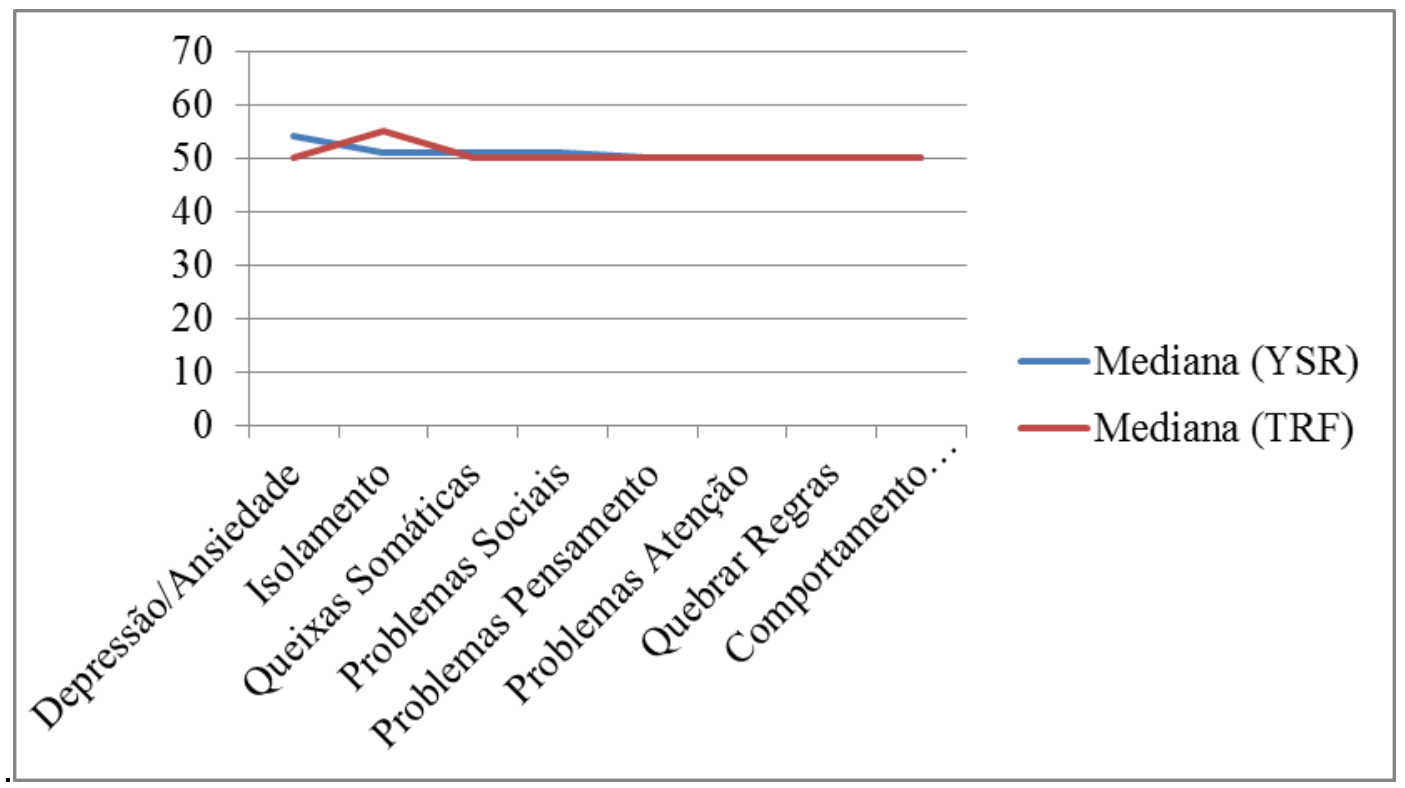

Figura 7. Diferença de medianas das escalas síndromes do YSR e TRF. 
O teste de Wilcoxon foi utilizado, separadamente para os grupos CA e CO, com o intuito de identificar possíveis diferenças estatisticamente significativas entre os escores relatados pelos alunos e os relatados pelos professores, referentes às escalas síndrome. A Tabela 19 apresenta os resultados do teste aplicado aos dados do grupo CA.

Tabela 19

Resultados do teste de Wilcoxon para identificar diferenças estatisticamente significativas, em cada subescala, entre os escores do TRF e do YRS no grupo CA

\begin{tabular}{lll}
\hline \multicolumn{1}{c}{ Escalas Síndrome } & $\mathbf{Z}$ & Valor $\mathbf{p}$ \\
\hline Depressão/Ansiedade & $-4,011^{\mathrm{c}}$ & 0,000 \\
\hline Isolamento &,$- 912^{\mathrm{c}}$ & n.s. ${ }^{*}$ \\
\hline Queixas Somáticas & $-4,092^{\mathrm{c}}$ & 0,000 \\
\hline Problemas Sociais & $-1,255^{\mathrm{c}}$ & n.s. $^{*}$ \\
\hline Problemas Pensamento & $-1,895^{\mathrm{c}}$ & 0,050 \\
\hline Problemas Atenção & $-1,241^{\mathrm{d}}$ & n.s. $^{*}$ \\
\hline Quebrar Regras &,$- 894^{\mathrm{d}}$ & n.s. $^{*}$ \\
\hline Comportamento Agressivo &,$- 823^{\mathrm{d}}$ & n.s. $^{*}$ \\
\hline
\end{tabular}

${ }^{*}$ n.s. = não significativo

Foram verificadas diferenças estatisticamente significativas entre o relato dos alunos vítimas de bullying e de seus professores nas escalas de Depressão e Ansiedade $(Z=-4,011$ e $p=0,000)$, de Queixas Somáticas $(Z=-$ 4,092 e $p=0,000)$ e de Problemas de Pensamento $(Z=-1,895$ e $p=0,05)$.

A Tabela 20 apresenta os resultados do teste de Wilcoxon aplicado para identificar possíveis diferenças entre os escores das escalas síndrome relatados por alunos não envolvidos em situações de bullying e os relatados pelos professores. 
Tabela 20

Resultados do teste de Wilcoxon para identificar diferenças estatisticamente significativas, em cada subescala, entre os escores do TRF e do YRS no grupo CO

\begin{tabular}{ccc}
\hline Escalas Síndrome & $\mathbf{Z}$ & Valor $\mathbf{p}$ \\
\hline Depressão/Ansiedade & $-3,113^{\mathrm{c}}$ & 0,002 \\
\hline Isolamento & $-1,144^{\mathrm{d}}$ & n.s. ${ }^{*}$ \\
\hline Queixas Somáticas & $-3,042^{\mathrm{c}}$ & 0,002 \\
\hline Problemas Sociais & $-1,877^{\mathrm{c}}$ & n.s. $^{*}$ \\
\hline Problemas Pensamento & $-1,296^{\mathrm{c}}$ & n.s. $^{*}$ \\
\hline Problemas Atenção &,$- 513^{\mathrm{c}}$ & n.s. $^{*}$ \\
\hline Quebrar Regras &,$- 566^{\mathrm{c}}$ & n.s. $^{*}$ \\
\hline Comportamento Agressivo &,$- 872^{\mathrm{d}}$ & n.s. $^{*}$ \\
\hline${ }^{*}$ n.s. $=$ não significativo & &
\end{tabular}

No grupo $\mathrm{CO}$, foram observadas diferenças estatisticamente significativas nas escalas de Depressão e Ansiedade $(Z=-3,113$ e $p=0,002)$ e de Queixas Somáticas $(Z=-3,042$ e $p=0,002)$.

\subsection{Adversidade Familiar}

Primeiramente, correlacionou-se o total dos escores de adversidade familiar e o envolvimento em situações de bullying como vítima, e em seguida, foi realizada uma análise de cada um dos itens que constituem o índice de adversidade familiar, bem como de seu poder preditivo para o engajamento em bullying. Foram avaliados 21 participantes do grupo CA, e seus respectivos controles, totalizando 42 participantes cuja adversidade familiar foi analisada. 
Tabela 21

Escores de adversidade familiar nos grupos caso e controle

\begin{tabular}{llllll}
\hline \multicolumn{5}{c}{ Índice de Adversidade Familiar } \\
\cline { 2 - 6 } & Média & Desvio Padrão & Mínimo & Mediana & Máximo \\
\hline CA & 0,3524 & 0,2522 & 0,0000 & 0,4000 & 0,8000 \\
\hline CO & 0,2190 & 0,2600 & 0,0000 & 0,2000 & 0,8000 \\
\hline
\end{tabular}

A fim de ilustrar as diferenças dos escores de adversidade entre os grupos CA e CO foram desenvolvidos histogramas para melhor visualização dos dados dos mesmos, apresentados na Figura 8.

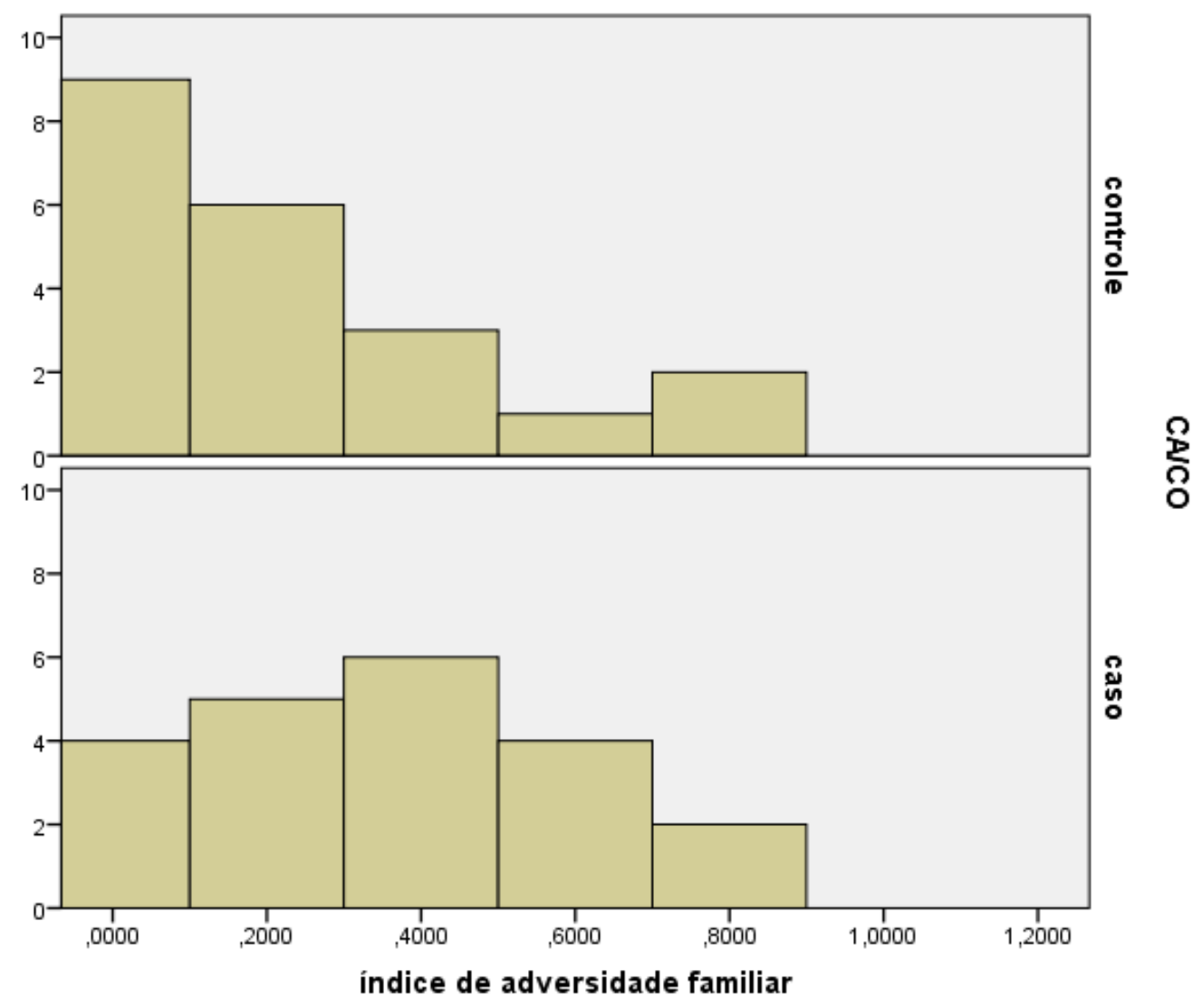

Figura 8. Histograma de adversidade familiar dos grupos Caso e Controle. 
A análise da distribuição da variável adversidade familiar mostrou que não é adequado considerá-la como tendo uma distribuição normal, tanto graficamente quanto a partir dos testes de Shapiro-Wilk e Kolmogorov-Smirnov. Por esta razão, optou-se por uma análise não paramétrica (teste de MannWhitney), cujos resultados estão descritos na Tabela 22.

Tabela 22

Resultados da análise do teste de Mann-Whitney dos escores de IAF

\begin{tabular}{ccc}
\hline Grupo & $\mathbf{n}$ & Ranking Médio \\
\hline Controle & 21 & 18,14 \\
\hline Caso & 21 & 24,86 \\
\hline Total & 42 & - \\
\hline
\end{tabular}

Observa-se que o ranking médio dos participantes identificados como vítimas de bullying foi mais elevado quando comparado ao do grupo controle.

A Tabela 23 apresenta a verificação de diferença estatisticamente significativa entre os grupos.

Tabela 23

Tabela descritiva da diferença dos rankings dos participantes dos grupos CA e CO

\begin{tabular}{lc}
\hline \multicolumn{1}{c}{ Teste } & IAF \\
\hline Mann-Whitney U & 150 \\
\hline Wilcoxon W & 381 \\
\hline Z & $-1,829$ \\
\hline Asymp. Sig. (2-tailed) & $\mathbf{0 , 0 6 7}$ \\
\hline Exact Sig. (2-tailed) & 0,068 \\
\hline Exact Sig. (1-tailed) & 0,034 \\
\hline Point Probability & 0,002 \\
\hline
\end{tabular}

Apesar de não ter sido possível identificar diferença entre os grupos ao nível de significância de 5\% $(Z=-1,829$ e $p=0,067)$, o p-valor foi próximo a 0,05. 
Considerando que a análise descritiva apontou que 15 dos participantes do grupo CO (71\%) tiveram escore igual ou menor que 0,2 , enquanto apenas nove dos participantes do grupo CA (43\%) apresentaram esse escore e que este resultado (ou seja, maior nível de adversidade familiar no grupo CA) é coerente com o esperado, compreende-se a importância de avaliar individualmente os subitens que compõem o IAF. Desta forma, a Tabela 24 mostra a distribuição dos grupos item a item.

Tabela 24

Subitens de adversidade familiar* analisados nos grupos CA e CO

\begin{tabular}{|c|c|c|c|c|c|c|c|}
\hline \multirow{4}{*}{$\begin{array}{c}\text { Razão } \\
\text { quarto/pessoa }\end{array}$} & \multirow[b]{3}{*}{ Não** } & \multicolumn{2}{|c|}{$\mathrm{CO}$} & \multicolumn{2}{|c|}{ CA } & \multicolumn{2}{|c|}{ Total } \\
\hline & & $\mathbf{N}$ & $\%$ & $\mathbf{N}$ & $\%$ & $\mathbf{N}$ & $\%$ \\
\hline & & 11 & 55 & 9 & 45 & 20 & 100 \\
\hline & $\operatorname{Sim}^{* * *}$ & 10 & 45,5 & 12 & 54,5 & 22 & 100 \\
\hline \multirow{2}{*}{ Número Filhos } & Não & 17 & 51,5 & 16 & 48,5 & 33 & 100 \\
\hline & Sim & 4 & 44,4 & 5 & 55,6 & 9 & 100 \\
\hline \multirow{2}{*}{ Renda Familiar } & Não & 17 & 54,8 & 14 & 45,2 & 31 & 100 \\
\hline & Sim & 4 & 36,4 & 7 & 63,6 & 11 & 100 \\
\hline \multirow{2}{*}{ Discórdia Conjugal } & Não & 18 & 60 & 12 & 40 & 30 & 100 \\
\hline & Sim & 3 & 25 & 9 & 75 & 12 & 100 \\
\hline \multirow{2}{*}{$\begin{array}{l}\text { Transtorno } \\
\text { Psiquiátrico }\end{array}$} & Não & 21 & 53,8 & 18 & 46,2 & 39 & 100 \\
\hline & Sim & 0 & 0,00 & 3 & 100 & 3 & 100 \\
\hline \multirow{2}{*}{ Criminalidade } & Não & 20 & 50 & 20 & 50 & 40 & 100 \\
\hline & Sim & 1 & 50 & 1 & 50 & 2 & 100 \\
\hline
\end{tabular}

* Para mais detalhes sobre como os itens foram classificados como adversos ou não, veja página 52;

** Não= fator de risco não presente na família;

${ }^{* * *} \operatorname{Sim}=$ Fator de risco presente na família.

A distribuição das variáveis é bastante semelhante nos grupos de vítimas e de não vítimas de bullying, com exceção das variáveis Discórdia Conjugal (presente em nove famílias do grupo CA e apenas três do grupo $\mathrm{CO}$ ) e Transtornos Psiquiátricos (presente em três famílias do grupo CA e nenhuma do CO). A fim de entender melhor os resultados, verificou-se se há associações entre as variáveis e os grupos a que os participantes foram 
alocados. Para isso, cada variável teve sua associação com os grupos CA e CO avaliada independentemente por meio de testes qui quadrado. Os resultados destes testes são descritos na Tabela 25.

Tabela 25

Associações entre as variáveis de adversidade familiar e os grupos CA e CO

\begin{tabular}{lcc}
\hline \multicolumn{1}{c}{ IAF } & Qui-Quadrado & Valor $\mathbf{p}$ \\
\hline Razão quarto/pessoa &, $382^{\mathrm{a}}$ & n.s. $^{*}$ \\
Filhos &, $141^{\mathrm{a}}$ & n.s. $^{*}$ \\
Renda familiar & $1,109^{\mathrm{a}}$ & n.s. $^{*}$ \\
Discórdia Conjugal & $4,200^{\mathrm{a}}$ & 0,04 \\
Transtorno Psiquiátrico & $3,231^{\mathrm{a}}$ & n.s. $^{*}$ \\
Criminalidade Pais &, $000^{\mathrm{a}}$ & n.s. $^{*}$ \\
\hline
\end{tabular}

${ }^{*}$ n.s. = não significativo

O teste qui quadrado mostrou que, a um nível de significância de 5\%, apenas a variável Discórdia Conjugal parece estar associada ao grupo que a criança pertence. Segundo a análise descritiva apresentada anteriormente, a discórdia é mais frequente no grupo de CAs.

Foi realizado um teste de correlação de Spearman para verificar possíveis associações entre os escores de adversidade familiar e os problemas de comportamento apontados pelos alunos. Considerando a amostra como um todo, encontrou-se uma correlação positiva (indicando que as variáveis são diretamente proporcionais), ligeira e marginalmente significativa ( $\rho=0,288$ e $\mathrm{p}=0,06)$, entre a adversidade familiar e os problemas de comportamento totais relatados pelos alunos. A Figura 9 é um gráfico de dispersão que ilustra a associação entre as variáveis. 


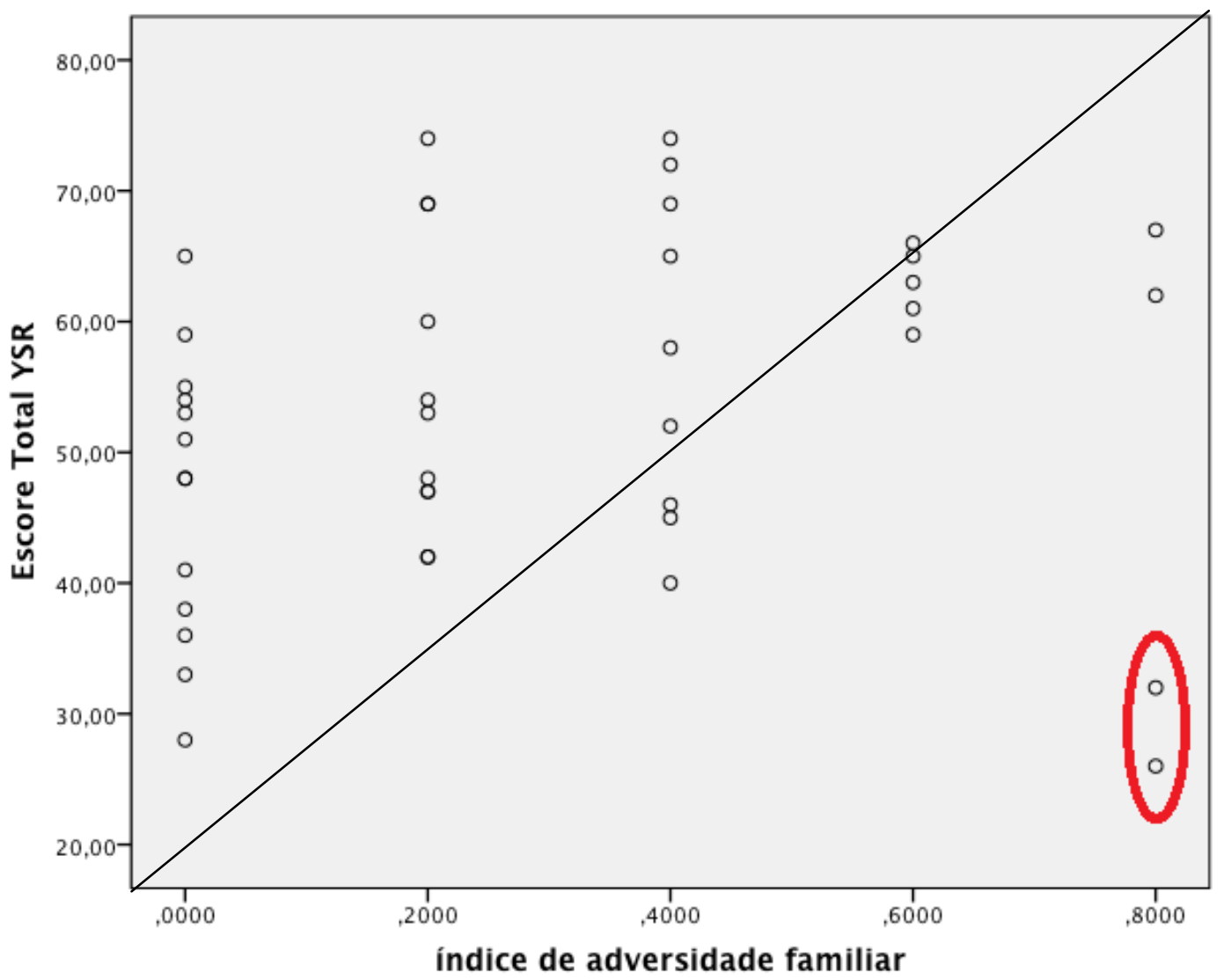

Figura 9. Figura ilustrativa da associação entre problemas de comportamento totais, relatados pelos adolescentes, e o índice de adversidade familiar.

O número de pontos apresentados na Figura 9 é, aparentemente, inferior ao de participantes, uma vez que houve sobreposições, ou seja, adolescentes que obtiveram o mesmo escore em problemas de comportamento totais e mesmo índice de adversidade familiar. Observa-se, ainda, a presença de dois outliers, marcados em vermelho, que, embora tenham apresentado escores não-clínicos em problemas de comportamento totais, pertenciam a famílias com altos índices de adversidade familiar. Excluindo-se da análise os dois participantes considerados outliers, foi realizado novamente o teste de correlação de Spearman, que encontrou uma correlação moderada e estatisticamente significativa entre os problemas de comportamento relatados pelos alunos e a adversidade familiar $(\rho=0,301$ e $p=0,001)$. 
Por fim, foi verificada a associação entre os escores de problemas de comportamento totais, relatados pelos professores, e os escores de adversidade familiar. Foi encontrada uma associação ligeira e estatisticamente significativa entre as variáveis $(\rho=0,103$ e $p=0,001)$. A Figura 10 ilustra a distribuição dos escores das duas variáveis.

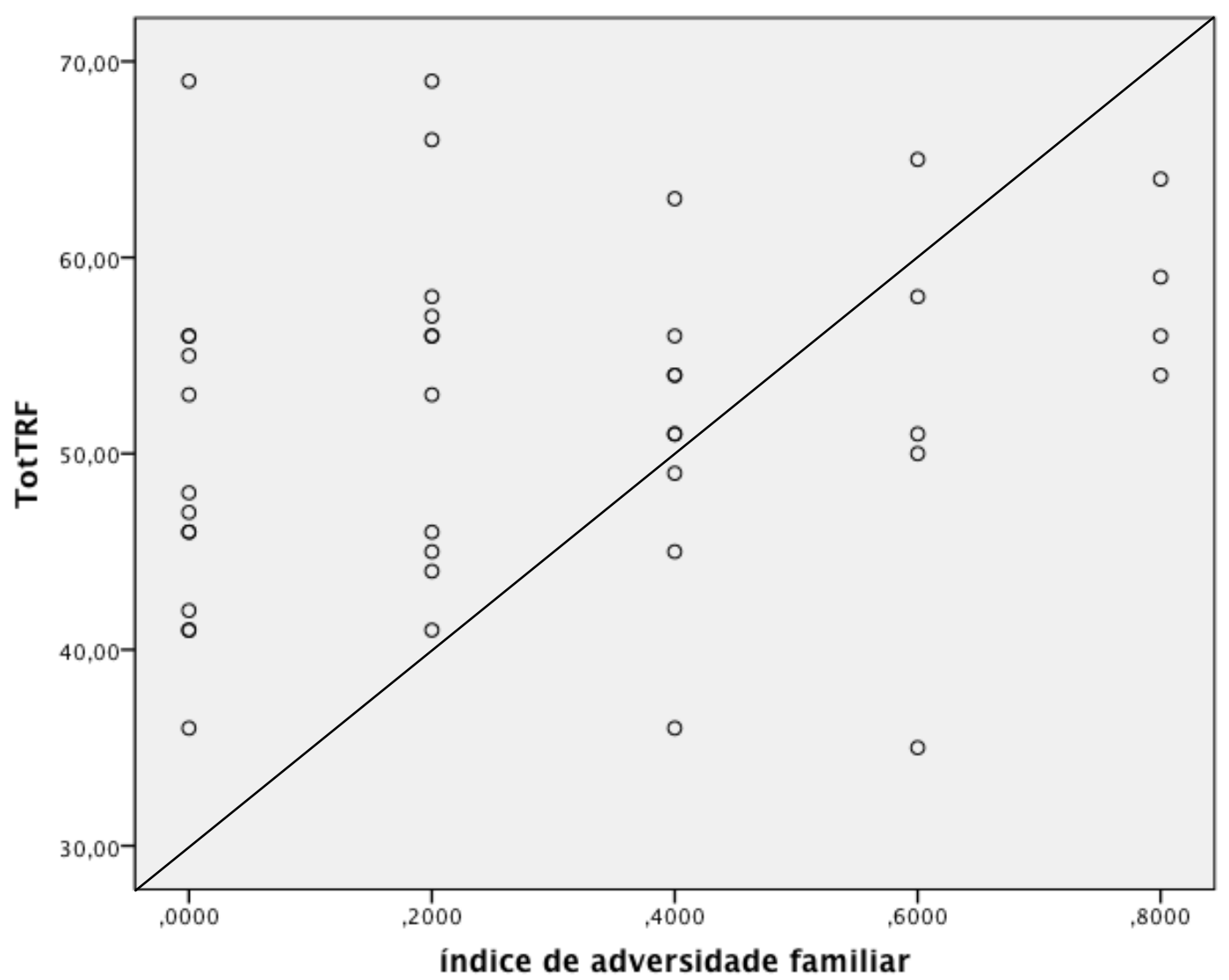

Figura 10. Figura ilustrativa da associação entre problemas de comportamento totais, relatados pelos adolescentes e adversidade familiar. 


\section{DISCUSSÃO}

esta seção foram retomados e sintetizados os principais
resultados do presente estudo - a partir dos objetivos propostos e das hipóteses formuladas - e a interlocução com os resultados de pesquisas nacionais e internacionais sobre o tema.

\subsection{Problemas de comportamento em vítimas e em não vítimas de bullying}

Neste estudo, buscou-se comparar os problemas de comportamento entre vítimas e não vítimas de bullying. Para este fim, o número de participantes vitimizados com problemas de comportamento em nível clínico e seus controles foram avaliados. Corroborando com as hipóteses deste estudo, encontrou-se que mais adolescentes vítimas de bullying foram avaliados com problemas de comportamento internalizantes, externalizantes e totais em nível clínico. O número de alunos vítimas de bullying com escores clínicos em problemas de comportamento internalizantes foi aproximadamente três vezes superior ao encontrado nos não envolvidos em situações de bullying. Além disso, as maiores diferenças entre os dois grupos avaliados foram encontradas no número de participantes com escores clínicos na subescala de Depressão e Ansiedade.

Corroborando com os achados deste estudo, Sourander et al. (2000) avaliaram, em um estudo longitudinal, problemas de comportamento em vítimas de bullying utilizando o CBCL e o YSR. Os autores encontraram que sofrer bullying na infância esteve fortemente associado a problemas de comportamento internalizantes aos 16 anos, sobretudo de depressão e de 
ansiedade. Os pesquisadores apontaram, ainda, que altos níveis de sintomas depressivos durante a infância, associados à vitimização, contribuíram para baixa autoestima, problemas de maturidade, solidão e déficits em habilidades de resolução de problemas. Estes déficits, por sua vez, contribuíram para a persistência dos episódios de vitimização.

Igualmente, Albores-Gallo et al. (2011), ao avaliarem problemas de comportamentos relatados pelos pais, por meio do CBCL, em uma amostra de 262 crianças em idade escolar identificadas como vítimas de bullying, encontraram escores clínicos nas escalas de depressão e de ansiedade, sendo as diferenças entre o grupo de vítimas e o de não envolvidos em situações de bullying estatisticamente significativas.

Na mesma direção, uma metanálise que avaliou os resultados de 181 estudos longitudinais, totalizando uma amostra de 13.978, apontou que os problemas de comportamento internalizantes são tanto antecedentes como consequentes à vitimização, ou seja, problemas de comportamento internalizantes funcionam como um fator de risco para ser vitimizado e, ao mesmo tempo, são maximizados quando a criança sofre bullying na escola. Os autores também apontaram que essa influência recíproca sugere um círculo vicioso que contribui para a perpetuação da vitimização, a qual está associada ao desenvolvimento de transtornos psiquiátricos em idade adulta (Reijntjes et al., 2010).

Zwierzynska et al. (2013), por sua vez, avaliaram, em uma amostra de 3.962 crianças canadenses, se o envolvimento em situações de bullying poderia predizer problemas de comportamento internalizantes na adolescência. Os autores concluíram que ser vitimizado pelos pares esteve associado a 
níveis estatisticamente significativos maiores para sintomas de depressão e ansiedade do que os apresentados pelo grupo controle. Estes achados são corroborados por outros estudos (e.g. Ledwell \& King, 2013; Reijntjes et al., 2010).

Com relação aos problemas de comportamento externalizantes, também encontrados, na presente pesquisa, em nível clínico em mais vítimas de bullying do que não vítimas, observa-se coerência com os dados apresentados na literatura. Uma metanálise, que avaliou 14 estudos longitudinais, examinado a relação entre ser vítima de bullying e o aparecimento de problemas de comportamento externalizantes, concluiu que problemas de comportamento como agressividade e desrespeito às regras funcionam tanto como antecedente (ou seja, fator de risco), quanto como consequente no envolvimento em situações de bullying como vítima (Reijntjes et al., 2011).

\section{2 relato de alunos vítimas de bullying e de seus professores}

Neste estudo, na comparação entre os escores de problemas de comportamento reportados por alunos vítimas de bullying e por seus professores, os resultados vão ao encontro da hipótese inicial, indicando que os alunos vitimizados relataram mais problemas de comportamento internalizantes, com diferenças estatisticamente significativas.

Foram encontrados diversos estudos que comparavam quais alunos se consideram vítimas de bullying e quais eram nomeados pelos professores como vitimizados (e.g. Ladd \& Kochenderfer-Ladd, 2002; Peets \& Kikas, 2006). No entanto, pouco foi encontrado a respeito das concordâncias e discordâncias entre o relato de alunos vitimizados e o de seus professores referente aos 
problemas de comportamento apresentados pelos estudantes vítimas de bullying.

Embora pesquisadores tenham identificado níveis de concordância que variam de moderado a elevado entre pai e mãe e entre pais e professores, na avaliação de problemas de comportamento, têm sido encontrados baixos níveis de concordância acerca da presença desses problemas na comparação entre o relato de professores e alunos (Grigorenko et al., 2010; Salbach-Andrae et al., 2009). Via de regra, professores tendem a avaliar mais problemas de comportamento externalizantes e menos problemas internalizantes (SalbachAndrae et al., 2009).

Esta tendência foi verificada também para diferenças no relato de problemas de comportamento avaliados por alunos vitimas de bullying e por seus professores. Este achado parece ter relação com a natureza dos problemas de comportamento internalizantes, vivenciados em nível privado, gerando pouco impacto no ambiente, e por isso, sendo mais difíceis de serem identificados por outros observadores que não a criança que se comporta (Achenbach \& Edelbrock, 1978; Bolsoni-Silva \& Del Prette, 2003; Gresham \& Kern, 2004).

Os problemas de comportamento externalizantes, por sua vez, expressos na forma de desobediência, agressividade e quebra de regras, geram um impacto direto no contexto de sala de aula (Achenbach \& Edelbrock, 1978; Bolsoni-Silva et al., 2006; Del Prette \& Del Prette, 2003). Supõe-se que, por este motivo, problemas de comportamento externalizantes foram mais observados pelos professores que pelos alunos, sendo a diferença novamente estatisticamente significativa. 


\subsection{Adversidade familiar em vítimas e não vítimas de bullying}

Um dos objetivos do presente estudo foi investigar se vítimas de bullying apresentam níveis de adversidade familiar mais elevados quando comparados aos alunos não vitimizados e não agressores e se há associações entre altos níveis de adversidade familiar e o envolvimento em situações de bullying como vítima. Embora, quando os itens de adversidade familiar foram avaliados em conjunto, tenha sido encontrada diferença apenas marginalmente significativa entre os grupos CA e CO, a presença de discórdia conjugal foi mais frequente em famílias de alunos vítimas de bullying, atingindo diferença estatisticamente significativa entre os grupos.

Diversos estudos têm apontado correlações entre a discórdia parental e o envolvimento em situações de bullying como agressor (Baldry \& Farrington, 2000; Connolly \& O'Moore, 2003). Entretanto, não há consenso entre pesquisadores entre a associação desta variável e a vitimização. Por exemplo, um estudo recente, com uma amostra de 41 crianças, com idades entre seis e 12 anos, encontrou uma correlação estatisticamente significativa entre o nível de conflito entre os pais e a vulnerabilidade para ser vitimizado na escola (Baker, 2012).

Igualmente ao estudo de Baker (2012), Holt et al. (2008), ao investigarem o nível de adversidade familiar e sua relação com a vitimização na escola, em uma amostra de 205 adolescentes, identificaram que as famílias das vítimas de bullying apresentavam, entre outras características, a presença de altos níveis de violência doméstica interparental. Este achado também foi compatível com um estudo de caso realizado no Brasil, no qual os pais de uma criança vitimizada procuraram atendimento em uma clínica de psicologia e 
tiveram o perfil comportamental avaliado. Entre os resultados, encontroaram-se altos níveis de conflito na forma de educar o filho e de conflitos conjugais (Detoni, 2008).

Por outro lado, segundo um estudo nacional, com uma amostra de 239 adolescentes, a exposição à violência interparental esteve associada a ser autor de bullying na escola, especialmente para as meninas, mas não à vitimização (Pinheiro \& Williams, 2009). Os autores do estudo apontam que os resultados devem ser analisados com cautela, uma vez que, por causa das fragilidades metodológicas, como o tamanho da amostra, os resultados não podem ser generalizados.

As sucessivas falhas no que se refere às estratégias empregadas pelos pais na resolução de problemas interpessoais, se constituem como um modelo negativo de resolução de problemas para os filhos, o qual pode ter como consequências para estes últimos déficits de habilidades sociais para lidar com seus pares e para obter um nível de convivência social satisfatório (Cummings et al.,2003), Os mesmo autores levantam a hipótese que esses déficits tornam o jovem mais vulnerável a ser vitimizado na escola. Na mesma direção, Mohr (2006) encontrou que crianças expostas a altos níveis de discórdia conjugal tendem a vivenciar mais frequentemente interações negativas com seus pares, sendo que um dos desfechos mais comumente reportados foi o envolvimento em situações de bullying.

Uma vez que se entende, a partir de um referencial analíticocomportamental, que o comportamento humano, tal como o envolvimento em situações de bullying, é multideterminado, selecionado e mantido na interação do indivíduo com os diversos contextos (Meyer et al., 2010; Skinner, 1978; 
Sampaio, 2005; Tourinho, 2003), não apenas características da família contribuem para o desfecho de envolvimento em bullying. Dentre outros fatores, devem-se considerar as características individuais dos jovens, as contingências do ambiente escolar e os valores da comunidade.

Nesse sentido, os resultados desta pesquisa devem ser utilizados para se pensar em alternativas de intervenção que minimizem a expressão da violência na escola e, consequentemente, diminuam as alterações comportamentais relacionadas ao envolvimento em situações de bullying. Tais resultados, entretanto, devem ser analisados com cautela, não devendo ser utilizados para culpabilizar as famílias, e sim auxiliar na compreensão do profissional sobre o fenômeno e desenvolver tecnologias sociais que envolvam, na medida do possível, os contextos com os quais o jovem convive.

\subsection{Relação entre adversidade familiar e problemas de comportamento}

O presente estudo investigou se a presença de baixo nível socioeconômico, histórico de transtornos psiquiátricos nos pais, discórdia conjugal, número excessivo de filhos, número excessivo de pessoas na mesma casa e criminalidade nos pais estiveram associados ao aparecimento de problemas de comportamento na amostra estudada. Encontrou-se uma correlação positiva, porém ligeira, entre problemas de comportamento reportados pelos participantes e os escores nesses índices de adversidade familiar. A análise descritiva dos resultados auxilia a interpretar estes achados, os quais indicam, como o esperado, que à medida que aumentam os escores de adversidade, aumentam também os problemas de comportamento. 
Os dois participantes avaliados como outliers, destacados na Figura 9 (página 84), embora tenham apresentado altos índices de adversidade familiar, não tiveram os escores de problemas de comportamentos totais em nível clínico. Uma vez que fatores de proteção podem minorar os prejuízos associados à combinação de fatores de risco (Dumka et al., 1995; Sá et al.,2010), tem-se como hipótese que os dois participantes outliers, embora pertençam a famílias com características adversas ao desenvolvimento, disponham de outras formas de apoio social que contemplem suas necessidades. Para confirmar ou refutar esta hipótese seria necessário o delineamento de um estudo de caso destinado a avaliar as características individuais e das famílias destes participantes.

Diversos estudos têm sido realizados com o objetivo de avaliar como as características familiares estão associadas ao aparecimento de problemas de comportamento em crianças e adolescentes (Assis et al., 2009; Bolsoni-Silva \& Marturano, 2002; Del Prette \& Del Prette, 2003; Santos et al., 2008; Silva et al., 2008), sendo que os fatores de risco estudados podem ser divididos duas categorias mais amplas. A primeira se refere aos aspectos comportamentais dos pais, tais como altos níveis de discórdia conjugal (Durand et al., 2011; Pesce, 2009), habilidades sociais educativas parentais deficitárias (BolsoniSilva \& Loureiro, 2011; O'Connel et al., 2009), falta de monitoramento e negligência (Biederman, et al., 1995; Costa et al., 2000; Fergusson \& Lynskey, 1996; Kim-Cohen, 2007; Silvares, 1993; Tavares da Silva et al., 2008). A segunda categoria corresponde às características da família, tais como baixo nível socioeconômico (Assis et al., 2009; Brancalhone et al., 2004), número excessivo de filhos e de moradores na casa (Assis et al., 2009; Luizzi \& Rose, 2010). 
É importante frisar que o desenvolvimento infantil é o resultado de uma complexa interação entre fatores biológicos, culturais, sociais, cognitivos e educacionais (Veleda, Soares, \& Cézar-Vaz, 2011), podendo ser prejudicado por diferentes fatores de risco (Miller, Maguire, \& Macdonald, 2011; Peacock, Konrad, Watson, Nickel, \& Muhajarine, 2013). Assim, embora a família seja o primeiro e mais importante contexto de socialização da criança, não é o único.

Deste modo, as considerações deste trabalho sobre a adversidade familiar vão mais na direção de apontar que o ambiente familiar é propício a intervenções precoces que diminuam fatores de risco familiares associados ao surgimento de problemas de comportamento levando em conta que os pais também foram expostos quando crianças, a características de seus pais, no tocante a forma de se relacionar e de educar. Neste sentido, intervenções voltadas às famílias com características adversas ao desenvolvimento infantil podem interromper o ciclo de problemas de comportamento e contribuir para o desenvolvimento de gerações mais saudáveis e felizes. 


\section{CONSIDERAÇÕES FINAIS}

objetivo do presente estudo foi avaliar e comparar os escores de
problemas de comportamento de vítimas de bullying com os de não vítimas, obtidos por meio do autorrelato e também a partir do relato dos professores, assim como verificar correlações entre os escores de adversidade familiar e de problemas de comportamento nos dois grupos.

Embora os escores de problemas de comportamento, sobretudo do tipo internalizante, relatados por vítimas de bullying tenham sido significativamente superiores aos relatados por não vítimas, e tenham atingido níveis clínicos na amostra avaliada, os professores parecem não estar sensíveis a estes indicadores.

A impunidade de situações de bullying é duplamente prejudicial, uma vez que provoca nos agressores a sensação de que é aceitável produzir sofrimento em seus pares e, na vítimas, o sentimento de falta de valor próprio e ódio contra a escola, que por vezes culmina em episódios de School Shooting. Acrescenta-se, ainda, que não é incomum que alunos vitimizados por um período perpetuem os episódios de agressão em um momento posterior, engajando-se em bullying como vítimas-agressoras. Este movimento contribui para o aumento do ciclo da violência em instituições de ensino, motivo pelo qual comportamentos de bullying devem ser identificados e combatidos por professores, auxiliares e outros funcionários da escola.

Uma vez que o envolvimento em situações de vitimização é, marcadamente, um fator de risco para o suicídio, investir em políticas públicas 
que tenham como objetivo diminuir a ocorrência do bullying possibilita, por consequência, prevenir o suicídio de crianças e adolescentes brasileiros. Tratase também de uma medida de política pública de segurança, uma vez que pode prevenir mortes associadas aos episódios de School Shooting, reportados por países desenvolvidos há décadas e que, mais recentemente, têm acontecido também em território nacional.

Para professores, identificar situações de bullying menos evidentes pode ser um desafio. No entanto, além da necessidade de serem capazes de identificar precocemente a ocorrência de bullying nas escolas, é fundamental que sejam instrumentalizados para o manejo comportamental dos casos identificados. A partir do desenvolvimento dessas habilidades, os professores poderão atuar de forma a gerar impacto positivo no prognóstico dos envolvidos, englobando indicadores de educação, saúde e segurança. Aponta-se ainda que o investimento em intervenções que desenvolvam habilidades sociais em crianças, jovens e professores tem se mostrado altamente eficientes para promover interações sociais mais positivas no contexto escolar (Melo, 2003; Melo \& Silvares, 2007).

Com relação à avaliação da adversidade familiar e o envolvimento em situações de bullying, a presença de discórdia conjugal na família, avaliada por Rutter (1981) como fator de risco para o desenvolvimento de problemas de comportamento e transtornos psiquiátricos, também se mostrou associada ao envolvimento em situações de bullying como vítima. Deste modo, programas destinados aos pais e cuidadores que tenham como finalidade o treino de habilidades sociais, sobretudo no tocante às estratégias de resolução de problemas entre o casal e na família, e ainda, o treino de habilidades sociais 
educativas parentais, a fim de melhorar a qualidade das relações entre pais e filhos, configuram-se como uma estratégia promissora.

Identificar problemas de comportamento e características familiares adversas associadas à vitimização, assim como avaliar a percepção dos próprios envolvidos e de seus professores acerca destes aspectos, contribui para o desenvolvimento de medidas preventivas de bullying em escolas brasileiras. Espera-se que este trabalho motive novas produções nacionais sobre o tema, a fim de verificar convergências e divergências entre os resultados. A partir disso, poder-se-á produzir conhecimentos que sustentem políticas públicas preventivas que visem a minorar o sofrimento individual de crianças e adolescentes expostos repetidamente a comportamentos intimidadores e humilhantes, assim como minimizar os custos econômicos do tratamento de problemas de comportamento e transtornos psiquiátricos, os quais constituem fatores de risco para ser vitimizado. 


\section{LIMITAÇÕES E DESDOBRAMENTOS}

o Brasil, este é um dos estudos pioneiros que utilizam múltiplos informantes, tanto para o rastreamento de vítimas de bullying quanto para a avaliação de problemas de comportamento na população nacional. Além disso, a pesquisa é inovadora por comparar os problemas de comportamento relatados por alvos de bullying e seus professores. Entretanto, considera-se que a presente pesquisa apresentou limitações metodológicas, as quais serão descritas a seguir.

Ainda que apenas um participante tenha sido perdido no momento da avaliação de problemas de comportamento e que tenham sido empreendidos esforços para a coleta dos dados acerca da adversidade familiar, houve perda de 18 participantes (30\%) para esta última avaliação, dos quais nove pertenciam ao grupo de vítimas e nove ao grupo de não vítimas. Estes participantes não retornaram os envelopes com o IAF preenchido e seus pais se recusaram a responder por telefone às perguntas que compõem a entrevista ou não foram encontrados a partir dos números de telefone fornecidos pela secretaria da escola. A perda destes dados, assim como a utilização de dois métodos para a coleta - o preenchimento do envelope e a entrevista por telefone - , tornou mais frágeis os resultados das correlações entre adversidade familiar e problemas de comportamento, que apontaram uma correlação apenas marginalmente significativa entre as variáveis. Levanta-se a hipótese, a partir das análises descritivas, de que, em uma amostra mais expressiva, esta correlação seja mais consistente. 
Outro ponto de vulnerabilidade do estudo se refere à utilização do TRF, o qual não apresenta, até o momento, evidências de validade para a população brasileira. Recomendam-se estudos futuros que apresentem evidências de validade deste instrumento, já utilizado em pesquisas no Brasil, para a realidade nacional, a fim de produzir resultados mais acurados.

Por fim, destaca-se que se firmou o compromisso, entre o pesquisador responsável e a coordenação da escola na qual os dados foram coletados, de que os resultados deste estudo serão devidamente informados, tanto aos coordenadores quanto aos pais, que terão a possibilidade de encaminhar seus filhos, identificados como vítimas de bullying, para atendimento psicológico no Laboratório de Terapia Comportamental da Universidade de São Paulo, a ser realizado pelos pesquisadores vinculados à linha de pesquisa da qual o trabalho faz parte. 


\section{REFERÊNCIAS}

Achenbach, T. M., \& Edelbrock, C. S. (1978). The classification of child psychopathology: a review and analysis of empirical efforts. Psychological Bulletin, 85(6), 1275-1301. doi: 10.1037/0033-2909.85.6.1275

Achenbach, T. M., \& Rescorla, L. A. (2001). Manual for the ASEBA School-Age Forms and Profiles [Manual]. Burlington, VT: University of Vermont, Research Center for Children, Youths, and Families.

Albores-Gallo, L., Sauceda-García, J. M., Ruiz-Velasco, S., \& Roque-Santiago, E. (2011). El acoso escolar (bullying) y su asociación con trastornos psiquiátricos en una muestra de escolares en México. Salud Pública de México, 53(3), 220-227.

Albuquerque, P. P. D., Williams, L. C. D. A., \& D'Affonseca, S. M. (2013). Long term effects of bullying and posttraumatic stress disorder: a literature review. Psicologia: Teoria e Pesquisa, 29(1), 91-98. doi:10.1590/S010237722013000100011

Alckmin-Carvalho, F., Izbicki, S., Barufi, L. F., \& Melo, M. H. S. (2014). Estratégias e instrumentos para a identificação de bullying em estudos nacionais. Avaliação Psicológica, 13(3). (Aceito para publicação)

Almeida, A., Lisboa, C., \& Jesús Caurcel, M. (2007). ¿ Por qué ocurren los malos tratos entre iguales?: explicaciones causales de adolescentes portugueses y brasileños. Interamerican Journal of Psychology, 41(2), 107118.

Anderson, M., Kaufman, J., Simon, T. R., Barrios, L., Paulozzi, L., Ryan, G., the School-Associated Violent Deaths Study Group. (2001). School-associated violent deaths in the United States, 1994-1999. The Journal of American Medical Association, 286(21), 2695-702. doi: 10.1001/jama.286.21.2695

Arsenio, W. F., Cooperman, S., \& Lover, A. (2000). Affective predictors of preschoolers' aggression and peer acceptance: direct and indirect effects. 
Developmental Psychology, 36(4), 438-448. doi: 10.1037/00121649.36.4.438

Assis, S. G., Avanci, J. Q., \& Oliveira, R. V. C. (2009). Desigualdades socioeconômicas e saúde mental infantil. Revista de Saúde Pública, 43(Supl 1), 92-100.

Baldry, A. C., \& Farrington, D. P. (2000). Bullies and delinquents: personal characteristics and parental styles. Journal of Community \& Applied Social Psychology, 10(1), 17-31. doi: 10.1002/(SICI)10991298(200001/02)10:1<17::AID-CASP526>3.0.CO;2-M

Bandeira, M., Rocha, S. S., Souza, T. D., Del Prette, Z. A. P., \& Del Prette, A. (2006). Comportamentos problemáticos em estudantes do ensino fundamental: características da ocorrência e relação com habilidades sociais e dificuldades de aprendizagem. Estudos em Psicologia, 11(2), 199-208.

Barrio, C., Martín, H. Montero, I., Fernández, I., \& Gutiérrez, H. (2001). Bullying in Spanish secondary schools: a study on a national scale for the Ombudsman's Report on School Violence. The International Journal of Children's Rights, 9, 241-257.

Baker, S. K. (2012). Peer victimization as it relates to interparental conflict, friendship support and anxiety (Tese de doutorado, Auburn University).

Berger, K. S. (2007). Update on bullying at school: science forgoten?. Developmental Review, 27(1), 90-126. doi: 10.1016/j.dr.2006.08.002

Biederman, J. Milberger, S., Faraone, S. V., Kiely, K., Guite, J., Mick, E., Reed, E. (1995). Family-environment risk factors for attention-deficit hyperactivity: a test of Rutter's indicators of adversity. Archives of General Psychiatry, 52(6), 464-470. doi:10.1001/archpsyc.1995.03950180050007

Bifulco, A., Schimmenti, A., Jacobs, C., Bunn, A., \& Rusu, A. C. (2014). Risk factors and psychological outcomes of bullying victimization: a communitybased study. Child Indicators Research, 1-16. doi: 10.1007/s12187-0149236-8 
Binsfeld, A. R., \& de Macedo Lisboa, C. S. (2010). Bullying: um estudo sobre papéis sociais, ansiedade e depressão no contexto escolar. Interpersona: An International Journal on Personal Relationships, 4(1), 74-105.

Bolsoni-Silva, A. T. (2003). Habilidades sociais educativas, variáveis contextuais e problemas de comportamento: comparando pais e mães de pré-escolares (Tese de Doutorado, Faculdade de Filosofia, Ciências e Letras de Ribeirão Preto da USP, Ribeirão Preto).

Bolsoni-Silva, J. W. S., \& Del Prette, A. (2003). Problemas de comportamento: um panorama da área. Revista Brasileira de Terapia Comportamental e Cognitiva, 5(2), 91-103.

Bolsoni-Silva, A. T., \& Loureiro, S. R. (2011) Práticas educativas parentais e repertório comportamental infantil: comparando crianças diferenciadas pelo comportamento. Paidéia, 21(48), 61-71.

Bolsoni-Silva, A. T., \& Marturano, E. M. (2002). Práticas educativas e problemas de comportamento: uma análise à luz das habilidades sociais. Estudos de Psicologia (Natal-RN), 7(2), 227-235.

Bolsoni-Silva, A. T., Paiva, M. M., \& Barbosa, C. G. (2009). Problemas de comportamento de crianças/adolescentes e dificuldades de pais/cuidadores: um estudo de caracterização. Psicologia Clínica, 21(1), 169-184.

Bordin, I. A., Rocha, M. M., Paula, C. S., Teixeira, M. C. T., Achenbach, T. M., Rescorla, L. A., \& Silvares, E. F. (2013). Child Behavior Checklist (CBCL), Youth Self-Report (YSR) and Teacher's Report Form (TRF): an overview of the development of the original and Brazilian versions. Cadernos de Saúde Pública, 29(1), 13-28. doi: 10.1590/S0102-311X2013000500004.

Borsa, J. C., \& Bandeira, D. R. (2011). Uso de instrumentos psicológicos de avaliação do comportamento agressivo infantil: análise da produção científica brasileira. Avaliação Psicológica, 10(2), 193-203.

Borsa, J. C., \& Nunes, M. L. T. (2008). Concordância parental sobre problemas de comportamento infantil através do CBCL. Paidéia, 18(40), 317-330. 
Brancalhone, P. G., Fogo, J. C., \& Williams, L. C. A. (2004). Crianças expostas à violência conjugal: avaliação do desempenho acadêmico. Psicologia: Teoria e Pesquisa, 20(2), 113-117.

Breakwell, G. M., Hammond, S., Fife-Schaw, C., \& Smith, J. A. (2010). Métodos de pesquisa em psicologia. Porto Alegre: Artmed.

Bosworth, K., Espelage, D., \& Simon, T. (1999). Factors associated with bullying behavior in middle school students. Journal of Early Adolescence, 19(3), 341-362. doi: 10.1177/0272431699019003003

Calbo, A. S., Busnello, F. de B., Rigoli, M. M., Schaefer, L. S., \& Kristensen, C. H. (2009). Bullying na escola: comportamento agressivo, vitimização e conduta pró-social entre pares. Contextos Clínicos, 2(2), 73-80.

Clabaugh, G. K., \& Clabaugh, A. A. (2005). Bad apples or sour pickles? Fundamental attribution error and the Columbine massacre. Educational Horizons, 83(2), 81-86.

Carvalhosa, S. F. (2010). Prevenção da violência e do bullying em contexto escolar. Lisboa: Climepsi Editores.

Connolly, I., \& O'Moore, M. (2003). Personality and family relations of children who bully. Personality and Individual Differences, 35(3), 559-567. doi: 0.1016/S0191-8869(02)00218-0

Constantini, A. (2004). Bullying: como combatê-lo? Prevenir e enfrentar a violência entre os jovens. São Paulo: Itália Nova.

Costa, F. T., Teixeira, M. A., \& Gomes, W. B. (2000). Responsividade e exigência: duas escalas para avaliar estilos parentais. Psicologia: reflexão e crítica, 13(3), 465-473.

Copeland, W. E., Wolke, D., Angold, A., \& Costello, E. J. (2013). Adult psychiatric outcomes of bullying and being bullied by peers in childhood and adolescence. JAMA Psychiatry, 70(4), 419-426. doi:10.1001/jamapsychiatry.2013.504 
Craig, W. M. (1998). The relationship among bullying, victimization, depression, anxiety, and aggression in elementary school children. Personality and Individual Differences, 24(1), 123-130. doi: 10.1016/S0191-8869(97)001451

Crick, N. R., \& Grotpeter, J. K. (1995). Relational aggression, gender, and social- psychological adjustment. Child development, 66(3), 710-722.

Cummings, E., Goeke-Morey, M., \& Pap, L. (2003). Children's responses to everyday marital conflict tactics in the home. Child Development, 74(6), 1918-1929. doi: 10.1046/j.1467-8624.2003.00646.x

D'abreu, L. C. F., \& Marturano, E. M. (2010). Associação entre comportamentos externalizantes e baixo desempenho escolar: uma revisão de estudos prospectivos e longitudinais. Estudos em Psicologia (Natal-RN), 15(1), 4351.

Del Prette, Z. A. P., \& Del Prette, A. (2003). Habilidades sociais e dificuldade de aprendizagem: teoria e pesquisa sob um enfoque multimodal. In A. Del Prette \& Z. A. P. Del Prette (Orgs.), Habilidades sociais, desenvolvimento e aprendizagem: questões conceituais, avaliação e intervenção (pp. 167206). Campinas: Alínea.

Dias, T. de O., Lisboa, C., Koller, S. H., \& DeSousa, D. (2011). Aggression and pro-sociability: risk and protective dynamics in popularity and bullying processes. Psykhe, 20(2), 53-63.

Dinkes, R., Cataldi, F. E., Kena, G., Baum, K. (2006). Indicators of School Crime and Safety: 2006. Washington, DC: U.S. Government Printing Office.

Duarte, C. S., \& Bordin, I. A. (2000). Instrumentos de avaliação. Revista Brasileira de Psiquiatria, 22(Supl 2), 55-58. doi: 10.1590/S151644462000000600015

Due, P., \& Holstein, B. E. (2008). Bullying victimization among 13 to 15 year old school children: results from two comparative studies in 66 countries and regions. International Journal of Adolescent Medicine and Health, 20(2), 209-222. doi: 10.1515/IJAMH.2008.20.2.209 
Due, P., Holstein, B. E., Lynch, J., Diderichsen, F., Gabhain, S. N., Scheidt, P., \& Currie, C. (2005). Bullying and symptoms among school-aged children: international comparative cross sectional study in 28 countries. The European Journal of Public Health, 15(2), 128-132. doi: 10.1093/eurpub/cki105

Dumka, L. E., Roosa, M. W., Michaels, M. L., \& Suh, K. W. (1995). Using research and theory to develop prevention programs for high-risk families. Family Relations, 44(1), 78-86.

Eslea, M., \& Rees, J. (2001). At what age are children most likely to be bullied at school?. Aggressive Behavior, 27(6), 419-29. doi: 10.1002/ab.1027

Espelage, D. L., \& Holt, M. K. (2013). Suicidal ideation and school bullying experiences after controlling for depression and delinquency. Journal of Adolescent Health, 53(1), S27-S31. doi: 10.1016/j.jadohealth.2012.09.017

Fante, C. (2005). O fenômeno bullying. Campinas: Versus Finkelhor.

Fekkes, M., Pijpers, F. I., \& Verloove-Vanhorick, S. P. (2005). Bullying: who does what, when and where? Involvement of children, teachers and parents in bullying behavior. Health Education Research, 20(1), 81-91. doi: 10.1093/her/cyg100

Ferguson, C. J., San Miguel, C., \& Hartley, R. D. (2009). A multivariate analysis of youth violence and aggression: the influence of family, peers, depression, and media violence. The Journal of pediatrics, 155(6), 904908.

Fergusson, D. M., Boden, J. M., \& Horwood, L. J. (2013). Bullying in childhood, externalizing behaviors, and adult offending: evidence from a 30-year study. Journal of School Violence, 13(1), 146-164. doi: $10.1080 / 15388220.2013 .840642$

Fergusson, D. M., \& Lynskey, M. T. (1996). Adolescent resiliency to family adversity. Journal of Child Psychology and Psychiatry, 37(3), 281-292. doi: 10.1111/j.1469-7610.1996.tb01405.x 
Finkelhor, D., Turner, H. A., \& Hamby, S. (2012). Let's prevent peer victimization, not just bullying. Child Abuse and Neglect, 36(4), 271-274.

Frank, R., \& Acle, A. V. (2014). Girl talk relational aggression by peers as an antecedent to eating disorders among girls and women. Journal of Adolescent Health, 54(2), S75.

Fundação Sistema Estadual de Análise de Dados. (2006). Pesquisa de condições de vida no Estado de São Paulo. São Paulo: SEADE.

George, M. (2013). Bullying increasingly listed as responsible for eating disorders. British Journal of School Nursing, 8(1), 45.

de Girolamo, G., Dagani, J., Purcell, R., Cocchi, A., McGorry, P. D. (2012). Age of onset of mental disorders and use of mental health services: needs, opportunities and obstacles. Epidemiology and Psychiatrics Sciences, 21(1), 47-57.

Griffin, R. S., \& Gross, A. M. (2004). Childhood bullying: current empirical findings and future directions for research. Aggression and Violent Behavior, 9(4), 379-400. doi:10.1016/S1359-1789(03)00033-8

Grigorenko, E. L., Geiser, C., Slobodskaya, H. R., \& Francis, D. J. (2010). Cross-informant symptoms from CBCL, TRF, and YSR: Trait and method variance in a normative sample of Russian youths. Psychological assessment, 22(4), 893.

Hamburger, M. E., Basile, K. C., \& Vivolo, A. M. (2011). Measuring bullying victimization, perpetration, and bystander experiences: a compendium of assessment tools. Atlanta: Editora.

Holt, M. K., Kaufman Kantor, G., \& Finkelhor, D. (2008). Parent/child concordance about bullying involvement and family characteristics related to bullying and peer victimization. Journal of School Violence, 8(1), 42-63. doi: 10.1080/15388220802067813 
Howard, A. M., Landau, S., \& Pryor, J. B. (2014). Peer bystanders to bullying: Who wants to play with the victim?. Journal of abnormal child psychology, 42(2), 265-276.

Instituto Brasileiro de Geografia e Estatística. (2010). Brasil: Tábua Completa de Mortalidade de 2010. Recuperado em 03 junho, /06/2012, de http://www.ibge.gov.br/home/estatistica/populacao/tabuadevida/2010/notas tecnicas.pdfE.

Jessor, R., Bos J. V., Vanderryn, J., Costa, F. M., \& Turbin, M. S. (1995). Protective factors in adolescent problem behavior: moderator effects and developmental change. Developmental Psychology, 31(6), 923-33. doi: 10.1037/0012-1649.31.6.923

Jiang, D., Walsh, M., \& Augimeri, L. K. (2011). The linkage between childhood bullying behaviour and future offending. Criminal Behaviour and Mental Health, 21(2), 128-135. doi: 10.1002/cbm.803

Kauffman, J. M. (2005). Characteristics of emotional and behavioral disorders of children and youth. New Jesey: Pearson Educational.

Kim, Y. S., \& Leventhal, B. (2008). Bullying and suicide. A review. International Journal of Adolescent Medicine and Health, 20(2), 133-154. doi: 10.1515/IJAMH.2008.20.2.133.

Kim, Y. S., Leventhal, B. L., Koh, Y. J., \& Boyce, W. T. (2009). Bullying increased suicide risk: prospective study of Korean adolescents. Archives of Suicide Research, 13(1), 15-30. doi: 10.1080/13811110802572098

Kim-Cohen, J. (2007). Resilience and developmental psychopathology. Child and Adolescent Psychiatric Clinics of North America, 16(2), 271-283. doi: 10.1016/j.chc.2006.11.003Klomek, A. B., Kleinman, M., Altschuler, E., Marrocco, F., Amakawa, L., \& Gould, M. S. (2013). Suicidal adolescents' experiences with bullying perpetration and victimization during high school as risk factors for later depression and suicidality. Journal of Adolescent Health, 53(1), S37-S42. doi: 10.1016/j.jadohealth.2012.12.008 
Kumpulainen, K., \& Räsänen, E. (2000). Children involved in bullying at elementary school age: their psychiatric symptoms and deviance in adolescence: an epidemiological sample. Child Abuse \& Neglect, 24(12), 1567-1577. doi: 10.1016/S0145-2134(00)00210-6

Ladd, G. W., \& Kochenderfer-Ladd, B. (2002). Identifying victims of peer aggression from early to middle childhood: analysis of cross-informant data for concordance, estimation of relational adjustment, prevalence of victimization, and characteristics of identified victims. Psychological Assessment, 14(1), 74. doi: 10.1037/1040-3590.14.1.74

Ledwell, M., \& King, V. (2013). Bullying and Internalizing Problems Gender Differences and the Buffering Role of Parental Communication. Journal of Family Issues. doi: 10.1177/0192513X13491410

Lima, R. D. (2011). Após o massacre de Realengo. Revista Espaço Acadêmico, 11(121), 130-134.

Lisboa, C. S. M. (2005). Comportamento agressivo, vitimização e relações de amizade de crianças em idade escolar: fatores de risco e proteção (Tese de Doutorado não publicada). Universidade Federal do Rio Grande do Sul, Porto Alegre, RS.

Lopes Neto, A. (2005). Bullying: comportamento agressivo entre estudantes. Jornal de Pediatria, 81(5), 164-72.

Lopes Neto, A., \& Saavedra, L. H. (2003). Diga não para o bullying - programa de redução do comportamento agressivo entre estudantes. Rio de Janeiro: ABRAPIA.

Lickel, B., Schmader, T., \& Hamilton, D. L. (2003). A case of collective responsibility: who else was to blame for the Columbine high school shootings? Personality and Social Psychology Bulletin, 29(2), 194-204. doi: $10.1177 / 0146167202239045$

Luizzi, L., \& Rose, T. M. S. D. (2010). Intervenções para a prevenção e redução de comportamentos agressivos e a formação de professores. Temas em Psicologia, 18(1), 57-69. 
Mesquita, M. L. G., Brunoni, D., de Pina Neto, J. M., Kim, C. A., Melo, M. H. S., \& Teixeira, M. C. T. (2010). Fenótipo comportamental de crianças e adolescentes com síndrome de Prader-Willi. Revista Paulista de Pediatria, 28(1), 63-9.

Malta, D. C., Silva, M. A., Mello, F. C., Monteiro, R. A., Sardinha, L. M. Crespo, C., Porto, D. L. (2010). Bullying in Brazilian schools: results from the National School-based Health Survey (PeNSE), 2009. Ciência \& Saúde Coletiva, 15(2), 3065-76. doi: 10.1590/S1413-81232010000800011

Marler, C., Trainor, B. C., \& Davis, E. (2005). Paternal behavior and offspring aggression. Current Directions in Psychological Science, 14(3), 163-166. doi: 10.1111/j.0963-7214.2005.00351.x

Melo, M. H. S. (2003). Crianças com dificuldades de interação no ambiente escolar: uma intervenção multifocal. (Tese de Doutorado, Departamento de Psicologia Clínica, Instituto de Psicologia, Universidade de São Paulo).

Melo, M. H. S., \& Silvares, E. F. M. (2007). Sociometric effects on rejection of children in grade 2 given a multifocal intervention involving teachers, parents, and children in one brazilian school. Psychological Reports, 101(3F), 1162-72. doi: 10.2466/pr0.101.4.1162-1172

Meyer, S. B., Del Prette, G., Zamignani, D. R., Banaco, R. A., Neno, S., \& Tourinho, E. Z. (2010). Análise do Comportamento e Terapia AnalíticoComportamental. In E. Z. Tourinho, \& S. V. Luna (Eds.), Análise do Comportamento: investigações históricas, conceituais e aplicadas (pp. 153174). São Paulo, SP: Roca.

Miller, S., Maguire, L. K., \& Macdonald, G. (2011). Home-based child development interventions for preschool children from socially disadvantaged families. Cochrane Database of Systematic Reviews, 12(CD008131). doi: 10.1002/14651858.CD008131.pub2

Mohapatra, S., Irving, H., Paglia-Boak, A., Wekerle, C., Adlaf, E., \& Rehm, J. (2010). History of family involvement with child protective services as a risk 
factor for bullying in ontario schools. Child and Adolescent Mental Health, 15(3), 157-63. doi: 10.1111/j.1475-3588.2009.00552.x

Mohr, A. (2006). Family variables associated with peer victimization: does family violence enhance the probability of being victimized by peers? Swiss Journal of Psychology, 65(2), 107-116. doi: 10.1024/14210185.65.2.107

Moura, D. R. D., Cruz, A. C. N., \& Quevedo, L. D. Á. (2011). Prevalence and characteristics of school age bullying victims. Jornal de pediatria, 87(1), 1923.

Muschert, G. W. (2007). Research in school shooting. Sociology Compass, 1(1), 60-80. doi: 10.1111/j.1751-9020.2007.00008.x

Olweus, D. (1983). Low school achievement and aggressive behaviour in adolescent boys. In D. Magnusson, \& V. Allen (Eds.), Human development: an interactional perspective (pp. 353-365). New York: Academic Press.

Olweus, D. (1991). Bully/victim problems among schoolchildren: basic factors and effects of a school-based intervention program. Hillsdale, NJ: Erlbaum.

Olweus, D. (1992). Victimization by peers: antecedents and long-term outcomes. In K. H. Rubin, \& J. B. Asendorf (Eds.), Social withdrawal, inhibition, and shyness in children (pp. 315-341). Hillsdale, NJ: Erlbaum.

Olweus, D. (1993). Bullying at school: what we know and what we can do. London: Blackwell.

Olweus, D., Limber, S., \& Mihalic, S. (1999). Blueprints for violence prevention: book nine: bullying prevention program. Boulder, CO: Center for the Study and Prevention of Violence.

Oram, S., Stöckl, H., Busza, J., Howard, L. M., \& Zimmerman, C. (2012). Prevalence and risk of violence and the physical, mental, and sexual health problems associated with human trafficking: systematic review. PLOS medicine, 9(5), e1001224. doi: 10.1371/journal.pmed.1001224 
O'Connel, M. E., Boat, T., \& Warner, K. E. (2009) Preventing mental, emotional, and behavioral disorders among young people: progress and possibilities. Washington, DC: National Academies Press.

Palácios, M., \& Rego, S. (2006). Bullying: mais uma epidemia invisível. Revista Brasileira de Educação Médica, 30(1), 3-5.

Pakaslahti, L., \& Keltikangas-Jaervinen, L. (2000). Comparison of peer, teacher and self-assessments on adolescent direct and indirect aggression. Educational Psychology, 20 (2), 177-190. doi: 10.1080/713663710

Patterson, G. R., Reid, J. B., \& Dishion, T. J. (2002). Antisocial boys: comportamento antissocial. Santo André, SP: Esetec.

Pessotto, F. (2012). A importância dos estudos psicométricos em instrumentos traduzidos e adaptados para o brasil: o caso PMK. Disponível em http://www.ibapnet.org.br/?cd=53\&titulo=a importancia dos estudos psico metricos em instrumentos traduzidos e adaptados para o brasil o ca so pmk

Peets, K., \& Kikas, E. (2006). Aggressive strategies and victimization during adolescence: grade and gender differences, and cross- informant agreement. Aggressive Behavior, 32(1), 68-79. doi: 10.1002/ab.20105

Pearce, J. B., \& Thompson, A. C. (1998). Practical approaches to reduce the impact of bullying. Archives of Disease in Childhood, 79(1), 528-31. doi:10.1136/adc.79.6.528

Peacock, S., Konrad, S., Watson, E., Nickel, D., \& Muhajarine, N. (2013). Effectiveness of home visiting programs on child outcomes: a systematic review. BioMed Central Public Health, 13(17), 1-14. doi:10.1186/14712458-13-17

Pepler, D. J., \& Craig, W. M. (2000). Making a difference in bullying. Disponível em

http://psycserver.psyc.queensu.ca/craigw/Craig_Pepler_2000_REPORT_M aking_a_Difference_in_Bullying.pdf. 
Pesce, R. (2009). Violência familiar e comportamento agressivo e transgressor na infância: uma revisão da literatura. Ciência e Saúde Coletiva, 14(2), 507-18.

Perry, D., Kusel, S., \& Perry, L. (1988). Victims of peer aggression. Developmental Psychology, 24(6), 807-814. doi: 10.1037/00121649.24.6.807

Phillips, D. A. (2007). Punking and bullying strategies in middle school, high school, and beyond. Journal of Interpersonal Violence, 22(2), 158-178.

Pinheiro, F. F. M., \& Williams, L. C. A. (2009). Violência intrafamiliar e intimidação entre colegas no ensino fundamental. Cadernos de Pesquisa, 39(138), 995-1018.

Primi, R., Muniz, M., \& Nunes, C. H. S. S. (2009). Definições contemporâneas de validade de testes psicológicos. In C. S. Hutz (Org.). Avanços e polêmicas em avaliação psicológica (pp 243-265). São Paulo: Casa do Psicólogo.

Ravens-Sieberer, U., Kökönyei, G., \& Thomas C. (2004). School and health. In C. Currie et al. (Eds.), Young people's health in context. Health Behavior in School-aged Children (HBSC) study: international report from the 2001/2002 survey (pp. 184-196). Denmark: World Health Organization.

Reijntjes, A., Kamphuis, J. H., Prinzie, P., Boelen, P. A., Van der Schoot, M., \& Telch, M. J. (2011). Prospective linkages between peer victimization and externalizing problems in children: a meta- analysis. Aggressive Behavior, 37(3), 215-222. doi: 10.1002/ab.20374

Reijntjes, A., Kamphuis, J. H., Prinzie, P., \& Telch, M. J. (2010). Peer victimization and internalizing problems in children: a meta-analysis of longitudinal studies. Child Abuse \& Neglect, 34(4), 244-252. doi: 10.1016/j.chiabu.2009.07.009

Ribeiro, W. S., de Jesus Mari, J., Quintana, M. I., Dewey, M. E., Evans-Lacko, S., Vilete, L. M. P., \& Andreoli, S. B. (2013). The impact of epidemic 
violence on the prevalence of psychiatric disorders in São Paulo and Rio de Janeiro, Brazil. PloS one, 8(5), e63545. doi: 10.1371/journal.pone.0063545

Rigby, K. (1996). Bullying in schools and what to do about it. Melbourne: Acer.

Rigby, K. (2003). Addressing Bullying in schools: theory and practice. Trends and Issues in Crime and Criminal Justice, 259, 1-6.

Rios, K. S. A., \& Williams, L. C. A. (2008). Intervenção com famílias como estratégia de prevenção de problemas de comportamento em crianças: uma revisão. Psicologia em Estudo, 13(4), 799-806.

Rivers, I., \& Noret, N. (2013). Potential suicide ideation and its association with observing bullying at school. Journal of Adolescent Health, 53(1), S32-S36. doi: 10.1016/j.jadohealth.2012.10.279

Rocha, M. M. (2012). Autoavaliação de competências e problemas de comportamento entre adolescentes brasileiros: um estudo de validação do Inventário de Autoavaliação para Jovens (YSR/2001) (Tese de Doutorado, Departamento de Psicologia Clínica, Instituto de Psicologia, Universidade de São Paulo).

Rocha, M. M., Costa, N. J., \& Silvares, E. F. (2008). Changes in parents' and self-reports of behavioral problems in Brazilian adolescents after behavioral treatment with urine alarm for nocturnal enuresis. International Braz J Urol, 34(6), 749-757. doi: 10.1590/S1677-55382008000600010

Rocha, M. M. D., Ferrari, R. A., \& Silvares, E. F. D. M. (2011). Padrões de concordância entre múltiplos informantes na avaliação dos problemas comportamentais de adolescentes: implicações clínicas. Estudos e Pesquisas em Psicologia, 11(3), 948-964.

Rubin, K. H., Bukowski, W. M., \& Parker, J. G. (1998). Peer interactions, relationships, and groups. In: Handbook of child psychology (pp. 571-645).

Rutter, M. (1981). The city and the child. American Journal of Orthopsychiatry, 51(4), 610-25. doi:10.1111/j.1939-0025.1981.tb01407.x 
Sá, D. G. F., Bordin, I. A. S., Martin, D., \& Paula, C. S. (2010). Fatores de risco para problemas de saúde mental na infância/adolescência. Psicologia Teoria e Pesquisa, 26(4), 643-52.

Salbach-Andrae, H., Lenz, K., \& Lehmkuhl, U. (2009). Patterns of agreement among parent, teacher and youth ratings in a referred sample. European Psychiatry, 24(5), 345-351. doi: 10.1016/j.eurpsy.2008.07.008

Samnani, A. K. (2013). "Is this bullying?" Understanding target and witness reactions. Journal of Managerial Psychology, 28(3), 290-305. doi: 10.1108/02683941311321196

Sampaio, A. A. S. (2005). Skinner: sobre ciência e comportamento humano. Psicologia: Ciência e Profissão, 25(3), 370-383.

Sampaio, A. A. S., \& Andery, M. A. P. B. (2012) Seleção por Consequências como Modelo de Causalidade e a Clínica Analítico-Comportamental. In N. B. Borges, \& F. A. Cassas (Eds.), Clínica Analítico-Comportamental (pp. 77-86). Porto Alegre: Artmed.

Santos, D. N., Assis, A. M. O., Bastos, A. C. S., Santos, L. M., Santos, C. M., Strina, A., \& Barreto, M. L. (2008). Determinants of cognitive function in childhood: a cohort study in a middle income context. BioMed Central Public Health, 8(1), 202-24. doi:10.1186/1471-2458-8-202

Sapienza, G., \& Pedromônico, M. R. M. (2005). Risco, proteção e resiliência no desenvolvimento da criança e do adolescente. Psicologia em estudo, 10(2), 209-216.

Seixas, S. R. (2005). Violência escolar: metodologias de identificação dos alunos agressores e/ou vítimas. Análise Psicológica, 2(23), 97-110.

Silva, M. D. F. D. T., Farias, M. A., Silvares, E. F. M., \& Arantes, M. C. (2008). Adversidade familiar e problemas comportamentais entre adolescentes infratores e não-infratores. Psicologia em Estudo, 13(4), 791-798. 
Silva, J. L. D., Oliveira, W. A. D., Bazon, M. R., \& Cecílio, S. (2013). Bullying na sala de aula: percepção e intervenção de professores. Arquivos Brasileiros de Psicologia, 65(1), 121-137.

Silvares, E. F. M. (1993). O papel preventivo das clínicas-escola de psicologia no seu atendimento a crianças. Temas em Psicologia, 1(2), 87-97.

Silvares, E. F. M. (2000). Invertendo o caminho tradicional do atendimento psicológico em uma clínica-escola brasileira. Estudos de Psicologia, 5(I), 149-80.

Skinner, B. F. (1978). Ciência e comportamento humano. São Paulo: Martins Fontes.

Smith, P. (2003). Violence in schools: the response in Europe. London: Routledge Falmer.

Smith, P. (2004), Bullying: recent developments. Child and Adolescent Mental Health, 9(3), 98-103. doi: 10.1111/j.1475-3588.2004.00089.

Smith, P., \& Sharp, S. (1994). School bullying: insights and perspectives. London: Routledge.

Stelko-Pereira, A. C. (2009). Violência em escolas com características de risco contrastantes (Dissertação de Mestrado, Universidade Federal de São Carlos, São Carlos, SP).

Stelko-Pereira, A. C. (2012). Avaliação de um programa preventivo de violência escolar: planejamento, implantação e eficácia (Tese de Doutorado, Laboratório de Análise e Prevenção da Violência, Universidade Federal de São Carlos, São Carlos, SP).

Stelko-Pereira, A. C., Williams, L. C. A., \& Freitas, L. C. (2010). Validade e consistência interna do Questionário de Prevalência de Violência Escolar: Versão Estudantes. Avaliação Psicológica, 9(3), 403-11.

Sourander, A., Helstelä, L., Helenius, H., \& Piha, J. (2000). Persistence of bullying from childhood to adolescence - a longitudinal 8-year follow-up 
study. Child Abuse \& Neglect, 24(7), 873-881. doi: 10.1016/S01452134(00)00146-0

Sourander, A., Ronning, J., Brunstein-Klomek, A., Gyllenberg, D., Kumpulainen, K., Niemelä, S., Almqvist, F. (2009). Childhood bullying behavior and later psychiatric hospital and psychopharmacologic treatment: findings from the Finnish 1981 birth cohort study. Archives of General Psychiatry, 66(9), 1005-1012.. doi:10.1001/archgenpsychiatry.2009.122

Sullivan, K. (2010). The anti-bullying handbook. Ireland: Sage.

Tortorelli, M. F. P., Carreiro, L. R. R., \& de Araújo, M. V. (2010). Correlações entre a percepção da violência familiar e o relato de violência na escola entre alunos da cidade de São Paulo. Psicologia: Teoria e Prática, 12(1), $32-42$.

Tavares da Silva, M. D. F. D., Farias, M. A., Silvares, E. F. M., \& Arantes, M. C. (2008). Adversidade familiar e problemas comportamentais entre adolescentes infratores e não-infratores. Psicologia em Estudo, 13(4), 791798.

Teixeira, M. C. T. V., Emerich, D. R., Orsati, F. T., Rimério, R. C., Gatto, K. R., Chappaz, I. O., \& Kim, C. A. A. (2011). A description of adaptive and maladaptive behaviour in children and adolescents with Cri-du-chat syndrome. Journal of Intellectual Disability Research, 55(2), 132-37. doi: 10.1111/j.1365-2788.2010.01377.x

Tourinho, E. Z. (2003). A produção de conhecimento em psicologia: a análise do comportamento. Psicologia: Ciência e Profissão, 23(2), 30-41.

Valverde, B. S. C. L., Vitalle, M. S. D. S., Sampaio, I. D. P. C., \& Schoen, T. H. (2012). Survey of behavioral/emotional problems in an adolescent outpatient service. Paidéia (Ribeirão Preto), 22(53), 315-323.

Van Lier, P. A., Vitaro, F., Barker, E. D., Brendgen, M., Tremblay, R. E., \& Boivin, M. (2012). Peer victimization, poor academic achievement, and the 
link between childhood externalizing and internalizing problems. Child Development, 83(5), 1775-1788. doi: 10.1111/j.1467-8624.2012.01802.x

Vaillancourt, T., Brittain, H. L., McDougall, P., \& Duku, E. (2013). Longitudinal links between childhood peer victimization, internalizing and externalizing problems, and academic functioning developmental cascades. Journal of Abnormal Child Psychology, 41(8), 1203-1215. doi: 10.1007/s10802-0139781-5

Veleda, A. A., Soareas, M. C. F., \& Cézar-Vaz, M. R. (2011). Fatores associados ao atraso no desenvolvimento em crianças, Rio Grande, Rio Grande do Sul, Brasil. Revista Gaúcha de Enfermagem, 32(1), 79-85.

Veloso, M. M. X., Magalhães, C. M. C., Dell'Aglio, D. D., Cabral, I. R., \& Gomes, M. M. (2013). Notification of violence as a strategy for health surveillance: profile of a metropolis in Brazil. Ciência \& Saúde Coletiva, 18(5), 12631272. doi: 10.1590/S1413-81232013000500011

Vieira, T. M., Mendes, F. D. C., \& Guimarães, L. C. (2009). De columbine à virgínia tech: reflexões com base empírica sobre um fenômeno em expansão. Psicologia: Reflexão e Crítica, 22(3), 493-501.

Youngstrom, E., Loeber, R., \& Stouthamer-Loeber, M. (2000). Patterns and correlates of agreement between parent, teacher, and male adolescent ratings of externalizing and internalizing problems. Journal of consulting and clinical psychology, 68(6), 1038.

Zwierzynska, K., Wolke, D., \& Lereya, T. S. (2013). Peer victimization in childhood and internalizing problems in adolescence: a prospective longitudinal study. Journal of abnormal child psychology, 41(2), 309-323.

Weare, K., \& Nind, M. (2011). Mental health promotion and problem prevention in schools: what does the evidence say?. Health Promotion International, 26(1), 29-69. doi: 10.1093/heapro/dar075

Webster-Stratton, C., Reid, M. J., \& Hammond, M. (2004). Treating children with early-onset conduct problems: intervention outcomes for parent, child, 
and teacher training. Journal of Clinical Child and Adolescent Psychology, 33(1), 105-24. doi: 10.1207/S15374424JCCP3301_11

Webster-Stratton, C., Reid, J. M., \& Stoolmiller, M. (2008). Preventing conduct problems and improving school readiness: evaluation of the Incredible Years Teacher and Child Training Programs in high-risk schools. Journal of Child Psychology and Psychiatry, 49(5), 471-88. doi: 10.1111/j.14697610.2007.01861.x

Wilkinson, L. (1999). Statistical methods in psychology journals: guidelines and explanations. American Psychologist, 54(8), 594-604. 
Anexo 1. Tabela Seade (2007/2008) de distribuição das famílias, número de pessoas na família e número médio de filhos, segundo tipo de arranjo familiar e sexo do chefe da família.

\begin{tabular}{|c|c|c|c|c|}
\hline \multirow{2}{*}{ Tipo de Arranjo Familiar } & \multicolumn{2}{|c|}{ Família (\%) } & \multirow{2}{*}{$\begin{array}{l}\text { Número de } \\
\text { Pessoas na } \\
\text { Família }\end{array}$} & \multirow{2}{*}{$\begin{array}{l}\text { Número Médio } \\
\text { de Filhos }\end{array}$} \\
\hline & Total & Total por Tipo & & \\
\hline Total (1) & 100,0 & 100,0 & 3,2 & 1,3 \\
\hline Chefe Mulher (1) & 27,5 & 27,5 & 2,7 & 1,2 \\
\hline Chefe Homem (1) & 72,5 & 72,5 & 3,4 & 1,3 \\
\hline Casal com Filhos (2) & 44,5 & 100,0 & 3,9 & 1,9 \\
\hline Chefe Mulher & 1,4 & 3,0 & 4,0 & 2,0 \\
\hline Chefe Homem & 43,1 & 97,0 & 3,9 & 1,9 \\
\hline Casal sem Filhos (2) & 13,5 & 100,0 & 2,0 & - \\
\hline Chefe Mulher & 0,6 & 4,1 & 2,0 & - \\
\hline Chefe Homem & 12,9 & 95,9 & 2,0 & - \\
\hline Chefe sem Cônjuge com Filhos (2) & 13,1 & 100,0 & 2,8 & 1,8 \\
\hline Chefe Mulher & 11,7 & 89,7 & 2,8 & 1,8 \\
\hline Chefe Homem & 1,4 & 10,3 & 2,5 & 1,5 \\
\hline Pessoa que Mora Sozinha & 12,1 & 100,0 & 1,0 & - \\
\hline Chefe Mulher & 6,6 & 54,1 & 1,0 & - \\
\hline Chefe Homem & 5,6 & 45,9 & 1,0 & - \\
\hline Demais & 16,9 & 100,0 & 4,2 & 1,3 \\
\hline Chefe Mulher & 7,3 & 43,4 & 3,9 & 1,2 \\
\hline Chefe Homem & 9,5 & 56,6 & 4,5 & 1,3 \\
\hline
\end{tabular}

Fonte: SEP. Convênio Seade - Dieese e MTE/FAT.

(1) Inclusive as familias sem filhos.

(2) Exclusive as familias com outro parente elou agregado. 


\section{Anexo 2. Escala de Violência Escolar (EVE) - Versão Estudante}

Nos últimos 6 meses, algum aluno da sua escola...

\begin{tabular}{|c|c|c|c|c|c|}
\hline 1) Destruiu seus materiais de propósito? & nenhuma & 1 ou 2 vezes & 3 ou 4 vezes & 5 ou 6 vezes & 7 vezes ou mais \\
\hline 2) O quanto isso te prejudicou ou te fez mal? & nada & um pouco & médio & Muito & muitissimo \\
\hline 3) Roubou ou furtou seus materiais? & nenhuma & 1 ou 2 vezes & 3 ou 4 vezes & 5 ou 6 vezes & 7 vezes ou mais \\
\hline 4) $O$ quanto isso te prejudicou ou te fez mal? & nada & um pouco & médio & Muito & muitissimo \\
\hline 5) Espalhou fofocas sobre você? & nenhuma & 1 ou 2 vezes & 3 ou 4 vezes & 5 ou 6 vezes & 7 vezes ou mais \\
\hline 6) O quanto isso te prejudicou ou te fez mal? & nada & um pouco & médio & Muito & muitissimo \\
\hline $\begin{array}{l}\text { 7) Não te convidou propositalmente para atividades acadêmicas, brin- } \\
\text { cadeiras e festas para te magoar? }\end{array}$ & nenhuma & 1 ou 2 vezes & 3 ou 4 vezes & 5 ou 6 vezes & 7 vezes ou mais \\
\hline 8) O quanto isso te prejudicou ou te fez mal? & nada & um pouco & médio & Muito & muitissimo \\
\hline 9) Xingou e/ou apelidou você para te ofender, durante a semana? & nenhuma & 1 ou 2 vezes & 3 ou 4 vezes & 5 ou 6 vezes & 7 vezes ou mais \\
\hline 10) O quanto isso te prejudicou ou te fez mal ? & nada & um pouco & médio & Muito & muitissimo \\
\hline 11) Ameaçou que iria te agredir fisicamente? & nenhuma & 1 ou 2 vezes & 3 ou 4 vezes & 5 ou 6 vezes & 7 vezes ou mais \\
\hline 12) O quanto isso te prejudicou ou te fez mal ? & nada & um pouco & médio & Muito & muitissimo \\
\hline 13) Ameaçou que iria te ridicularizar/zoar? & nenhuma & 1 ou 2 vezes & 3 ou 4 vezes & 5 ou 6 vezes & 7 vezes ou mais \\
\hline 14) O quanto isso te prejudicou ou te fez mal? & nada & um pouco & médio & Muito & muitissimo \\
\hline 15) Deu tapas em você? & nenhuma & 1 ou 2 vezes & 3 ou 4 vezes & 5 ou 6 vezes & 7 vezes ou mais \\
\hline 16) $O$ quanto isso te prejudicou ou te fez mal ? & nada & um pouco & médio & Muito & muitissimo \\
\hline 17) Deu socos em você? & nenhuma & 1 ou 2 vezes & 3 ou 4 vezes & 5 ou 6 vezes & 7 vezes ou mais \\
\hline 18) O quanto isso te prejudicou ou te fez mal ? & nada & um pouco & médio & Muito & muitissimo \\
\hline 19) Deu chutes em você? & nenhuma & 1 ou 2 vezes & 3 ou 4 vezes & 5 ou 6 vezes & 7 vezes ou mais \\
\hline 20) $O$ quanto isso te prejudicou ou te fez mal ? & nada & um pouco & médio & Muito & Muitissimo \\
\hline 21) Fez você tropeçar propositalmente? & nenhuma & 1 ou 2 vezes & 3 ou 4 vezes & 5 ou 6 vezes & 7 vezes ou mais \\
\hline
\end{tabular}

\begin{tabular}{|c|c|c|c|c|c|}
\hline 22) O quanto isso te prejudicou ou te fez mal ? & nada & um pouco & médio & Muito & muitissimo \\
\hline 23) Enviou mensagens para te ofender ou xingar? & nenhuma & 1 ou 2 vezes & 3 ou 4 vezes & 5 ou 6 vezes & 7 vezes ou mais \\
\hline 24) $\mathrm{O}$ quanto isso te prejudicou ou te fez mal ? & nada & um pouco & médio & Muito & Muitissimo \\
\hline 25) Foi por qual meio? & telefone & internet & não ocorreu & & \\
\hline $\begin{array}{l}\text { 26) Te enviou mensagens para ameaçar que iria te agredir fisicamen- } \\
\text { te? }\end{array}$ & nenhuma & 1 ou 2 vezes & 3 ou 4 vezes & 5 ou 6 vezes & 7 vezes ou mais \\
\hline 27) $O$ quanto isso te prejudicou ou te fez mal ? & nada & um pouco & médio & Muito & Muitissimo \\
\hline 28) Foi por qual meio? & telefone & internet & não ocorreu & & \\
\hline 29) Te enviou mensagens para ameaçar que iria te ridicularizar? & nenhuma & 1 ou 2 vezes & 3 ou 4 vezes & 5 ou 6 vezes & 7 vezes ou mais \\
\hline 30) O quanto isso te prejudicou ou te fez mal? & nada & um pouco & médio & Muito & Muitissimo \\
\hline 31) Foi por qual meio? & telefone & internet & não ocorreu & & \\
\hline 32) Publicou mensagens sobre você te xingando ou tirando sarro? & nenhuma & 1 ou 2 vezes & 3 ou 4 vezes & 5 ou 6 vezes & 7 vezes ou mais \\
\hline 33) O quanto isso te prejudicou ou te fez mal ? & nada & um pouco & médio & Muito & Muitissimo \\
\hline 34) Foi por qual meio? & telefone & internet & não ocorreu & & \\
\hline 35) Publicou vídeo sobre você de modo a te ofender? & nenhuma & 1 ou 2 vezes & 3 ou 4 vezes & 5 ou 6 vezes & 7 vezes ou mais \\
\hline 36) O quanto isso te prejudicou ou te fez mal? & Nada & um pouco & médio & Muito & Muitissimo \\
\hline 37) Foi por qual meio? & telefone & internet & não ocorreu & & \\
\hline $\begin{array}{l}\text { 38) Publicou vídeo no qual você aparece de maneira que possa ser } \\
\text { tirado sarro ou ridicularizado? }\end{array}$ & nenhuma & 1 ou 2 vezes & 3 ou 4 vezes & 5 ou 6 vezes & 7 vezes ou mais \\
\hline 39) O quanto isso te prejudicou ou te fez mal? & Nada & um pouco & médio & Muito & Muitíssimo \\
\hline 40) Foi por qual meio? & telefone & internet & não ocorreu & & \\
\hline $\begin{array}{l}\text { 41) Fingiu que é você e mandou mensagens e vídeos a outras pesso- } \\
\text { as para te prejudicar? }\end{array}$ & nenhuma & 1 ou 2 vezes & 3 ou 4 vezes & 5 ou 6 vezes & 7 vezes ou mais \\
\hline 42) O quanto isso te prejudicou ou te fez mal ? & Nada & um pouco & médio & Muito & Muitissimo \\
\hline 43) Foi por qual meio? & Telephone & internet & nẫo ocorreu & & \\
\hline
\end{tabular}


Nos últimos 6 meses, você para algum aluno da sua escola...

\begin{tabular}{|c|c|c|c|c|c|}
\hline 71) Destruiu materiais de propósito? & Nenhuma & 1 ou 2 vezes & 3 ou 4 vezes & 5 ou 6 vezes & 7 vezes ou mais \\
\hline 72) Roubou ou furtou materiais? & Nenhuma & 1 ou 2 vezes & 3 ou 4 vezes & 5 ou 6 vezes & 7 vezes ou mais \\
\hline 73) Espalhou fofocas ? & Nenhuma & 1 ou 2 vezes & 3 ou 4 vezes & 5 ou 6 vezes & 7 vezes ou mais \\
\hline 74) Excluiu de atividades de propósito? & Nenhuma & 1 ou 2 vezes & 3 ou 4 vezes & 5 ou 6 vezes & 7 vezes ou mais \\
\hline 75) Xingou e/ou apelidou para ofender, durante a semana? & Nenhuma & 1 ou 2 vezes & 3 ou 4 vezes & 5 ou 6 vezes & 7 vezes ou mais \\
\hline 76) Fez ameaças de agredir fisicamente? & Nenhuma & 1 ou 2 vezes & 3 ou 4 vezes & 5 ou 6 vezes & 7 vezes ou mais \\
\hline 77) Jogou objetos nele (a) para machucar? & Nenhuma & 1 ou 2 vezes & 3 ou 4 vezes & 5 ou 6 vezes & 7 vezes ou mais \\
\hline 78) Deu tapas nele (a)? & Nenhuma & 1 ou 2 vezes & 3 ou 4 vezes & 5 ou 6 vezes & 7 vezes ou mais \\
\hline 79) Deu socos nele (a)? & Nenhuma & 1 ou 2 vezes & 3 ou 4 vezes & 5 ou 6 vezes & 7 vezes ou mais \\
\hline 80) Deu chutes nele (a)? & Nenhuma & 1 ou 2 vezes & 3 ou 4 vezes & 5 ou 6 vezes & 7 vezes ou mais \\
\hline 81) Fez ele (a) tropeçar propositalmente? & Nenhuma & 1 ou 2 vezes & 3 ou 4 vezes & 5 ou 6 vezes & 7 vezes ou mais \\
\hline 82) Enviou mensagens para ofender ou xingar? & Nenhuma & 1 ou 2 vezes & 3 ou 4 vezes & 5 ou 6 vezes & 7 vezes ou mais \\
\hline 83) Foi por qual meio? & Telephone & internet & não ocorreu & & \\
\hline 84) Enviou mensagens para ameaçar que iria agredir fisicamente? & Nenhuma & 1 ou 2 vezes & 3 ou 4 vezes & 5 ou 6 vezes & 7 vezes ou mais \\
\hline 85) Foi por qual meio? & Telephone & internet & não ocorreu & & \\
\hline 86) Enviou mensagens para ameaçar que iria ridicularizar? & Nenhuma & 1 ou 2 vezes & 3 ou 4 vezes & 5 ou 6 vezes & 7 vezes ou mais \\
\hline 87) Foi por qual meio? & Telephone & internet & não ocorreu & & \\
\hline 88) Publicou mensagens xingando ou tirando sarro? & Nenhuma & 1 ou 2 vezes & 3 ou 4 vezes & 5 ou 6 vezes & 7 vezes ou mais \\
\hline 89) Foi por qual meio? & Telephone & internet & não ocorreu & & \\
\hline 90) Publicou vídeo da pessoa de modo a ofendê-la? & Nenhuma & 1 ou 2 vezes & 3 ou 4 vezes & 5 ou 6 vezes & 7 vezes ou mais \\
\hline 91) Foi por qual meio? & Telephone & internet & não ocorreu & & \\
\hline $\begin{array}{l}\text { 92) Publicou vídeo no qual a pessoa aparece para tirado sarro dela ou } \\
\text { ridicularizá-la? }\end{array}$ & Nenhuma & 1 ou 2 vezes & 3 ou 4 vezes & 5 ou 6 vezes & 7 vezes ou mais \\
\hline 93) Foi por qual meio? & Telephone & internet & não ocorreu & & \\
\hline $\begin{array}{l}\text { 94) Fingiu que é o aluno e mandou mensagens e vídeos a outras pes- } \\
\text { soas para o prejudicar? }\end{array}$ & Nenhuma & 1 ou 2 vezes & 3 ou 4 vezes & 5 ou 6 vezes & 7 vezes ou mais \\
\hline 95) Foi por qual meio? & Telephone & internet & não ocorreu & & \\
\hline
\end{tabular}


Anexo 3. Questões utilizadas do Peer Assessment, referentes à vitimização (em negrito).

Peer Assessment - Lista de características dos amigos/colegas de sala de aula da escola (Rubin, Bukowski \& Parker, 1998)

NOME:

SEXO: MASCULINO / FEMININO

IDADE:

ANO:

ESCOLA:

Na folha seguinte você lerá diferentes características. Ao lado verá também espaços em branco. Nos espaços, escreva o nome dos (das) seus (suas) colegas que mais têm a ver com estas características. Podem ser meninos ou meninas. Você pode escrever mais de um nome ao lado de cada frase

POR FAVOR, RESPONDA COM TODA A SINCERIDADE, PORQUE NINGUÉM, EXCETO O PESQUISADOR, LERÁ ESTES QUESTIONÁRIOS. NÃO EXISTE CERTO OU ERRADO. O MELHOR QUe VOCÊ PODE FAZER É falaR A VERDADE. 
CARACTERÍSTICA

ALUNOS

1. É esperto (a) e vai bem na escola.

2. Chuta, bate, empurra os outros.

3. É bom (boa) nos esportes (futebol, vôlei, entre outros.)

4. Os outros costumam roubar, rasgar ou estragar as coisas dele.

5. Ninguém o (a) convida para brincar, jogar, entre outros.

6. Tem boas ideias sobre brincadeiras ou jogos para se divertir.

7. Os outros batem nele (a).

8. É "encrenqueiro (a)", se mete muito em confusões.

9. É um (a) bom (boa) líder.

10. Os outros o (a) agridem.

11. Bate ou xinga os outros só se estes batem ou xingam ele(a).

12. Fica bravo (a) com facilidade.

13. Se importa que os outros estejam bem.

14. Muitas pessoas gostam dele (a).

15. Ninguém o (a) escuta.

16. É rejeitado (a), ou deixado(a) de lado pelos colegas.

17. Se preocupa em ter certeza de que todos são tratados iguais.

18. Fala "mal" dos outros.

19. Os outros xingam ele(a), dizem palavrões ou colocam apelidos.

20. Ele ou ela "joga limpo", não mente. 


\begin{tabular}{|l|l|}
\hline 21. Sempre sabe a resposta certa. & \\
\hline 22. Fala palavrões para os outros. & \\
\hline 23. Ameaça os outros. & \\
\hline 24. Pega as coisas dos outros sem pedir. & \\
\hline $\begin{array}{l}\text { 25. Faz sucesso entre os colegas na escola, todos o(a) } \\
\text { conhecem. }\end{array}$ & \\
\hline 26. Os outros o(a) provocam. & \\
\hline 27. Bate nos outros, se não fazem sua vontade. & \\
\hline 28. Ajuda os outros quando estes precisam. & \\
\hline $\begin{array}{l}\text { 29. Faz fofocas, inventa histórias ou diz coisas ruins dos colegas } \\
\text { para que os outros não sejam mais amigos. }\end{array}$ & \\
\hline 30. Xinga, briga para conseguir o que quer. & \\
\hline
\end{tabular}


Anexo 4. Parecer de aprovação do referido projeto pelo Comitê de Ética em Pesquisa da Universidade de São Paulo.

\author{
INSTITUTO DE PSICOLOGIA \\ DA UNIVERSIDADE DE SÃO

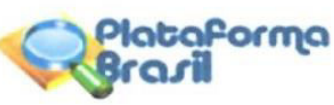

\title{
PARECER CONSUBSTANCIADO DO CEP
}

\section{DADOS DO PROJETO DE PESQUISA}

Título da Pesquisa: VITIMIZAÇÃO ENTRE PARES, PROBLEMAS DE COMPORTAMENTO E ESTRUTURA FAMILIAR DE ADOLESCENTES DE ESCOLAS PAULISTAS

Pesquisador: Felipe Alckmin Carvalho

Área Temática:

Versão: 1

CAAE: 04741913.3 .0000 .5561

Instituição Proponente: INSTITUTO DE PSICOLOGIA ((USP))

Patrocinador Principal: INSTITUTO DE PSICOLOGIA ((USP))

\section{DADOS DO PARECER}

Número do Parecer: 210.822

Data da Relatoria: $11 / 03 / 2013$

\section{Apresentação do Projeto:}

Trata-se de um projeto de pesquisa com delineamento transversal, para estudo do fenômeno da vitimização entre pares, ou bullying.

Estima-se a participaçăo de 300 adolescentes, de 12 a 14 anos, regularmente matriculados em escolas públicas, no município de São Paulo, e seus pais. A coleta de dados inclui a utilização do Inventário de Autoavaliação para Adolescentes (Youth Self Report), a fim de identificar problemas de comportamento, de entrevista semiestruturada para obtenção do Índice de adversidade familiar, e de uma versão traduzida do KIDSCAPE, questionário de múltipla escolha destinado ao rastreamento de bullying entre os adolescentes. Os dados serão submetidos à análise estatística e espera-se que eles possam mostrar um retrato do relacionamento entre adolescentes em idade escolar, em população brasileira, bem como contribuir para o entendimento das associações entre bullying, funcionamento familiar e problemas de comportamento. Somado a isso, os dados obtidos poderão servir de referência para que formas de atendimento psicológico, em nivel preventivo e remediativo, possam ser planejadas para esta população.

Todas as análises de dados serão realizadas com o auxilio de um especialista em estatística do Instituto de Psicologia da Universidade de São Paulo, com a finalidade de embasar estatisticamente as conclusões do trabalho.

Objetivo da Pesquisa:

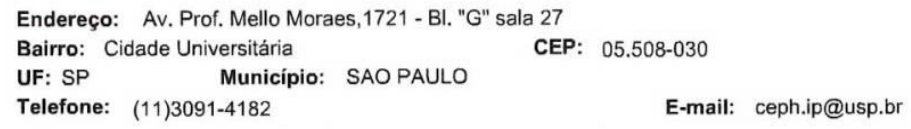




\section{INSTITUTO DE PSICOLOGIA DA UNIVERSIDADE DE SÃO}

Partindo da premissa de que a vitimizaçăo entre pares é um fenômeno complexo e com etiologia multicausal, o presente estudo tem como objetivos:

(1) Verificar a ocorrência de bullying entre adolescentes de escolas públicas da capital paulista; (2) Descrever o perfil comportamental da amostra, rastreando problemas de comportamento e possíveis associações com bullying; (3) Avaliar possiveis relaçōes entre o grau de adversidade familiar e o fenômeno da vitimização entre pares no contexto escolar.

\section{Avaliação dos Riscos e Benefícios:}

Riscos: O preenchimento dos questionários, tanto para os adolescentes quanto para seus pais, apresenta risco mínimo. Caso alguma questão cause qualquer tipo de desconforto,o pesquisador responsável se compromete a oferecer apoio psicológico individualizado aos participantes.

Benefícios: A elucidação de questões relacionadas ao bullying junto à população brasileira é fundamental para a compreensão desse fenômeno, assim como para subsidiar a implementação de medidas preventivas, a exemplo do que vem sendo realizado em países mais desenvolvidos.

\section{Comentários e Considerações sobre a Pesquisa:}

Pesquisa descrita de modo claro e objetivo em relação a sua relevância, justificativa, bem como referencial teórico e método pertinente aos objetivos propostos.

\section{Considerações sobre os Termos de apresentação obrigatória:}

Folha de rosto com assinaturas e identificações requeridas. Carta de apresentação do projeto às escolas também foi anexada.

\section{Recomendações:}

Conclusões ou Pendências e Lista de Inadequações:

O projeto foi Aprovado.

Apenas uma sugestão de rever frase que parece incompleta no termo de assentimento. Rever título repetido no TCLE.

\section{Situação do Parecer:}

Aprovado

Necessita Apreciação da CONEP:

Não

Considerações Finais a critério do CEP:

Endereço: Av. Prof. Mello Moraes, 1721 - Bl. "G" sala 27
Bairro: Cidade Universitária
CEP: $05.508-030$
UF: SP Município: SAOPAULO
Telefone: (11)3091-4182
E-mail: ceph.ip@usp.br 
Apêndice 1. Entrevista Semiestruturada para aferição do Índice de Adversidade Familiar (IAF)

\section{IDENTIFICAÇÃO}

Nome do Responsável:

Idade

Nome do

adolescente: Idade

Telefone: ( )

Endereço:

\section{ÍNDICE DE ADVERSIDADE FAMILIAR}

(1) Número de pessoas na mesma casa: Número de quartos na casa:

(2) Número de filhos:

(3) Renda familiar: $\square$ Não possuem renda $\square$ até 1 SM $\square$ de 2 a 4 SM

de 5 a 8 SM

$\square$ de 9 a 12 SM

acima de 12 SM

(4) Divórcio: $\quad \square$ SIM

$\square$ NÃO

(6) Há discórdia conjugal grave? Em caso afirmativo, descrever:

(7) Há histórico de transtorno psiquiátrico nos pais? $\square \mathbf{S I M}$

\section{NÃO}

Em caso afirmativo, qual o transtorno psiquiátrico?

Qual o grau de parentesco com o jovem?

(8) Há histórico de criminalidade dos pais? $\square$ SIM

\section{NÃO}

Em caso afirmativo, descrever: 


\title{
Apêndice 2. Termo de Consentimento Livre e Esclarecimento para Pais
}

\author{
Universidade de São Paulo \\ Instituto de Psicologia - Departamento de Psicologia Clínica \\ TERMO DE CONSENTIMENTO LIVRE E ESCLARECIMENTO
}

(Obrigatório para Pesquisas em Seres Humanos - Resolução n. ํ 196/96 CNS)

Você e seu/sua filho(a) estão sendo convidados a participar da pesquisa "BULlying, PROBlemas DE COMPORTAMENTO E CARACTERÍsticas FAMILIARES DE ADOLESCENTES DE ESCOLAS PAULISTAS”.

Este estudo tem a finalidade de verificar a ocorrência da violência entre alunos, assim como entender melhor como os adolescentes se envolvem nessas situações. Em um primeiro momento, os adolescentes responderão um questionário autoaplicável (EVE), que possibilitará a identificação de situações de violência vividas ou observadas por eles na escola. Todos os adolescentes com idade entre 11 e 13 anos, matriculados na escola serão convidados a participar desta primeira fase, que durará aproximadamente vinte minutos.

Os alunos que relatarem, através de suas respostas no EVE, envolvimento em situação de violência, serão solicitados, em um segundo momento, a responder outro questionário (INVENTÁRIO DE AUTOAVALIAÇÃO PARA ADOLESCENTES). Esse questionário deverá ser preenchido pelos próprios adolescentes e dura cerca de 30 minutos.

Por fim, na terceira etapa, vocês serão convidados a participar de uma entrevista, cujas perguntas se referem às características de sua família. Essas entrevistas serão realizadas na própria escola, em sala designada pelo Coordenador ou Diretor e terá a duração de aproximadamente 30 minutos.

As informações fornecidas por vocês e por seus filhos, nesses encontros, assim como suas identificações, serão mantidas em sigilo em quaisquer circunstâncias. Vocês poderão desistir em qualquer momento da pesquisa, sem qualquer dano ou prejuízo. 
Confirmo que após entender todas estas informações sobre o estudo, aceito participar como voluntário(a), sem receber nenhuma forma de pagamento. Autorizo a publicação dos resultados da pesquisa em revistas científicas de psicologia, de medicina, aulas e congressos, sem que meu nome venha a público.

Qualquer dúvida entre em contato com o pesquisador responsável Felipe Alckmin Carvalho, pelo telefone (11) 6662-1437 ou pelo e-mail: felipcarvalho@usp.br. Se você tiver alguma consideração ou dúvida sobre a ética dessa pesquisa, entre em contato com o Comitê de Ética em Pesquisa (CEP) do Instituto de Psicologia da Universidade de São Paulo, pelo Av. Prof. Mello Moraes, 1721, Bloco G, sala 27- Cidade Universitária - São Paulo/SP _ CEP: 05508-030. Telefone (11) 3091-4182, e-mail ceph.ip@usp.br

Este Termo de Consentimento Livre e Esclarecido foi elaborado em duas vias; uma delas ficará com você e outra com o pesquisador.

São Paulo, de de 2013

Assinatura do colaborador

Felipe Alckmin Carvalho (Pesquisador responsável) 
Apêndice 3. Termo de Assentimento Informado

\author{
Universidade de São Paulo \\ Instituto de Psicologia - Departamento de Psicologia Clínica \\ TERMO DE ASSENTIMENTO INFORMADO
}

(Obrigatório para Pesquisas em Seres Humanos - Resolução n.ำ441/2011)

Assentimento Informado para participação na pesquisa "BULLYING, PROBLEMAS DE COMPORTAMENTO E CARACTERÍSTICAS FAMILIARES DE ADOLESCENTES DE ESCOLAS PAULISTAS".

Este formulário de assentimento informado é para adolescentes com idades entre 11 e 13 anos, convidados a participarem de avaliações a serem realizadas na escola em que estudam.

\title{
Parte I - Informações sobre a pesquisa
}

Meu nome é Felipe e estou aqui para conhecer como é o ambiente na escola onde você estuda. Conversaremos sobre suas atividades, sobre suas amizades e dificuldades na escola. Com esse estudo quero saber se há adolescentes em sua escola que estão envolvidos em situação de violência.

Você pode discutir qualquer informação deste formulário com seus pais, amigos ou qualquer pessoa com quem você se sentir a vontade de conversar. Pode haver algumas palavras que você não entenda ou alguma coisa que você queira que eu explique mais detalhadamente Se isso acontecer, pergunte-me e eu explicarei.

Caso você decida participar desta pesquisa, nós vamos passar algum tempo conversando sobre seu dia a dia na escola, seus relacionamentos com os amigos, entre outras coisas, para que assim eu possa conhecer mais sobre você. Tudo que conversarmos ficará apenas entre nós.

Nossas conversas geralmente não têm risco algum, mas poderemos falar sobre coisas que podem te deixar desconfortável. Se isto acontecer, caso você queira, poderemos, em outro momento, falar mais sobre isto para tentar entender o que está acontecendo. 
A sua participação é muito importante porque este estudo nos ajudará a entender as dificuldades que adolescentes como você podem enfrentar na escola, e assim poderemos desenvolver formas de ajudá-los. Para isso, talvez eu tenha que conversar sobre nossos encontros com outros pesquisadores que fazem do meu grupo de estudo sobre esse tema. Se isto acontecer, eu não vou mencionar seu nome ou nenhuma informação que permita que eles identifiquem quem você é.

Qualquer dúvida entre em contato com o pesquisador responsável Felipe Alckmin Carvalho, pelo telefone (11) 6662-1437 ou pelo e-mail: felipcarvalho@usp.br. Se você tiver alguma consideração ou dúvida sobre a ética dessa pesquisa, entre em contato com o Comitê de Ética em Pesquisa (CEP) do Instituto de Psicologia da Universidade de São Paulo, pelo Av. Prof. Mello Moraes, 1721, Bloco G, sala 27- Cidade Universitária - São Paulo/SP CEP: 05508-030. Telefone (11) 3091-4182, e-mail ceph.ip@usp.br

São Paulo, de de 2013

Nome do adolescente:

Assinatura do adolescente:

Assinatura do

Pesquisador: 
Apêndice 4. Carta de apresentação do Projeto à Escola

TERMO DE CONSENTIMENTO LIVRE E ESCLARECIDO - ESCOLA *

\title{
BULLYING, PROBLEMAS DE COMPORTAMENTO E CARACTERÍSTICAS \\ FAMILIARES DE ADOLESCENTES DE ESCOLAS PAULISTAS
}

\author{
Pesquisador: Felipe Alckmin Carvalho \\ Orientadora: Profa. Dra. Márcia Helena da Silva Melo Bertolla
}

Natureza da pesquisa. Este estudo pretende verificar a ocorrência, na escola EMEF EDUCANDARIO DOM DUARTE, de episódios de violência entre alunos em escolas públicas da capital paulista; identificar problemas de comportamento e investigar relações entre problemas familiares e o fenômeno da vitimização entre pares no contexto escolar. A avaliação envolve o preenchimento, pelos adolescentes do INVENTÁRIO DE AUTOAVALIAÇÃO PARA ADOLESCENTES e da ESCALA DE VIOLÊNCIA ESCOLAR.

Os pais/responsáveis dos adolescentes em questão serão convidados a participar de uma entrevista, a ser realizada por telefone, acerca das características familiares, como número de filhos, escolaridade, entre outros.

Ressaltamos que todos os participantes deverão consentir, por escrito, os procedimentos de avaliação da presente pesquisa.

Participantes da pesquisa. Alunos do $6^{\circ}$ ao $9^{\circ}$ ano, com idades entre 11 e 13 anos; professores de Português e Matemática e pais.

Envolvimento na pesquisa. A participação dos professores, alunos e pais consistirá em preencher questionários. Todos os participantes poderão interromper sua participação a qualquer momento.

Confidencialidade. Todas as informações colhidas são confidenciais e não exporão os participantes. 
Benefícios. A participação permitirá a realização de discussões teóricoempíricas que possibilitarão o delineamento de estratégias mais precisas e eficazes de intervenção, no que concerne ao relacionamento entre alunos na escola.

Felipe Alckmin Carvalho (pesquisador responsável)

Coordenação / Direção

Orientadora: Profa. Dra. Márcia Helena da Silva Melo Bertolla

E-mail:mmelo@usp.br

Pesquisador: Felipe Alckmin Carvalho

E-mail: felipcarvalho@usp.br

Endereço: Av. Prof. Mello Moraes 1721 - Bloco F

CEP 05508-030 / Cidade Universitária - São Paulo - SP

Telefone (11) 3091-1947

* O pesquisador se colocará à disposição para sanar quaisquer dúvidas acerca do estudo. O presente Termo de Consentimento foi elaborado em 2 (duas) vias, das quais uma ficará com a instituição participante e, outra, com o pesquisador 
Apêndice 5. Carta destinada aos pais explicativa do Índice de Adversidade familiar

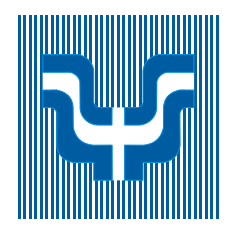

$$
\text { UNIVERSIDADE DE SÃO PAULO }
$$

DEPARTAMENTO DE PSICOLOGIA CLÍNICA

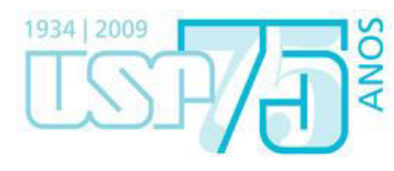

Cara Mãe,

Dentro do envelope há um questionário sobre algumas características de sua família.

Por favor, responda com cuidado às questões para que possamos conhecer um pouco melhor o perfil de cada uma das famílias da escola em que seu filho (a) estuda.

Devolva este envelope assim que possível na escola de seu filho (a). Use uma etiqueta que há dentro dele para lacrá-lo antes de devolvê-lo.

Desde já agradeço a colaboração. 